\title{
1st Canadian Respiratory Conference: A Breath of Fresh Air
}

\author{
June $19-21,2008$
}

Montreal, Quebec

1st Canadian Respiratory Conference: A Breath of Fresh Air. Can Respir J 2008;15(Suppl C):3C-35C.

The present supplement is a synopsis of presentations from the founding Canadian Respiratory Conference of June 2008, in Montreal, Quebec. I would like to acknowledge the supplement editors - Drs Kylie Hill and Samir Gupta - who have worked closely in cooperation with the many authors to bring it to you in an abbreviated format. The Journal welcomes your feedback to enable us to plan future conference supplements.

The meeting was a great success, with over 600 attendees. The co-location of so many of our affiliated respiratory clinical, academic, teaching and research societies greatly added to its strength, as did the presence of our colleagues in pediatric respiratory medicine. My thanks to the four founding partners (the Canadian Lung Association, the Canadian Thoracic Society, the Canadian Respiratory Health Professionals and the Canadian COPD Alliance) as well as the conference organizing committee, the scientific program committee and the university division directors across the country, all health care professional participants, the organizing staff and our sponsors, for enabling this conference to achieve its success.

The material included from the plenary and concurrent sessions, as well as the poster session abstracts, reflect the depth and breadth of the meeting. Several of the faculty are internationally recognized for their expertise in respiratory health. The program itself further confirms that Canadian respiratory medicine has reached a critical mass and maturity as a multidisciplinary specialty of which we can be proud. Our next meeting will be held in Toronto on April 23 to 25,2009 , and we look forward to seeing you there.

Roger Goldstein, Chair, Scientific Program Committee

\section{Le premier congrès canadien sur la santé respiratoire : Une bouffée d'air frais}

Le présent supplément contient un synopsis des présentations du tout premier congrès canadien sur la santé respiratoire qui a eu lieu en juin 2008 à Montréal. Je tiens à remercier les docteurs Kylie Hill et Samir Gupta, rédacteurs en chef du supplément, qui ont travaillé en étroite collaboration avec les nombreux auteurs afin de vous fournir le congrès en format abrégé. La Revue sera heureuse de recevoir vos commentaires afin de planifier les futurs suppléments du congrès.

Le congrès a obtenu un franc succès, puisque plus de 600 personnes y ont assisté. La présence conjointe d'un grand nombre de sociétés cliniques, universitaires, d'enseignement et de recherche a largement contribué à son dynamisme, tout comme la présence de nos collègues de la pédiatrie respiratoire. Je tiens à remercier les quatre partenaires fondateurs (Association pulmonaire du Canada, Société canadienne de thoracologie, Professionnels canadiens en santé respiratoire et Alliance canadienne sur la MPOC) et le comité organisateur du congrès, le comité du programme scientifique et les directeurs d'unités universitaires du pays, tous les professionnels de la santé participants, le personnel organisateur et les commanditaires d'avoir permis la réussite de ce congrès.

Le matériel provenant des séances plénières et concomitantes ainsi que les résumés des séances d'affiche reflètent la profondeur et l'ampleur du congrès. Plusieurs conférenciers sont réputés sur la scène internationale pour leurs compétences en santé respiratoire. Le programme lui-même confirme que la médecine respiratoire au Canada est parvenue à une masse critique et à la maturité à titre de spécialité multidisciplinaire dont nous pouvons être fiers. Le prochain congrès aura lieu à Toronto, du 23 au 25 avril 2009, et nous espérons bien vous y rencontrer.

Roger Goldstein, Président, Comité scientifique

\section{GRADE: An emerging consensus within the respiratory community on rating quality of evidence and strength of recommendations}

\author{
Gordon H Guyatt MD \\ Department of Clinical Epidemiology \& Biostatistics, \\ McMaster University, Hamilton, Ontario \\ E-mail guyatt@mcmaster.ca
}

$\mathrm{B}$ ecause guideline developers are inconsistent in how they rate quality of evidence and grade strength of recommendations, guideline users face challenges in understanding the messages that grading systems communicate. The Grading of Recommendations Assessment, Development and Evaluation (GRADE) working group (1) offers unique advantages over other rating systems (Table 1) (2).

\section{TABLE 1}

\section{GRADE advantages}

- Developed by a representative group of international guideline developers

- Separation between quality of evidence and strength of recommendations

- Evaluation of the importance of outcomes of alternative management strategies

- Comprehensive criteria for downgrading and upgrading quality of evidence ratings

- Transparent process of moving from evidence to recommendations

- Acknowledgement of values and preferences

- Pragmatic interpretation of 'strong' versus 'weak' recommendations

- Also useful for systematic reviews and health technology assessments

\section{QUALITY OF EVIDENCE}

What is 'quality of evidence' and why is it important? In making health care management decisions, patients and clinicians must trade off the benefits and downsides of alternative 
strategies. Decision-makers will be influenced by the best estimates of the expected advantages and disadvantages, as well as their confidence in these estimates.

Recommendations must take account of the quality of evidence (3). For example, organizations recommended that postmenopausal women use hormone replacement therapy (4) believing that it decreased cardiovascular risk. However, these data came from observational studies with inconsistent results (very low quality) (5). Randomized controlled trials (RCTs) have shown that hormone replacement therapy fails to reduce cardiovascular risk, and may even increase it $(6,7)$.

Some antiarrhythmic agents were recommended based on their ability to reduce asymptomatic ventricular arrhythmias associated with sudden death. However, arrhythmia reduction only reflected indirectly on the outcome of sudden death, so the evidence of benefit was of low quality. An RCT demonstrated that the risk of sudden death was increased (8).

Failure to recognize high-quality evidence occurred when recommendations lagged a decade behind good RCT evidence that thrombolytic therapy reduced mortality in myocardial infarction (9). Insufficient attention to quality of evidence risks inappropriate guidelines and recommendations.

How should guideline developers alert clinicians to quality of evidence?

A formal system that categorizes quality of evidence - from high to very low - represents an obvious strategy, but has some limitations. Because quality of evidence is a continuum, any discrete categorization involves some degree of arbitrariness. Nevertheless, the advantages of simplicity, transparency and vividness outweigh these limitations.

\section{Strength of recommendation}

A recommendation for treatment may arise from large, rigorous RCTs that demonstrate consistent impressive benefits with few side effects and minimal inconvenience and cost; for example, a short course of oral steroids for asthma exacerbation. Alternatively, recommendations may arise from observational studies that involve harms, burdens or costs. Antithrombotic therapy in pregnant women with prosthetic heart valves must trade off the magnitude of reduction in valve thrombosis, inconvenience, cost and risk of teratogenesis. Clinicians offering such treatments must help patients weigh the desirable and undesirable effects carefully according to their values and preferences.

Guidelines must indicate whether there is high-quality evidence with the desirable effects outweighing the undesirable effects, or whether there is a close or uncertain balance.

\section{GRADING SYSTEMS}

Grading systems should separate the quality of evidence from the strength of recommendations. High-quality evidence doesn't necessarily imply strong recommendations, and strong recommendations can arise from low-quality evidence.

Patients with a first deep venous thrombosis and no obvious provoking factor must decide whether to continue warfarin long term. High-quality RCTs show that continuing warfarin decreases the risk of recurrent thrombosis, at the cost of increased risk of bleeding and inconvenience. Because patient values and preferences will result in different choices, guideline panels should - despite the high quality evidence - offer a weak recommendation.
There is an association between acetylsalicylic acid administration and Reye syndrome (10). Because acetylsalicylic acid and acetaminophen are similar in their analgesic and antipyretic effects, the low-quality evidence regarding the association between acetylsalicylic acid and Reye syndrome does not preclude a strong recommendation for acetaminophen. Explicit criteria for ratings of quality and grading of strength enable judgments to be more transparent (2). GRADE has been widely adopted in the respiratory community where it is used by most major European and North American organizations.

Quality of evidence

GRADE classifies quality of evidence as high, moderate, low and very low (Table 2). RCT evidence is high quality, but five factors may decrease our confidence in the evidence:

- Study limitations

- Inconsistency of results

- Indirectness of evidence

- Imprecision

- Reporting bias

While cohort and case-control studies are 'low quality', grading upwards may be warranted if the treatment effect is very large (hip replacement), if there is evidence of a doseresponse relationship, or if all biases increase the magnitude of an apparent treatment effect.

TABLE 2

Quality of evidence and their definitions

\begin{tabular}{ll}
\hline Grade & Definition \\
\hline High & $\begin{array}{l}\text { Further research is very unlikely to change our confidence in the } \\
\text { estimate of effect }\end{array}$ \\
Moderate & $\begin{array}{l}\text { Further research is likely to have an important impact on our } \\
\text { confidence in the estimate of effect and may change the estimate }\end{array}$ \\
Low & $\begin{array}{l}\text { Further research is very likely to have an important impact on our } \\
\text { confidence in the estimate of effect and is likely to change the } \\
\text { estimate }\end{array}$ \\
Very low & Any estimate of effect is very uncertain
\end{tabular}

\section{Strength of recommendation}

Recommendations are 'strong' or 'weak'. If an intervention's desirable effects outweigh its undesirable effects, or clearly do not, the recommendations are strong. If tradeoffs are less certain (low-quality evidence or a balanced desirable and undesirable effects) the recommendations are weak. Table 3 summarizes the factors that affect the strength of recommendations.

TABLE 3

Factors that affect the strength of a recommendation

\begin{tabular}{|c|c|c|}
\hline Factor & $\begin{array}{c}\text { Strong } \\
\text { recommendations }\end{array}$ & $\begin{array}{c}\text { Weak } \\
\text { recommendations }\end{array}$ \\
\hline Quality of evidence & $\begin{array}{l}\text { High-quality randomized } \\
\text { trials show the benefit } \\
\text { of inhaled steroids in } \\
\text { asthma }\end{array}$ & $\begin{array}{l}\text { Only case series have } \\
\text { examined the utility } \\
\text { of pleurodesis in } \\
\text { pneumothorax }\end{array}$ \\
\hline $\begin{array}{l}\text { Uncertainty about } \\
\text { the balance between } \\
\text { desirable and } \\
\text { undesirable effects }\end{array}$ & $\begin{array}{l}\text { ASA in myocardial } \\
\text { infarction reduces } \\
\text { mortality with minimal } \\
\text { toxicity, inconvenience } \\
\text { and cost }\end{array}$ & $\begin{array}{l}\text { Warfarin in low-risk } \\
\text { patients with atrial } \\
\text { fibrillation results in } \\
\text { small stroke reduction } \\
\text { but increased bleeding } \\
\text { risk and substantial } \\
\text { inconvenience }\end{array}$ \\
\hline
\end{tabular}


TABLE 3 - CONTINUED

Factors that affect the strength of a recommendation

\begin{tabular}{lcl}
\hline Factor & \multicolumn{1}{c}{$\begin{array}{c}\text { Strong } \\
\text { recommendations }\end{array}$} & $\begin{array}{c}\text { Weak } \\
\text { recommendations }\end{array}$ \\
\hline $\begin{array}{l}\text { Uncertainty or variability } \\
\text { in values and } \\
\text { preferences }\end{array}$ & $\begin{array}{c}\text { Young patients with } \\
\text { lymphoma place a } \\
\text { higher value on the } \\
\text { life-prolonging effects } \\
\text { of chemotherapy over } \\
\text { treatment toxicity }\end{array}$ & $\begin{array}{l}\text { Older patients with } \\
\text { lymphoma may not } \\
\text { place a higher value } \\
\text { on chemotherapy over } \\
\text { treatment toxicity }\end{array}$ \\
$\begin{array}{ll}\text { Uncertainty about } \\
\text { whether the interven- } \\
\text { tion represents a wise } \\
\text { use of resources }\end{array}$ & $\begin{array}{l}\text { prophylaxis against } \\
\text { stroke in patients with } \\
\text { transient ischemic } \\
\text { attacks }\end{array}$ & $\begin{array}{l}\text { The high cost of } \\
\text { clopidogrel and } \\
\text { dipyridamole/ASA as } \\
\text { prophylaxis against } \\
\text { stroke in patients with } \\
\text { transient ischemic } \\
\text { attacks }\end{array}$ \\
\hline
\end{tabular}

ASA Acetylsalicylic acid

\section{CONCLUSION}

A summary of quality of evidence and strength of recommendations can aid clinicians in using formal guidelines. The GRADE system represents a clear, transparent approach, adopted by leading respiratory organizations.

CONFLICTS OF INTEREST: Dr Guyatt is a member of the GRADE working group, has an intellectual investment in the wide adoption of GRADE, and receives invitations to various events and offers for consultation in part as a function of his involvement with GRADE.

\section{REFERENCES}

1. Guyatt GH, Oxman AD, Vist GE, et al. GRADE: An emerging consensus on rating quality of evidence and strength of recommendations. BMJ 2008;336:924-6.

2. Atkins D, Eccles M, Flottorp S, et al. Systems for grading the quality of evidence and the strength of recommendations I: Critical appraisal of existing approaches. The GRADE Working Group. BMC Health Serv Res 2004;4:38.

3. Lacchetti C, Ioannidis J, Guyatt G. Surprising results of randomized trials. In: Guyatt G et al, eds. The Users' Guides to the Medical Literature: A Manual for Evidence-Based Clinical Practice. New York: McGraw-Hill, 2008.

4. Guidelines for counseling postmenopausal women about preventive hormone therapy. American College of Physicians. Ann Intern Med 1992;117:1038-41.

5. Humphrey LL, Chan BK, Sox H.C. Postmenopausal hormone replacement therapy and the primary prevention of cardiovascular disease. Ann Intern Med 2002;137:273-84.

6. Hulley S, Grady D, Bush T, et al. Randomized trial of estrogen plus progestin for secondary prevention of coronary heart disease in postmenopausal women. Heart and Estrogen/progestin Replacement Study (HERS) Research Group. JAMA 1998;280:605-13.

7. Rossouw JE, Anderson GL, Prentice RL, et al. Risks and benefits of estrogen plus progestin in healthy postmenopausal women: Principal results From the Women's Health Initiative randomized controlled trial. JAMA 2002;288:321-33.

8. Echt DS, Liebson PR, Mitchell LB, et al. Mortality and morbidity in patients receiving encainide, flecainide, or placebo. The Cardiac Arrhythmia Suppression Trial. N Engl J Med 1991;324:781-8.

9. Antman EM, Lau J, Kupelnick B, Mosteller F, Chalmers TC. A comparison of results of meta-analyses of randomized control trials and recommendations of clinical experts. Treatments for myocardial infarction. JAMA 1992;268:240-8.

10. Aspirin and Reye syndrome. Committee on Infectious Diseases. Pediatrics $1982 ; 69: 810-2$

\section{New developments in the pharmacotherapy of asthma}

\author{
Louis-Philippe Boulet MD FCCP FRCPC \\ Centre de pneumologie, Institut de Cardiologie et de \\ pneumologie de l'Université Laval, Hôpital Laval, Québec \\ E-mail Ipboulet@med.ulaval.ca
}

$\mathrm{R}$ eviews of potential new targets and agents for the treatment of asthma have been published in recent years (1-4). This document briefly summarizes some potential new targets for asthma therapy (Table 1).

TABLE 1

Potential new asthma medications*

\begin{tabular}{ll}
\hline $\begin{array}{l}\text { Bronchodilators } \\
\text { Muscarinic receptors antagonists. }\end{array}$ & Theophylline derivatives \\
Potassium channel openers & Ultra-long-acting $\beta$-agonists \\
Prostaglandin $\mathrm{E}_{2}$ & Vasoactive intestinal peptide \\
Agents acting on airway inflammation and/or remodelling \\
Antagonists of endothelin receptors & Immunomodulators (T-cells) \\
Antagonists of proinflammatory cytokines & Kinase inhibitors \\
Anti-inflammatory cytokines & LT/5-LO/FLAP inhibitors \\
Blockers of inflammatory cell migration & Nicotine receptors agonists \\
Drugs acting on neutrophils & Nitric oxide inhibitors \\
Fibrogenic cytokine antagonists & Phosphodiesterase inhibitors \\
Gene therapy & Soft/dissociated corticosteroids \\
Heparin-like substances & Transcription factor inhibitors \\
Immunoglobulin E inhibitors & Tryptase inhibitors \\
\hline
\end{tabular}

*Partial list. 5-LO 5-lipoxygenase; Flap 5-lipoxygenase activating protein; LT Leukotriene

\section{POTENTIAL NEW TARGETS FOR ASTHMA THERAPY}

New bronchodilators

Ultra-long $\beta_{2}$-receptor agonists $(24 \mathrm{~h})$ such as indacaterol showed fast and prolonged (greater than $24 \mathrm{~h}$ ) bronchodilation and are well tolerated (5). A variety of new agents with bronchodilating properties have been studied, but their frequent side effects and/or poor efficacy, especially when compared with the highly effective $\beta_{2}$-agonists, make their usefulness uncertain $(2,3)$.

Novel corticosteroids

The nonhalogenated inhaled corticosteroid ciclesonide, activated by lung esterases, has a favourable safety profile with efficacy that is at least equivalent to currently used inhaled corticosteroids (6). The new so-called dissociated corticosteroids, which can selectively transrepress proinflammatory genes without transactivation of genes involved in the metabolic effects of corticosteroids, are currently being investigated.

\section{Phosphodiesterase inhibitors}

Phosphodiesterases break down cyclic nucleotides such as cyclic AMP and act on airway smooth muscle as well as on immune and neural mechanisms. Phosphodiesterase-4 inhibitors such as cilomilast and roflumilast have shown some benefit in asthma $(2,7)$. 


\section{5-LO/FLAP inhibitors}

New agents that could possibly block not only the cysteinyl leukotrienes, but also leukotriene B4, therefore possibly influencing neutrophilic as well as eosinophilic inflammation, could be of interest (8).

Immunomodulators acting on $\mathrm{T}$ cells, and immunotherapy A shift in the helper T cells (Th) Th1/Th2 balance may induce a tolerance to allergens and may be useful in the treatment and prevention of allergic diseases. In this regard, immunotherapy with 'CpG' DNA oligonucleotides may reduce airway inflammation and hyperresponsiveness in animal models (9). Vaccination with Bacille Calmette-Guérin has been proposed to induce protective effects in increasing Th1 responses, although more studies are needed (10).

\section{Inhibitors of transcription factors}

Various transcription factors such as nuclear factor- $\kappa \mathrm{B}$, nuclear factor-AT, and GATA-binding protein 3 are involved in the expression of inflammatory genes and may be a target for inhibitors (11).

\section{Nicotine receptor agonists}

Nicotinic agonists may inhibit various aspects of the inflammatory response and recently developed analogues have provided interesting preliminary results (12).

\section{Antagonists of proinflammatory cytokines}

Various agents have been developed to block the effects of interleukins (ILs) such as IL-4, IL-5, IL-9, IL-13 and GM-CSF. In regard to IL-5 antagonists, 'mepolizumab' suppressed allergen-induced eosinophilic influx but not clinical asthmatic responses, and did not improve clinical measures of asthma (13). Such agents may be more effective in patients with high levels of eosinophils. Other potential targets include IL-4 and IL-13, two closely related ILs that play a role in immunoglobulin (Ig)E sensitization by B cells, and IL-9, a Th2 cytokine (14). Patients with refractory asthma may also have evidence of upregulation of the tumour necrosis factor-alpha, and etanercept, an IgG1-tumour necrosis factor p75 receptor fusion protein, has been associated with a significant reduction in airway inflammation and hyperresponsiveness and improvement in asthma-related quality of life in severe asthma (15).

\section{Anti-inflammatory cytokines}

IL-10 inhibits the synthesis of many inflammatory proteins and may have anti-inflammatory properties that are useful in asthma. Interferon-alpha treatment may possibly reduce corticosteroid requirements in corticosteroid-resistant asthmatic patients (16). Other anti-inflammatory cytokines, including IL-12, IL-18 and interferon-gamma, may be potential targets for therapy.

\footnotetext{
Agents blocking the migration of inflammatory cells

More than 50 different chemokines act on inflammatory cell recruitment via the activation of G-protein-coupled surface receptors, and may be potential targets for therapy (17). We recently reported that TPI ASM-8, containing two antisense oligonucleotides down-regulating human CC chemokine receptor 3 and the common beta chain of IL-3, IL-5 and granulocyte-macrophage colony-stimulating factor receptors, blunted the increase in total cells after allergen challenge while significantly inhibiting the early asthmatic response (18).
}

\section{Adhesion molecule inhibitors}

Cell adhesion molecules such as selectins and integrins play a major role in cell trafficking and have been under intense investigation as potential new treatments (19). We reported that efalizumab, a monoclonal antibody against the lymphocyte function antigen-1 alpha chain, reduced the allergen-induced late asthmatic response (by 50\%) and the postallergen increase in sputum EG2-positive and metachromatic cells (20).

\section{IgE inhibitors}

Recombinant humanized monoclonal antibody against IgE (omalizumab) reduces allergen-induced asthmatic responses and has anti-inflammatory effects, while improving asthma and reducing asthma exacerbations, even in patients with relatively severe asthma (21). This mechanism could also be the target of new drugs.

\section{Agents acting on airway remodelling}

There is increasing interest in developing drugs that could act on certain aspects of airway remodelling, for example by antagonizing key cytokines such as transforming growth factorbeta, matrix metalloproteinase-9, ADAM-33 and vascular endothelial growth factor (22). This field remains to be explored.

\section{Gene therapy and pharmacotargeting}

Genetic markers could help to predict the efficacy and safety of asthma medications in any given individual (23). When the role of specific genes in the development of asthma will be determined, new therapeutic interventions could be developed to influence asthma outcomes.

\section{CONCLUSION}

A large number of new targets for asthma therapy have been identified, but it is likely that only a few new agents will demonstrate sufficient efficacy and safety to be of use, particularly in severe asthma. Among those agents, immunomodulators are of particular interest.

CONFLICTS OF INTEREST: Advisory Boards: AstraZeneca, GlaxoSmithKline, Merck Frosst, Novartis and Schering-Plough. Lecture fees: Altana, AstraZeneca, GlaxoSmithKline, Merck Frosst, Novartis and MedImmune. Sponsorship for investigatorgenerated research: AstraZeneca, GSK, Merck Frosst, ScheringPlough and Novartis. Research funding for participating in multicenter studies: Alexion, AsthmaTx, AstraZeneca, Boehringer-Ingelheim, Ception, GlaxoSmithKline, Genentech, IVAX, MedImmune, Novartis, Topigen, Wyeth. Support for the production of educational materials and initiatives: AstraZeneca, GlaxoSmithKline and Merck Frosst. Other forms of compensation or salary from industrial sources: None.

\section{REFERENCES}

1. Adcock IM, Caramori G, Chung KF. New targets for drug development in asthma. Lancet 2008;372:1073-87.

2. Barnes PJ. New drugs for asthma. Nat Rev Drug Discov 2004;3:831-44.

3. Belvisi MG, Hele DJ, Birrell MA. New anti-inflammatory therapies and targets for asthma and chronic obstructive pulmonary disease. Expert Opin Ther Targets 2004;8:265-85.

4. Walsh GM. Targeting airway inflammation: Novel therapies for the treatment of asthma. Curr Med Chem 2006;13:3105-11.

5. LaForce C, Alexander M, Deckelmann R, et al. Indacaterol provides sustained $24 \mathrm{~h}$ bronchodilation on once-daily dosing in asthma: A 7-day dose-ranging study. Allergy 2008;63:103-11 
6. Colice GL. New developments in inhaled corticosteroids. Allergy Asthma Proc 2006;27:332-40.

7. Souness JE, Aldous D, Sargent C. Immunosuppressive and antiinflammatory effects of cyclic AMP phosphodiesterase (PDE) type 4 inhibitors. Immunopharmacology 2000;47:127-62.

8. Evans JF, Ferguson AD, Mosley RT, Hutchinson JH. What's all the FLAP about?: 5-lipoxygenase-activating protein inhibitors for inflammatory diseases. Trends Pharmacol Sci 2008;29:72-8.

9. Jain VV, Businga TR, Kitagaki K, George CL, O'Shaughnessy PT, Kline JN. Mucosal immunotherapy with $\mathrm{CpG}$ oligodeoxynucleotides reverses a murine model of chronic asthma induced by repeated antigen exposure. Am J Physiol Lung Cell Mol Physiol 2003;285:1137-46.

10. Barlan IB, Bahceciler N, Akdis M, Akdis CA. Role of bacillus CalmetteGuérin as an immunomodulator for the prevention and treatment of allergy and asthma. Curr Opin Allergy Clin Immunol 2005;5:552-7.

11. Zhou M, Ouyang W. The function role of GATA-3 in Th1 and Th2 differentiation. Immunol Res 2003;28:25-37.

12. Blanchet MR, Langlois A, Israël-Assayag E, et al. Modulation of eosinophil activation in vitro by a nicotinic receptor agonist. J Leukoc Biol 2007;81:1245-51.

13. Leckie MJ, ten Brinke A, Khan J, et al. Effects of an interleukin-5 blocking monoclonal antibody on eosinophils, airway hyperresponsiveness, and the late asthmatic response. Lancet 2000;356:2144-8.

14. Temann UA, Ray P, Flavell RA. Pulmonary overexpression of IL-9 induces Th2 cytokine expression, leading to immune pathology. J Clin Invest 2002;109:29-39.

15. Berry MA, Hargadon B, Shelley M, et al. Evidence of a role of tumor necrosis factor alpha in refractory asthma. N Engl J Med 2006;354:697-708.

16. Simon HU, Seelbach H, Ehmann R, Schmitz M. Clinical and immunological effects of low-dose IFN-alpha treatment in patients with corticosteroid-resistant asthma. Allergy 2003;58:1250-5.

17. Palmqvist C, Wardlaw AJ, Bradding P. Chemokines and their receptors as potential targets for the treatment of asthma. $\mathrm{Br} \mathrm{J}$ Pharmacol 2007 151:725-36.

18. Gauvreau GM, Boulet LP, Cockcroft DW, et al. Antisense therapy against CCR3 and the common beta chain attenuates allergen-induced eosinophilic responses. Am J Respir Crit Care Med 2998;177:952-8.

19. Woodside DG, Vanderslice P. Cell adhesion antagonists: Therapeutic potential in asthma and chronic obstructive pulmonary disease. BioDrugs 2008;22:85-100.

20. Gauvreau GM, Becker AB, Boulet LP, et al. The effects of an anti$\mathrm{CD11a} \mathrm{mAb}$, efalizumab, on allergen-induced airway responses and airway inflammation in subjects with atopic asthma. J Allergy Clin Immunol 2003;112:331-338.

21. Holgate ST, Djukanović R, Casale T, Bousquet J. Antiimmunoglobulin $\mathrm{E}$ treatment with omalizumab in allergic diseases: An update on anti-inflammatory activity and clinical efficacy. Clin Exp Allergy 2005;35:408-16.

22. Mauad T, Bel EH, Sterk PJ. Asthma therapy and airway remodeling. J Allergy Clin Immunol 2007;120:997-1009.

23. Bossé Y, Hudson TJ. Toward a comprehensive set of asthma susceptibility genes. Ann Rev Med 2007;58:171-84.

\section{New diagnostics and emerging technologies for tuberculosis}

\author{
Madhukar Pai MD PhD \\ Department of Epidemiology, Biostatistics \& Occupational \\ Health, McGill University, Montreal, \& Montreal Chest Institute, \\ Montreal, Quebec \\ E-mailmadhukar.pai@mcgill.ca
}

$\mathrm{T}$ uberculosis (TB) is a major threat to global health, with nearly nine million people developing TB each year and 1.6 million dying from it (1). TB case detection continues to be a problem, with one-half of all patients being undiagnosed. The situation is worsened by HIV infection, multidrug-resistant $\mathrm{TB}$ and extensively drug-resistant TB.

In many settings, TB diagnosis still relies on sputum smear microscopy, culture, tuberculin skin test and chest radiography, tests with known limitations, especially in countries with high
HIV rates. Tests for detection of drug resistance are time consuming, tedious, and inaccessible in many settings.

The involvement of agencies such as the Stop TB Partnership's Working Group on New Diagnostics, the World Health Organization, the Special Programme for Research \& Training in Tropical Diseases, and the Foundation for Innovative New Diagnostics has led to a resurgence of interest in TB diagnostics (2-4). Figure 1 illustrates the types of technology platforms that are currently in the pipeline, from simple microscopic and growth detection systems to molecular and immune-based systems.

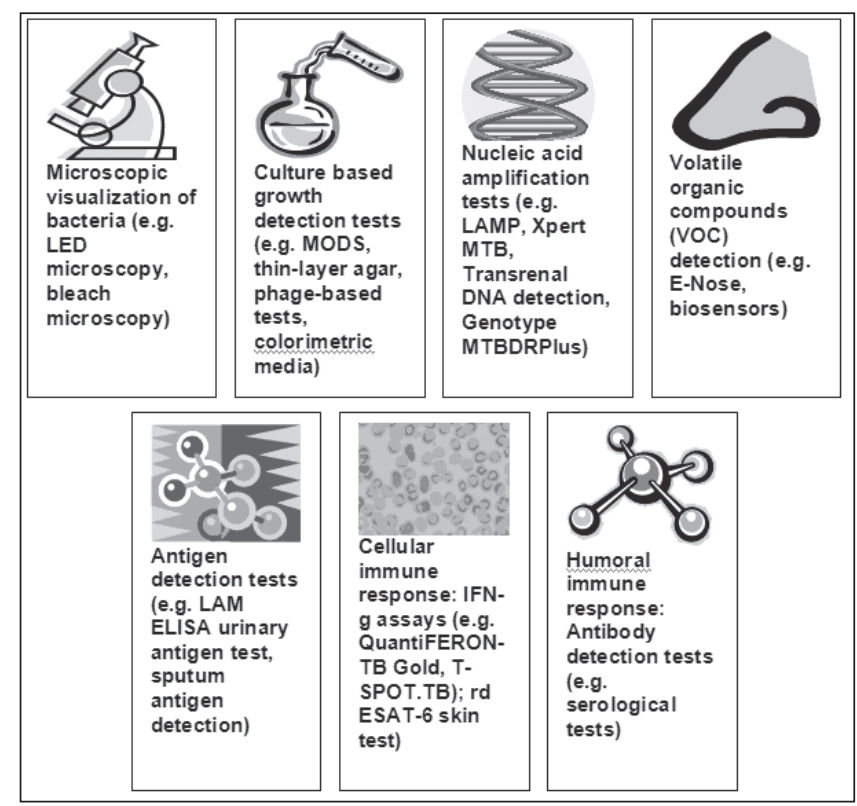

Figure 1) Tuberculosis (TB) diagnostics pipeline. ESAT-6 Early secreted antigen target 6; IFN-g Interferon-gamma; LAMP Loopmediated isothermal amplification; LED Light-emitting diode; MODS Microscopic-observation drug susceptibility assay; VOC Volatile organic compounds

For latent TB infection, interferon-gamma release assays $(5,6)$ offer in vitro tests, more specific than the tuberculin skin test with several logistical advantages. An improved rdESAT-6 based skin test is also under evaluation for latent TB.

For active TB, efforts are being made to optimize sputum smear microscopy using simple light-emitting diode-based fluorescence microscopy systems, and sputum processing methods such as bleach $(7,8)$. Automated liquid cultures (eg, the Mycobacteria Growth Indicator Tube), microscopic observation drug susceptibility, and newer nucleic acid amplification tests such as loop-mediated isothermal amplification are other approaches being evaluated $(3,4)$. While existing serological antibody tests have largely failed (9), antigen detection tests have shown some promise.

For rapid detection of drug resistance, bacteriophage-based tests, microscopic observation drug susceptibility, colorimetric culture media and molecular tests such as line probe assays have been evaluated in many settings (10), and line probe assays promise rapid detection of rifampin and isoniazid resistance $(10,11)$.

The TB diagnostics pipeline now includes several technologies showing great promise. With the resurgence of interest in TB control and the recent influx of funding and political support, the 
next few years will see the introduction of new tools in TB control programs. The Stop TB Partnership has recently established a Retooling Task Force to catalyze the healthcare profession towards the introduction of new tools for TB control.

\section{CONFLICTS OF INTEREST: None declared.}

\section{REFERENCES}

1. World Health Organization. Global tuberculosis control. Surveillance, planning, financing. WHO Report 2007. WHO/HTM/TB/2007.376. Geneva: World Health Organization, 2007.

2. Perkins MD, Roscigno G, Zumla A. Progress towards improved tuberculosis diagnostics for developing countries. Lancet 2006;367:942-3.

3. Pai M, Kalantri S, Dheda K. New tools and emerging technologies for the diagnosis of tuberculosis: Part 1. Latent tuberculosis. Expert Rev Mol Diagn 2006;6:413-22.

4. Pai M, O'Brien R. New diagnostics for latent and active tuberculosis: State of the art and future prospects. Semin Respir Crit Care Med 2008;29:560-68.

5. Menzies D, Pai M, Comstock G. Meta-analysis: New tests for the diagnosis of latent tuberculosis infection: Areas of uncertainty and recommendations for research. Ann Intern Med 2007;146:340-54.

6. Pai M, Zwerling A, Menzies D. T-cell based assays for the diagnosis of latent tuberculosis infection: An update. Ann Intern Med 2008;149:177-84.

7. Steingart KR, Henry M, Ng V, et al. Fluorescence versus conventional sputum smear microscopy for tuberculosis: a systematic review. Lancet Infect Dis 2006;6:570-81.

8. Steingart KR, Ramsay A, Pai M. Optimizing sputum smear microscopy for the diagnosis of pulmonary tuberculosis. Expert review of anti-infective therapy 2007;5:327-31.

9. Steingart KR, Henry M, Laal S, et al. Commercial serological antibody detection tests for the diagnosis of pulmonary tuberculosis: A systematic review. PLoS Medicine 2007;4:e202.

10. Migliori GB, A Matteelli A, Cirillo D, Pai M. Diagnosis of multidrugresistant tuberculosis and extensively drug-resistant tuberculosis: Current standards and challenges. Can J Infect Dis Med Microbiol 2008;19:169-72.

11. Pai M, Ramsay A, O’Brien R. Evidence-based tuberculosis diagnosis. PLoS Med 2008;5:e156.

\section{The challenge of managing multiple drug-resistant tuberculosis}

\author{
J Mark FitzGerald MD \\ Respiratory Medicine, University of British Columbia, Vancouver, \\ British Columbia \\ E-mailmarkf@interchange.ubc.ca
}

\section{BACKGROUND}

$\mathrm{I}$ global terms, tuberculosis (TB) remains a major public health problem (1). Although overall rates of TB are relatively low in Canada, they remain unacceptably high among the foreign-born and marginalized populations including Aboriginal Canadians and the urban poor. In Canada, rates of drug-resistant disease are relatively low, being $11 \%$ overall, with $8.6 \%$ of cases showing mono resistance, $0.9 \%$ multiple drug-resistant $\mathrm{TB}$, (MDRTB - defined as resistance to both isoniazid [INH] and rifampin), and $1.5 \%$ of cases showing resistance to more than one drug other than INH or rifampin. Between 1998 and 2007 there were 170 MDRTB cases reported in Canada, with 102 (60\%) reported in Ontario and 34 (20\%) in British Columbia. This pattern reflects, in part, the fact that both of these provinces receive a disproportionate number of immigrants from high-prevalence TB countries where the number of resistant cases is also higher. So far, there have only been isolated reports of extremely drug-resistant TB (XDRTB) in Canada. XDRTB has recently been redefined as resistance to at least INH, rifampin, any quinolone and at least one of the following injectable drugs: capreomycin, kanamycin or amikacin.

\section{Management of drug-sensitive TB}

The management of drug-sensitive TB involves an initial twomonth treatment with at least three drugs: INH, rifampin and pyrazinamide, and where drug resistance is suspected, the addition of ethambutol and/or streptomycin (1). Once drug sensitivities are available, in the presence of a drug-sensitive organism, the continuation phase usually consists of INH and rifampin for a further four months. In the presence of extensive disease and especially if associated with cavitation on chest radiograph and persistent positive cultures at two months, treatment for nine months is recommended (1). The use of directly observed therapy has been recommended in all cases of TB. Although the level of evidence supporting this recommendation has been questioned (2), many still advocate such a treatment modality, especially in the presence of a poor social support network and drug-resistant disease.

\section{Management of drug-resistant TB}

The emergence of XDRTB has focused clinicians' attention on the need for greater vigilance in the management of TB cases (3). Globally, it is estimated that approximately 420,000 MDRTB cases were diagnosed in 2006 and it has been extrapolated from surveillance studies that there were approximately 42,000 cases of XDRTB globally during the same period. Although the frequency of drug resistant TB is relatively low in Canada, given the pattern of immigration, Canadian physicians caring for patients with TB are likely to see such patients intermittently. Given the infrequent nature of such clinical cases, drug-resistant TB should be managed in collaboration with a physician and/or centre with expertise in the care of such cases. The key principles in the management of drug resistant TB are briefly outlined in Table 1 .

\section{TABLE 1}

\section{Important principles in the management of drug-resistant} tuberculosis

1. Start with a standard four-drug regimen

2. If resistance is strongly suspected, and especially if the patient has been previously treated, add at least two new drugs not used previously

3. Single drugs should never be added to a failing regimen

4. Use directly observed therapy

5. Perform drug susceptibility on all initial isolates, and subsequently if the regimen is failing

6. If resistance is confirmed, use at least three drugs and preferably more known to be active against the organism

7. In resistant cases, therapy may be required for 24 months, but at least six months postbacterial conversion

8. Drug susceptibility testing should be repeated if cultures remain positive after three months of therapy

9. Consider drug level assessments as part of management

10. Refer selected cases for surgery

Adapted from reference 4

As noted, in the presence of a prior history of treatment for TB, the possibility of drug-resistant TB should be considered. This is especially important if the patient was treated in a region where drug resistance is known to be common. In such cases, an attempt should be made to identify what treatment 
the patient received. Although a patient may not be familiar with his or her treatment regimen, it may be documented in immigration papers, especially if a postlanding surveillance was conducted. If the patient does not recall receiving injections as part of his or her TB treatment, it can be assumed that streptomycin was not administered, and this drug may be used, along with a quinolone, most commonly moxifloxacin, in addition to the other first line drugs (INH, rifampin, pyrazinamide and ethambutol). These drugs should be continued until drug sensitivities are available, at which point the treatment regimen can be adjusted accordingly. In the presence of drug-resistant disease, the regimen must be of longer duration, and careful patient follow-up including monitoring not only of clinical but also of bacteriological and radiological response is required.

If the disease is localized, adjunctive therapy with surgical resection has been shown to increase cure rates. Such an intervention needs to be planned carefully, with attention to infection control and involvement of a centre with appropriate surgical expertise. It has been our clinical experience that assessment of drug levels can be especially helpful when a recurrence occurs despite what appears to have been an adequate regimen delivered in a directly observed fashion.

Due to the complexity of regimens needed to treat drug resistant disease, their detailed description is beyond the scope of this brief overview. However, it suffices to say that because of the empirical nature of many of the suggested regimens and their associated toxicity, careful ongoing monitoring for response to therapy and side effects is required. A detailed overview of the management of drug-resistant TB is provided in two recently published papers $(4,5)$.

Unfortunately, XDRTB, especially when it occurs in association with HIV infection, has a dismal prognosis (6). A more recent study from Peru has reported better outcomes (7). A major challenge faced by clinicians caring for such patients is that drug-resistant disease is often not immediately identifiable, and many patients will have died before results from drug sensitivity testing using traditional methods becomes available. Although there are promising new technologies that will provide drug sensitivities earlier, their availability where they are most needed will be limited for the foreseeable future (8).

In conclusion, although we had effective drug treatment for $\mathrm{TB}$ for many years, the convergence of high rates of dual HIV and TB infection coupled with a lack of political will to tackle this issue has now left us with rising rates of TB and the emergence of drugresistant disease. Overcoming the challenge of drug-resistant TB will be difficult unless there is a fundamental recognition of the global public health impact of these resistant cases. It will also require the discovery of novel new therapies, ideally requiring a shorter duration of treatment, coupled with the widespread availability of better diagnostic technologies, and especially those with the capacity for earlier detection of drug-resistant TB. Unfortunately, the lack of political will to provide the necessary resources to address this issue does not bode well for success $(9,10)$.

ACKNOWLEDGEMENTS: Dr FitzGerald is a recipient of a CIHR/BC Lung Scientist Award and also a Michael Smith Foundation for Health Research Distinguished Scholar Award.

CONFLICTS OF INTEREST: None.

\section{REFERENCES}

1. Cook V, FitzGerald JM. Tuberculosis. In: Repchinsky C, ed. Therapeutic Choices, 5th edn. 2007:1261-77.

2. Drug Resistant Tuberculosis. In: Long R, Ellis E, eds. Canadian Tuberculosis Standards, 6th edn. Ministry of Health, 2007:147-81.

3. Cox HS, Morrow M, Deutschmann PW. Long term efficacy of DOTS regimens for tuberculosis: systematic review. BMJ 2008;336:484-7.

4. Yew WW, Leung CC. Management of multi-drug resistant tuberculosis: Update 2007. Respirology 2008;13:21-46.

5. Grant A, Gothard P, Thwaites G. Managing drug resistant tuberculosis. BMJ 2008;337:564-9.

6. Basu, S Galvani AP. Extensively drug-resistant tuberculosis in South Africa. Lancet 2007;369:272-3.

7. Mitnick CD, Shin SS, Seung KJ, et al. Comprehensive treatment of extensively drug-resistant tuberculosis. N Engl J Med 2008;359:563-74.

8. Battista G, Matteeli A, Cirillo D, Pai M. Diagnosis of multi drug resistant tuberculosis and extensively drug resistant tuberculosis: Current standards and challenges. Can J Infect Dis Med Microbiol 2008;19:169-72.

9. Maartens G, Wilkinson RJ. Tuberculosis. Lancet 2007;370:2030-43.

10. Editorial: The rise and spread of drug-resistant tuberculosis. Lancet 2008;371:698.

\section{Keeping ventilated and 'at-risk' patients out of the intensive care unit}

\author{
Douglas A McKim MD \\ Medical Director, Respiratory Rehabilitation Services, The \\ Ottawa Hospital Rehabilitation Centre, Ottawa, Ontario \\ E-maildmckim@ottawahospital.on.ca
}

\section{PREVENTION}

$T$ he approximately 70 intensive care unit (ICU) beds in Ontario used by long-term ventilated patients have been estimated to prevent the admission of 1000 to 2000 critical care patients (1). Preventive strategies will reduce critical care utilization in conditions such as neuromuscular diseases (NMD) including amyotrophic lateral sclerosis, spinal cord injury, muscular dystrophies and chest-wall disorders. Patients benefit from preventive techniques of airway management, elective noninvasive ventilation, and most importantly, airway clearance.

Respiratory muscle weakness impairs the ability to ventilate and the ability to cough to clear airway secretions. In NMD, respiratory muscle weakness results in an inadequate vital capacity and insufficient expiratory force to achieve effective cough and airway clearance. Cough capacity declines further during an upper respiratory infection (2). This increases the risk of pneumonia and respiratory failure from a simple upper respiratory tract infection. Once ventilated in an emergency department or an ICU, the risk for longterm invasive ventilation is very high. Bulbar weakness further increases the risk due to an inability to protect the airway and to coordinate glottic function for cough. Peak cough flows (PCF) greater than $160 \mathrm{~L} / \mathrm{min}$ are necessary to prevent reintubation in patients with NMD (3) and those capable of PCFs $270 \mathrm{~L} / \mathrm{min}$ or greater are at minimal risk for acute respiratory compromise $(4,5)$.

\section{Lung volume recruitment}

Patients with motivation, bulbar function, and sufficient respiratory system compliance can learn to recruit lung volume by adding pressure and volume to the restricted respiratory system. This is termed lung volume recruitment (LVR) or "breathstacking'. It augments expiratory flow rate during coughing. A higher PCF is more effective for airway clearance. LVR is performed by adding sequential volumes of air on top of each other using the glottis as a valve (Figure 1). 


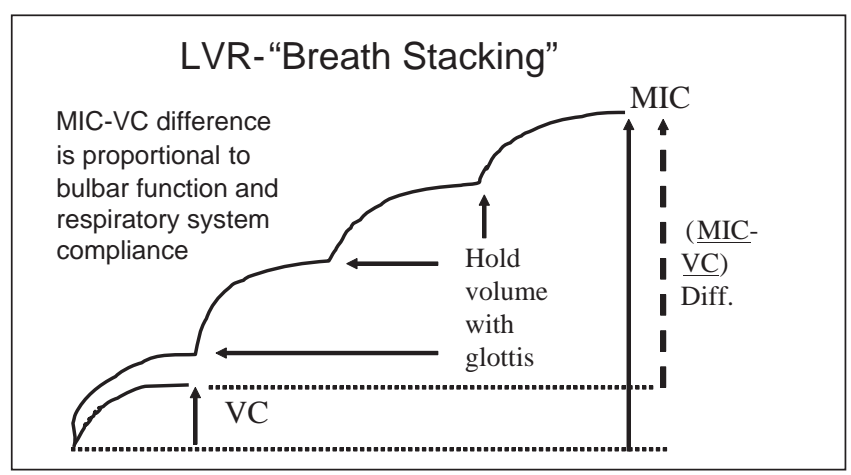

Figure 1) Lung volume recruitment (LVR). Volumes are stacked, using the glottis to hold each sequential volume. The maximum insufflation capacity (MIC) (6) is the maximal volume that can be held by a closed glottis. The MIC-vital capacity (VC) difference reflects respiratory system compliance and bulbar function

LVR is achieved with a modified hand-held resuscitation bag with corrugated tubing, a one-way valve, and a mouth piece or full face mask if significant bulbar impairment is present. Detailed instructions are available at <www.irrd.ca/ education $>(7)$.

LVR can also be achieved with a home volume ventilator with a mouth piece, or with glosso-pharyngeal breathing. It is very important to provide visual feedback to patients and to illustrate the numeric value of the unassisted vital capacity and the increase to maximum insufflation capacity (Figure 2). PCFs can be measured using a peak flow meter and expressed in litres per minute, as in asthma. Patients must understand the effect of LVR on PCFs in order to use these techniques during an acute URTI or following aspiration. This circuit must not be applied to a cuffed tracheostomy during resuscitation, because a closed system could result in a tension pneumothorax.

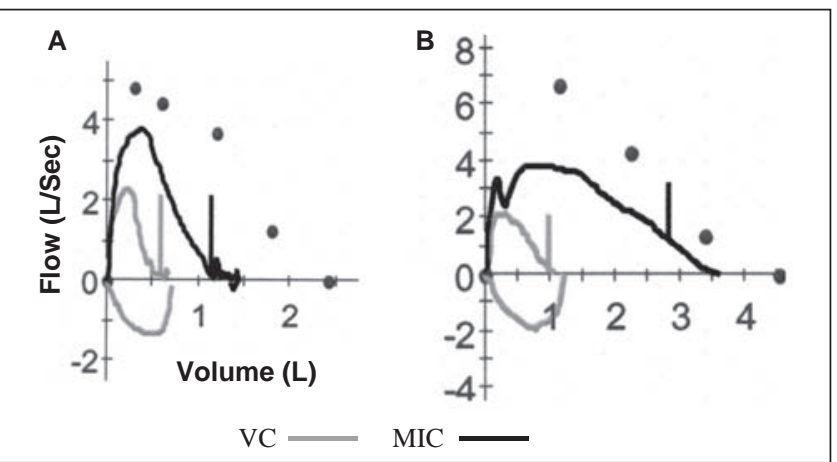

Figure 2) Flow volume loops: spontaneous and following lung volume recruitment to achieve maximum insufflation capacity (MIC). A Postpolio: greater increase in peak expiratory flow (low compliance), B Tetraplegia: greater increase in MIC (normal compliance)

\section{Manually assisted cough}

During a cough, compression of the abdomen, just before glottic opening, is referred to as manually assisted cough, sufficient in some individuals to achieve an adequate cough without breath stacking. However, LVR alone is superior to manually assisted cough alone in increasing the maximum insufflation capacity and PCF (8). Augmentation of PCFs allows for adequate airway clearance during an upper respiratory tract infection or following aspiration and has been shown to reduce hospitalization (4).

Mechanical insufflation-exsufflation, (CoughAssist ${ }^{\mathrm{TM}}$ )

The CoughAssist device (http://www.irrd.ca/education) is a bedside apparatus, applied noninvasively through a full face mask, which generates a positive inspiratory pressure to provide lung inflation followed rapidly by a negative pressure to create high expiratory flows that shear mucous away from the airway. It can also be applied through an artificial airway. Although limited by the quality of evidence, reports demonstrate positive outcomes with an absence of adverse effects. The device is most applicable in NMD or chest wall diseases (9).

\section{Elective noninvasive ventilation}

Patients at risk of respiratory failure should be monitored to determine an appropriate time for initiation of noninvasive ventilation. This varies with the type of NMD, but in general is applied at the earliest onset of symptoms of sleep-related breathing difficulties, nocturnal desaturation, orthopnea or daytime elevation of $\mathrm{CO}_{2}$ above $45 \mathrm{mmHg}$. Outpatient initiation is been better accepted by patients and families and achieved similar results to inpatient initiation (10).

\section{CONCLUSION}

The combination of education and skills in airway clearance techniques and the provision of elective noninvasive ventilation will reduce unnecessary critical care utilization and improve access to critical care beds.

\section{CONFLICTS OF INTEREST: None.}

\section{REFERENCES}

1. Chronic ventilation strategy task force, Final report, June 30, 2006. Critical Care Secretariat, MOHLTC.

2. Poponick JM, Jacobs I, Supinski G, DiMarco AF. Effect of upper respiratory tract infection in patients with neuromuscular disease. Am J Respir Crit Care Med 1997;156:659-64.

3. Bach JR, Saporito LR. Criteria for extubation and tracheostomy tube removal for patients with ventilatory failure: A different approach to weaning. Chest 1996;110:1566-71.

4. Bach JR, Ishikawa Y, Kim H. Prevention of pulmonary morbidity for patients with Duchenne muscular dystrophy. Chest 1997;112;1024-8.

5. Respiratory care of the patient with Duchenne muscular dystrophy; ATS Consensus Statement. Am J Respir Crit Care Med 2004;170:456-65.

6. Kang SW, Bach JR. Maximum insufflation capacity. Chest 2000;118:61-5.

7. McKim D, LeBlanc C, Walker K, Liteplo J. Respiratory care protocols for spinal cord injuries and neuromuscular diseases. 2002. Institute for Rehabilitation Research and Development. <www.irrd.ca/education> (Version current at November 5, 2008).

8. Ishikawa Y, Bach JR, Komaroff E, Miura T, Jackson-Parekh R. Cough augmentation in Duchenne muscular dystrophy. Am J Phys Med Rehabil 2008;87:726-30.

9. Winck JC, Gonçalves MR, Lourenço C, et al. Effects of mechanical insufflation-exsufflation on respiratory parameters for patients with chronic airway secretion encumbrance. Chest 2004;126:774-80.

10. Chatwin M, Ward S, Nickol AH, Polkey MI, Simonds AK.

Randomised trial of outpatient versus inpatient initiation of noninvasive ventilation (NIV) in nocturnal hypoventilation due to neuromuscular and chest wall disease Eur Respir J 2004;24(Suppl 48):476s. 


\section{Liberation from long-term intensive care unit ventilation}

\author{
Ian M Fraser MD \\ Respirology, Toronto East General Hospital and Department of \\ Medicine, University of Toronto, Ontario \\ E-mail ifras@tegh.on.ca
}

$\mathrm{P}$ rolonged mechanical ventilation, defined as being ventilated for $6 \mathrm{~h}$ or more per day for 21 or more days, identifies a patient group at risk for long-term (formerly chronic) ventilation (1). Despite a $50 \%$ to $60 \%$ weaning rate, one-year survival varies from $23 \%$ to $76 \%$ in this population, and only $8 \%$ to $10 \%$ achieve functional independence (1-3). A 2005 survey conducted in Ontario (4) identified acute lung injury/acute respiratory distress syndrome, chronic obstructive pulmonary disease, and nonobstructive lung disease (ie, progressive neuromuscular disease, thoracic cage abnormalities and high spinal cord injury) as the major long-term intensive care unit (ICU) ventilation diagnoses.

Mechanisms of ventilator dependence include systemic factors such as comorbid conditions and poor nutrition; mechanical factors such as reduced respiratory muscle capacity due to myopathy/neuropathy, and upper airway obstruction; iatrogenic factors such as inappropriate ventilator settings; medical errors; psychological factors such as delirium, depression, anxiety, and sleep deprivation; and process of care factors such as a lack of weaning and sedation protocols, and inadequate nursing staffing (1).

Weaning venues include the ICU, in-house weaning units, "Tele"-weaning, regional weaning centres and long-term assisted ventilation centres. The ideal patient-focused venue should incorporate: relative quiet and day/night cycles; easily visible outdoors; relative roominess; encouragement of supportive visitors; increased mobility; personal objects; independence; time and devices to increase communication; transition to oral feeding; time, space and personnel for reconditioning; active patient interactions; emphasis on staff nurturing; time and opportunity for counselling; time and space for patient/family palliative care; and home-geared discharge planning (1).

Management can be approached from a health care system, unit and individual patient viewpoint. Health care system management involves strategic planning to avoid unnecessary future ICU use and identification of service and capacity gaps (4). Unit management involves integrating, within local resource availability (5), evidence-based practice, knowledge translation (6) and an understanding of the biases in guideline development (7). "Hardwiring" best practice includes: specific weaning approach (1) (slow-paced with gradually lengthening of self-breathing trials with nonfatiguing comfortable ventilatory support between weaning trials); continuing ICU weaning best practice (daily spontaneous breathing trials, minimized sedation, nurse and/or respiratory therapist weaning protocols, daily wakeup and breathe) (8-10); and minimizing complications (central line and ventilator bundles, daily goals rounds, nutritional support, guideline-directed ventilator-acquired pneumonia treatment) (11-14), and possibly earlier tracheostomy. Optimal individual patient management requires an interdisciplinary team care $(15,16)$, an understanding of ethical issues in long term ventilation, and reliable palliative (17) and follow-up care (18).
In Canada, there are significant observational (prevalence, distribution, outcomes, capacity) and comparative (systematic health care delivery, models of care and outcomes, hardwired unit performance) knowledge gaps as well as a need to develop a national community of practice.

The challenge of liberating these patients in whole or in part from ventilator assistance requires a purposeful strategy by a dedicated interdisciplinary team, evidence-based practice, ethical decision-making and an integrated local approach to health care system delivery.

\section{CONFLICT OF INTEREST: None.}

\section{REFERENCES}

1. MacIntyre NR, Epstein SK, Carson S, Scheinhorn D, Christopher K, Muldoon S. Management of patients requiring prolonged mechanical ventilation: Report of a NAMDRC consensus conference. Chest 2005;1328:3937-54.

2. Scheinhorn DJ, Stearn Hassenpflug M, Votto JJ, et al. Post-ICU mechanical ventilation at 23 long-term care hospitals: A multicenter outcomes study. Chest 2007;131:85-93.

3. Mauri T, Pivi S, Bigatello M. Prolonged mechanical ventilation after critical illness. Minerva Anestesiol 2008;74:297-301.

4. Chronic Ventilation Strategy Taskforce, Final Report, June 30, 2006. <www.health.gov.on.ca/english/providers/program/critical_care/docs/ report_cvtg.pdf> (Version current at June 22, 2008).

5. Bucknall TK, Elizabeth Manias E, Presneill JJ. A randomized trial of protocol-directed sedation management for mechanical ventilation in an Australian intensive care unit. Crit Care Med 2008;36:1444-50.

6. van Nieuwenhoven CA, Vandenbroucke-Grauls C, van Tiel FH, et al. Feasibility and effects of the semirecumbent position to prevent ventilator-associated pneumonia: A randomized study. Crit Care Med 2006;34:396-402.

7. Tobin MJ, Jubran A. Meta-analysis under the spotlight: Focused on a meta-analysis of ventilator weaning. Crit Care Med 2008;36:1-7.

8. McIntyre NR, Cook DJ, Ely EW, et al. Evidence-based guidelines for weaning and discontinuing ventilatory support: A collective task force facilitated by the American College of Chest Physicians; the American Association for Respiratory Care; and the American College of Critical Care Medicine. Chest 2001;120:375s-396s.

9. Girard TD, Ely EW. Protocol-driven ventilator weaning: Reviewing the evidence. Clin Chest Med 2008;29:241-52.

10. Girard TD, Kress JP, Fuchs BD, et al. Efficacy and safety of a paired sedation and ventilator weaning protocol for mechanically ventilated patients in intensive care (Awakening and Breathing Controlled trial): A randomized controlled trial. Lancet 2008;371:126-34.

11. Safer Health Care Now <www.saferhealthcarenow.ca> (Version current at June 22, 2008).

12. Pronovost P, Brenholtz S, Dorman T, Lipsett PA, Simmonds T, Haraden C. Improving communication in the ICU using daily goals. J Crit Care 2003;18:71-5.

13. Martin CM, Doig GS, Heyland DK, Morrison T, Sibbald WJ. Multicentre, cluster- randomized clinical trial of algorithms for critical-care enteral and parenteral therapy (ACCEPT) CMAJ 2004;170:197-204.

14. Rotstein C, Evans G, Born A, at al. Clinical practice guidelines for hospital-acquired pneumonia and ventilator-associated pneumonia in adults. Can J Infect Dis Med Microbiol 2008;19:19-53.

15. Baggs JG, Schmitt MH, Mushlin AI, et al. Association between nurse-physician collaboration and patient outcomes in three intensive care units. Crit Care Med 1999;27:1991-8.

16. Zwarenstein M, Bryant W. Interventions to promote collaboration between nurses and doctors. Cochrane Database of Systematic Reviews 2000, Issue 2. Art. No.: CD000072. DOI: 10.1002/14651858. CD000072.

17. Lanken PN, Terry PB, DeLisser HM, et al. An official American Thoracic Society clinical policy statement: Palliative care for patients with respiratory diseases and critical illnesses. Am J Respir Crit Care Med 2008;177:912-27.

18. Herridge MS. Mobile, awake and critically ill. CMAJ 2008;78:725-6. 


\section{Repatriation, or the road to home ventilation}

\author{
Jeremy Road MD \\ Medical Director, Provincial Respiratory Outreach Program, \\ Respiratory Division, Vancouver Coastal Health and the \\ University of British Columbia, Vancouver, British Columbia \\ E-mail jeremy.road@vch.ca
}

$\mathrm{T}^{\mathrm{h}}$ here is an emerging body of evidence supporting long-term ventilation (LTV) for patients with neuromuscular disease and chronic thoracic restrictive disorders. Moderate-sized, randomized, controlled trials and retrospective studies have shown improvement in quality of life and survival such that the available evidence supports a strong positive recommendation for home ventilation. The data supporting chronic home ventilation in chronic obstructive pulmonary disease are less robust

LTV can be initiated in the home (home ventilation [HV]), thus avoiding the problem of repatriation. Small studies comparing ventilation initiated at home versus in-hospital have shown similar outcomes $(1,2)$. However, respiratory failure may precipitate hospitalization and a subsequent need for discharge home (repatriation). The approach to this is discussed below.

The first step is to establish whether the patient has a diagnosis known to benefit from LTV and whether the patient can be safely managed at home. If support is available, patients usually prefer to be at home. However, should they reside far from a support network or have a condition that requires frequent attention, a hospice or 'low-tech' hospital may be an alternative to the home.

To be discharged, the patient must be stable, on minimal positive end-expiratory pressure and have modest requirements for supplemental oxygen. Bronchial secretions must also be manageable. Discharge planning is undertaken by a hospitalbased case manager who co-ordinates with the home care team. In British Columbia, community respiratory therapists, designated for this purpose, as part of the Provincial Respiratory Outreach Program (PROP), need to be involved early on to establish the home support network before discharge. Caregivers and care aids may need to be trained. Family and friends can act as caregivers, and aids can also be hired, to provide support. If the case manager can address home care provider needs and respiratory therapy needs, repatriation should proceed without difficulty (3).

Potential risks in HV include power failure, ventilator malfunction, accidental disconnection, circuit obstruction, difficulties with the tracheotomy and concurrent medical problems (4). The goal of HV is to minimize risk through client and caregiver education. Tele-Medicine is an evolving technology for following patients in the community (5). The European Ventilation study (6) found that ventilation centre size varied across countries. In Canada, McKim et al surveyed 12 centers and found that $45 \%$ of patients on LTV had their ventilation initiated at home (Personal communication). The greatest barriers to repatriation were an inadequate caregiver network and nursing issues, both of which often relate to resource insufficiency.

The BC Association of Individualized Technology and Supports for People with Disabilities enables people to meet their respiratory and assisted devices needs within a community-based environment that is responsive to and respectful of their individual goals. The organization includes: Technologies for Independent Living, which produces electronic devices for living at home, and the PROP, which provides comprehensive services for individuals needing assisted ventilation. PROP services include a ventilator pool and all respiratory supplies. Education and communication is a cornerstone of the PROP program, using written and Web-based materials, client booklets, manuals and client as well as caregiver training. The program has grown from 279 patients in 2002 to 395 in 2007. Ventilators are purchased through a selection committee of clients, a respirologist, respiratory therapists and biomedical engineers, trained to service and maintain equipment, at no charge to the client.

After identifying an $\mathrm{HV}$ patient, the case manager contacts the PROP and begins the process of educating the caregivers. Advantages of the PROP program include accessibility, standardization of quality of care, an equipment pool with trained engineers, and a database. This program is cost-saving, while satisfying caregivers and improving patient quality of life.

CONFLICTS OF INTEREST: Nothing to declare in regard to the content of the present article.

ACKNOWLEDGEMENTS: The author would like to recognize the hard work and commitment to patient care of the PROP team.

\section{REFERENCES}

1. Chatwin M, Ward S, Nickol AH, et al. A randomized trial of outpatient versus inpatient initiation of non-invasive ventilation (NIV) in nocturnal hypoventilation due to neuromuscular and chest wall disease. Eur Respir J 2004;(Suppl 48):476s.

2. Lujan M, Moreno A, Veigas C, et al. Non-invasive home mechanical ventilation: Effectiveness and efficiency of an outpatient initiation protocol compared with standard in-hospital model. Respir Med 2007;101:1177-82.

3. Warren ML, Jarrett C, Senegal R, et al. An interdisciplinary approach to transitioning ventilator-dependent patients to home. J Nurse Care Qual 2004;19:67-73.

4. Simonds AK. Risk management of the home ventilator dependent patient. Thorax 2006;61:369-71.

5. Vitacca M, Assoni G, Pizzocaro P, et al. A pilot study of nurse-led home monitoring for patients with chronic respiratory failure and with mechanical ventilation assistance. J Telemed Telecare 2006; $12: 337-42$.

6. Lloyd-Owen SJ, Donaldson GG, Ambrosino M, et al. Patterns of home mechanical ventilation use in Europe: Results from the Eurovent survey. Eur Resp J 2005;25:1025-31.

\section{Assessing activity limitation in chronic obstructive pulmonary disease}

\author{
Darcy D Marciniuk MD FRCPC \\ Division of Respirology, Critical Care and Sleep Medicine, Royal \\ University Hospital, University of Saskatchewan, Saskatoon, \\ Saskatchewan \\ E-mail darcy.marciniuk@usask.ca
}

A ctivity limitation is a cardinal symptom of chronic obstructive pulmonary disease (COPD). In optimizing management of these patients, the clinician must therefore be aware of the differing methods of evaluating activity limitation and exercise responses, the evidence supporting their utility, and be able to select and perform the most appropriate test.

Assessing activity limitation in COPD enables objective evaluation of the integration of respiratory, cardiovascular and metabolic function. Exercise places an increased demand on the 
functional reserve of the body, and because organs (and in particular, the lungs) have such a large physiological reserve, impairment may not become apparent at rest until functional capacity is significantly reduced. Both exercise performance and aerobic capacity correlate with mortality in COPD $(1,2)$. Recognizing the importance of both symptoms and disability, the recent "Canadian Thoracic Society recommendations for management of Chronic Obstructive Pulmonary Disease - 2007 update" (3) proposed a disease stratification based on either symptoms and disability (as assessed by the Medical Research Council dyspnea scale), or impaired lung function (as assessed by spirometry).

There are many options for assessing activity limitation in COPD (Table 1), beginning with a thorough clinical assessment, which is often all that is required. When more objective evaluation is desired, simple tests are readily performed and more widely available, but provide limited physiological understanding, while comprehensive tests are more technically demanding and less widely available, but provide further information and understanding.

\section{TABLE 1}

Options for assessing activity limitation and exercise performance in chronic obstructive pulmonary disease

- Clinical history and assessment

- Questionnaires (self-reported physical activity)

- Activity motion sensors - pedometers, accelerometers

- Stair climbing

- Timed walk tests - 6 min or 12 min walk test

- Shuttle walk test - incremental or endurance protocols

- Cardiopulmonary exercise testing - incremental or endurance protocols

Questionnaires are a simple and validated technique, but are subject to the limitations of any self-reported data. Similarly, stair-climbing testing has become less popular with the advent of other validated techniques that yield more meaningful and reproducible data.

The popularity of activity motion sensors is increasing. Pedometers are simple and economical, and their use has been validated in other populations $(5,6)$. Although more costly, accelerometers provide additional information and are more sensitive than pedometers for light-intensity activities (characteristic of COPD) such as slow walking. Reports using accelerometers have recently shown that pulmonary rehabilitation programming lasting longer than three months may be necessary to significantly enhance daily physical activity in COPD patients (7).

Timed walk tests (typically 6 min or $12 \mathrm{~min}$ ) are the standard 'simple' test for assessing activity limitation. They are safe and practical, and mimic activities of daily living. Their utility has been shown to improve with standardization, although they are susceptible to a training effect (similar to other tests). Though they provide restricted information regarding physiologic contributors and mechanisms of exercise limitation, they are now used commonly (8).

Shuttle walk tests are another emerging option, and recent reports have validated their usefulness in detecting a treatment effect in this population $(9,10)$. As further reports validating their utility are published, our understanding of the role of both incremental and endurance protocols will mature.
Finally, cardiopulmonary exercise testing is the gold standard for assessing exercise performance. It provides for mechanistic insights, recognition of coexistent and multiple exercise-limiting factors, and a thorough evaluation of respiratory responses and constraint. Both incremental and endurance protocols may be used, and endurance protocols have been found to be more responsive to treatment than either incremental exercise or 6 min walk tests. Though testing is not widely available, if a thorough evaluation of exercise performance is required, particularly in patients with multiple comorbidities, it remains the test of choice.

\section{CONFLICTS OF INTEREST: None.}

\section{REFERENCES}

1. Myers J, Prakash M, Froelicher V, Do D, Partington S, Atwood JE. Exercise capacity and mortality among men referred for exercise testing. N Engl J Med 2002;346:793-801.

2. Oga T, Nishimura K, Tsukino M, et al. Analysis of the factors related to mortality in chronic obstructive pulmonary disease: Role of exercise capacity and health status. Am J Respir Crit Care Med 2003;167:544-9.

3. O'Donnell DE, Aaron S, Bourbeau J, et al. Canadian Thoracic Society recommendations for management of Chronic Obstructive Pulmonary Disease - 2007 update. Can Resp J 2007;14(Suppl B):5B-32B.

4. O'Donnell DE, Aaron S, Bourbeau J, et al. Canadian Thoracic Society recommendations for management of chronic obstructive pulmonary disease - 2003. Can Respir J 2003;10:11A-33A.

5. Iwane $M$, Arita $M$, Tomimoto $S$, et al. Walking 10,000 steps/day or more reduces blood pressure and sympathetic nerve activity in mile essential hypertension. Hypertens Res 2000;23:573-80.

6. Chan CB, Ryan DA, Tudor-Locke C. Health benefits of a pedometerbased physical activity intervention in sedentary workers. Prev Med 2004;39:1215-22.

7. Pitta F, Troosters T, Probst VS, Langer D, Decramer M, Gosselink R. Are patients with COPD more active after pulmonary rehabilitation? Chest 2008;134:273-80.

8. Marciniuk DD, Butcher SJ, Reid JK, et al. The effects of heliumhyperoxia on 6-min walking distance in COPD: A randomized, controlled trial. Chest 2007;131:1659-65.

9. Pepin V, Brodeur J, Lacasse Y, et al. 6-minute walking versus shuttle walking: Responsiveness to bronchodilation in chronic obstructive pulmonary disease. Thorax 2007;62:291-8.

10. Brouillard D, Pepin V, Milot J, Lacasse Y, Maltais F. Endurance shuttle waling test: Responsiveness to salmeterol in COPD. Eur Respir J 2008;31:579-84.

\section{Optimizing exercise: Practical strategies to improve exercise rehabilitation}

\author{
Neil D Eves $\mathrm{PhD}^{1,2}$, Warren J Davidson $\mathrm{MD}^{2}$, \\ Gordon T Ford $\mathrm{MD}^{2}$ \\ ${ }^{1}$ Faculty of Kinesiology; ${ }^{2}$ Division of Respiratory Medicine, \\ Faculty of Medicine, University of Calgary, Calgary, Alberta \\ E-mailneves@ucalgary.ca
}

Q espiratory rehabilitation improves exercise capacity, Realth-related quality of life (HRQL) and exertional symptoms in patients with chronic obstructive pulmonary disease (COPD) (1), and may help reduce health care utilization (2) and mortality (3). The essential component of rehabilitation is exercise, as it has the potential to alter the underlying physiology of the disease $(4,5)$. While exercise of any form is beneficial to sedentary patients, it is more difficult to maximize the benefits of exercise for each patient throughout rehabilitation and an individualized, well-structured exercise program is often needed to optimize outcomes (6). 
While exercise programs designed for athletes are often too complex for patients with COPD, appreciating the principles on which they are based can make exercise prescriptions more effective. Figure 1 depicts a number of training principles that should be considered when attempting to optimize rehabilitation for patients with COPD. Examples include: 1) individuality principle - because patients with COPD have different limitations to exercise, differing abilities to perform functional tasks, and a wide variety of comorbidities, exercise should be tailored to the needs of each individual; 2) specificity principle - exercises should be prescribed to specifically improve identified functional deficits; 3) progressive overload principle workloads greater than habitual levels should be prescribed and progressed over time to ensure continued improvement; 4) variety principle - the mode and types of exercise should be varied to ensure that exercise continues to be enjoyed and benefits and behaviours are maintained following rehabilitation; and 5) regularity and rest and recovery principles - patients should be encouraged to exercise regularly in addition to rehabilitation but with adequate rest to promote optimal physiological adaptation while avoiding excessive fatigue.

Individual responses to any rehabilitation program vary, and some patients may be unable to achieve the necessary volume (intensity $\times$ duration $\times$ frequency) of exercise to gain noticeable improvements in functional status. This is especially true for those with debilitating dyspnea and it may be necessary to use alternative or adjunct strategies to increase the intensity and/or duration of exercise. Of the growing number of strategies available, interval training and oxygen supplementation are likely the most practical. Interval training consists of multiple bouts of high intensity exercise interspersed with periods of recovery, which allows patients to perform at higher exercise intensities with similar, or reduced, dyspnea (7). In addition to the known benefits of oxygen for maintaining arterial saturation, oxygen supplementation may also be beneficial for nonhypoxemic patients as oxygen slows ventilation and reduces dyspnea (8). As a result, oxygen supplementation allows patients to perform a greater intensity of exercise and gain greater benefits from exercise training (9). Another more novel strategy may be the use of helium-hyperoxia, which reduces dyspnea more than oxygen or normoxic-helium (10). Breathing helium-hyperoxia during exercise rehabilitation increases the intensity and duration of exercise that patients with COPD can perform and results in greater improvements in exercise tolerance and health-related quality of life compared with the standard practice of rehabilitation with air (11).

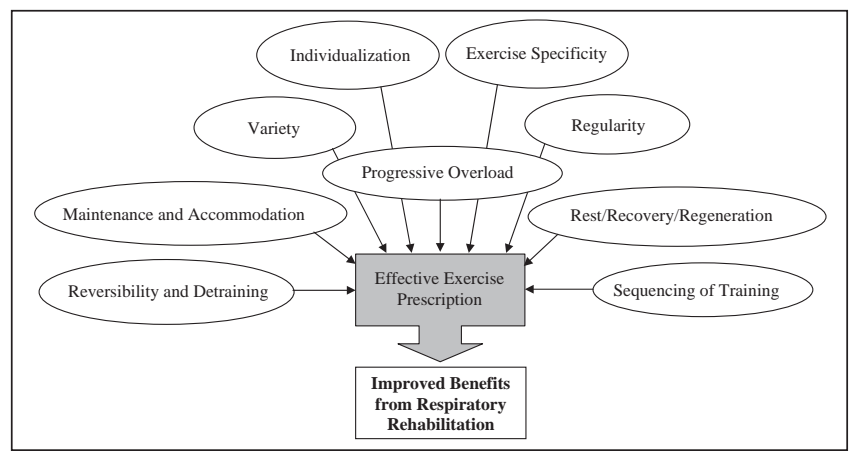

Figure 1) The principles of training to guide effective exercise prescription for patients with chronic obstructive pulmonary disease
In summary, the benefits of respiratory rehabilitation in patients with COPD are well known, and a number of practical changes in exercise prescription may further augment these benefits. Furthermore, using novel strategies to reduce exertional symptoms may also enable patients to perform a greater volume of exercise and optimize the benefits of a rehabilitation program.

\section{CONFLICTS OF INTEREST: None.}

\section{REFERENCES}

1. Ries AL, Bauldoff GS, Carlin BW, et al. Pulmonary rehabilitation: Joint ACCP/AACVPR evidence-based clinical practice guidelines. Chest 2007;131:4S-42S.

2. Goldstein RS, Gort EH, Guyatt GH, et al. Economic analysis of respiratory rehabilitation. Chest 1997;112:370-9.

3. Ries AL, Kaplan RM, Limberg TM, et al. Effects of pulmonary rehabilitation on physiologic and psychosocial outcomes in patients with chronic obstructive pulmonary disease. Ann Intern Med 1995;122:823-32.

4. Porszasz J, Emtner M, Goto S, et al. Exercise training decreases ventilatory requirements and exercise-induced hyperinflation at submaximal intensities in patients with COPD. Chest 2005;128:2025-34.

5. Puente-Maestu L, Tena T, Trascasa C, et al. Training improves muscle oxidative capacity and oxygenation recovery kinetics in patients with chronic obstructive pulmonary disease. Eur J Appl Physiol 2003;88:580-7.

6. Varga J, Porszasz J, Boda K, et al. Supervised high intensity continuous and interval training vs. self-paced training in COPD. Respir Med 2007;101:2297-304.

7. Vogiatzis I, Nanas S, Roussos C. Interval training as an alternative modality to continuous exercise in patients with COPD. Eur Respir J 2002;20:12-9.

8. O'Donnell DE, D'Arsigny C, Webb KA. Effects of hyperoxia on ventilatory limitation during exercise in advanced chronic obstructive pulmonary disease. Am J Respir Crit Care Med 2001;163:892-8.

9. Emtner M, Porszasz J, Burns M, et al. Benefits of supplemental oxygen in exercise training in nonhypoxemic chronic obstructive pulmonary disease patients. Am J Respir Crit Care Med 2003;168:1034-42.

10. Eves ND, Petersen SR, Haykowsky MJ, et al. Helium-hyperoxia, exercise, and respiratory mechanics in chronic obstructive pulmonary disease. Am J Respir Crit Care Med 2006;174:763-71.

11. Eves ND, Sandermeyer LC, Wong EY, et al. Helium-hyperoxia: A novel intervention to improve the benefits of pulmonary rehabilitation for patients with COPD. Chest 2008. (In press).

\section{Management and prevention of venous thromboembolism: The 8th American College of Chest Physicians Guidelines}

\author{
William Geerts MD FRCPC \\ Thromboembolism Program, Sunnybrook Health Sciences \\ Centre, University of Toronto, Toronto, Ontario \\ E-mailWilliam.Geerts@Sunnybrook.ca
}

\section{THE IMPORTANCE OF VENOUS THROMBOEMBOLISM}

Venous thromboembolism (VTE) is a common disease with $\checkmark$ two linked components, deep vein thrombosis (DVT) and pulmonary embolism (PE). Symptomatic VTE occurs in more than one of every 1000 persons in the population every year. It is associated with increased mortality and with substantial acute and long-term morbidity.

THE AMERICAN COLLEGE OF CHEST PHYSICIANS ANTITHROMBOTIC GUIDELINES The American College of Chest Physicians (ACCP) Guidelines $(1-3)$ are prepared by multidisciplinary, international groups of 
clinician-methodologists. Extensive literature reviews lead to recommendations that are based on available evidence as well as on patient and societal values and preferences and economic considerations. In addition to extensive formal peer review, the primary principle is to have a transparent link between the evidence and the graded recommendations. The 2008 ACCP antithrombotic guidelines are presented in a 900-page supplement to Chest (1); key points are presented below.

\section{Treatment of venous thromboembolism}

The guidelines on the treatment of VTE (2) emphasize that, with few exceptions, the acute and long-term management of patients with DVT or with PE is identical. For most patients with VTE, anticoagulation with fixed-dose low molecular weight heparin (LMWH) based on body weight is the initial treatment of choice; no dosage adjustment or laboratory monitoring are subsequently required unless the patient has at least moderate renal dysfunction. For both DVT and nonmassive $\mathrm{PE}$, subcutaneous LMWH is recommended over intravenous heparin. In addition to subcutaneous LWMH and intravenous heparin, two new, but infrequently used, acute treatment options have been added: fixed subcutaneous doses of the factor Xa inhibitor, fondaparinux, and unfractionated heparin given subcutaneously in doses that are based on body weight without the need for either dose alteration or laboratory monitoring. Most patients with DVT and many patients with hemodynamically stable PE can be treated as outpatients. Early ambulation is recommended for both DVT and PE.

The new guidelines recommend rapid risk stratification to identify patients with acute PE who have hemodynamic compromise to determine if thrombolytic therapy or catheterdirected interventions should be considered. If appropriate expertise is available, catheter-directed pharmaco-mechanical thrombus reduction is also suggested for selected patients with acute iliofemoral DVT. The guidelines recommend against the insertion of an inferior vena cava filter unless the patient has acute VTE and a contraindication to therapeutic anticoagulation. In these situations, removable filters are preferred and conventional anticoagulation should be implemented when the high bleeding risk resolves.

For most patients with acute VTE, warfarin should be started on the same day as LMWH, heparin or fondaparinux, and should overlap with the parenteral anticoagulant for at least five days and until the patient's international normalized ratio is at least 2.0 for 24 h. For VTE in cancer patients, the guidelines recommend therapy with LMWH rather than warfarin at least for the first three months of treatment and perhaps longer.

The guidelines clarify the duration of anticoagulation after VTE. For DVT or PE associated with a reversible cause, three months of anticoagulation with warfarin (international normalized ratio 2.0 to 3.0 ) is recommended. For VTE that is unprovoked, indefinite anticoagulation is recommended if the risks of anticoagulation are acceptable and if the patient agrees. In cases where long-term anticoagulation is instituted, periodic reassessment of this decision should be performed.

\section{Prevention of venous thromboembolism}

Approximately $70 \%$ of all VTE is related to hospitalization. Because VTE is one of the most common complications of hospital stay and is associated with substantial short- and long-term morbidity and death, prevention is the key to reducing the burden of this disease (3). Several hundred clinical trials confirm the effectiveness, safety and cost-effectiveness of thromboprophylaxis for a variety of patient groups. The use of recommended thromboprophylaxis has been shown to reduce the risk of DVT, proximal DVT, PE and fatal PE by more than $60 \%$.

The guidelines discuss the risks of VTE separately in 23 patient groups and the evidence for thromboprophylaxis (or not) in each of these groups with particular emphasis on randomized clinical trials. It is recommended that every general hospital develop a formal, active strategy to prevent VTE, which should generally be in the form of a written, institution-wide thromboprophylaxis policy. Mechanical thromboprophylaxis with compression stockings, pneumatic compression devices or foot pumps is recommended for patients at high risk of bleeding. Particular attention should be directed toward ensuring the proper use of, and optimal adherence with, mechanical methods of prophylaxis. Furthermore, it is recommended that pharmacologic prophylaxis be substituted for or added to the mechanical prophylaxis when the high bleeding risk decreases. The guidelines recommend against the use of acetylsalicylic acid alone as venous thromboprophylaxis for any patient group.

A summary of the 2008 ACCP Guidelines on the Prevention of VTE is found in Table 1. Most hospital patients at risk for VTE should continue thromboprophylaxis until discharge and not stop as soon as they start to ambulate. For major orthopedic surgery, the recommended duration of prophylaxis is at least 10 days with a strong recommendation to continue for up to five weeks.

\section{TABLE 1}

Risk groups and recommended thromboprophylaxis options

\begin{tabular}{|c|c|c|}
\hline $\begin{array}{l}\text { Risk } \\
\text { group }\end{array}$ & Examples & $\begin{array}{c}\text { Thromboprophylaxis } \\
\text { options* }\end{array}$ \\
\hline $\begin{array}{l}\text { Low } \\
\text { TE risk }\end{array}$ & $\begin{array}{l}\text { - Medical - fully mobile, brief } \\
\text { admission, no additional risk factors } \\
\text { - Surgical - procedure }<30 \text { min, } \\
\text { mobile, no additional risk factors }\end{array}$ & $\begin{array}{l}\text { - No prophylaxis } \\
\text { - Ambulation }\end{array}$ \\
\hline $\begin{array}{l}\text { Moderate } \\
\text { TE risk }\end{array}$ & $\begin{array}{l}\text { - Medical - acute illness, bedrest } \\
\text { - Major general surgery } \\
\text { - Major gynecological surgery } \\
\text { - Major urological surgery } \\
\text { - Thoracic surgery } \\
\text { - Bariatric surgery }\end{array}$ & $\begin{array}{l}\text { - Low molecular weight } \\
\text { heparin } \\
\text { - Low-dose heparin } \\
\text { - Fondaparinux }\end{array}$ \\
\hline $\begin{array}{l}\text { High } \\
\text { TE risk }\end{array}$ & $\begin{array}{l}\text { - Hip or knee arthroplasty } \\
\text { - Hip fracture surgery }\end{array}$ & $\begin{array}{l}\text { - Low molecular weight } \\
\text { heparin } \\
\text { - Fondaparinux } \\
\text { - Warfarin (target INR 2-3) }\end{array}$ \\
\hline $\begin{array}{l}\text { High } \\
\text { bleeding } \\
\text { risk }\end{array}$ & $\begin{array}{l}\text { - Active bleeding } \\
\text { - High bleeding risk }\end{array}$ & $\begin{array}{l}\text { - Physical method of pro- } \\
\text { phylaxis (GCS, PCD, } \\
\text { VFP) } \\
\text { - Consider anticoagulant } \\
\text { prophylaxis when } \\
\text { bleeding risk decreases }\end{array}$ \\
\hline
\end{tabular}

${ }^{\star}$ For further details, see the 8th ACCP Conference on Antithrombotic Therapy (3). GCS Graduated compression stockings; INR International normalized ratio; PCD Pneumatic compression device; TE Thromboembolism; VFP Venous foot pump

CONFLICTS OF INTEREST: Dr Geerts has received research support, honoraria or fees as a consultant for: Bayer Healthcare, Boehringer-Ingelheim, Covidien, Daiichi Sankyo, Leo Pharma, Pfizer and Sanofi Aventis. 


\section{REFERENCES}

1. Hirsh J, Guyatt G, Albers GW, Harrington R, Schunemann HJ, eds. Antithrombotic and thrombolytic therapy: American College of Chest Physicians Evidence-Based Clinical Practice Guidelines (8th Edition). Chest 2008;133(Suppl):67S-968S.

2. Kearon C, Kahn SR, Agnelli G, Goldhaber S, Raskob GE, Comerota AJ. Antithrombotic therapy for venous thromboembolic disease: American College of Chest Physicians Evidence-Based Clinical Practice Guidelines (8th Edition). Chest 2008;133(Suppl):454S-545S.

3. Geerts WH, Bergqvist D, Pineo GF, et al. Prevention of venous thromboembolism: American College of Chest Physicians EvidenceBased Clinical Practice Guidelines (8th Edition). Chest 2008;133(Suppl):381S-443S.

\section{Advances In endoscopic imaging}

Stephen Lam MD FRCPC, Annette McWilliams MB FRCPC, Michael Short PhD, Calum MacAulay PhD, Haishan Zeng PhD

Cancer Imaging Department, BC Cancer Agency \& the University of British Columbia, Vancouver, British Columbia

E-mailslam2@bccancer.bc.ca

\section{INTRODUCTION}

Tmaging modalities such as computed tomography, magnetic resonance imaging and ultrasound can detect objects in the sub-millimetre scale (Table 1). Optical imaging such as autofluorescence bronchoscopy, optical coherence tomography (OCT) or confocal microendoscopy offer resolution down to the submicron range, measuring biochemical, structural and functional changes in cells and tissues (Table 2).

TABLE 1

Resolution of thoracic imaging modalities

\begin{tabular}{ccccc}
\hline $\begin{array}{l}\text { Multidetector } \\
\text { CT scanner }\end{array}$ & MRI & Ultrasound & OCT & $\begin{array}{c}\text { Confocal microen- } \\
\text { doscopy }\end{array}$ \\
\hline $0.6 \mathrm{~mm}$ & $\sim 300 \mu \mathrm{m}$ & $\sim 50 \mu \mathrm{m}$ & $2 \mu \mathrm{m}-6 \mu \mathrm{m}$ & $0.3 \mu \mathrm{m}$ \\
\hline
\end{tabular}

CT Computed tomography; MRI Magnetic resonance imaging; OCT Optical coherence tomography

\section{TABLE 2}

\section{Optical imaging In bronchoscopic assessment}

Structural features
Surface: Broad-band (white) light reflectance imaging
Depth: Optical coherent tomography; confocal microscopy
Microvasculature: Narrow band imaging
Molecular/biochemical/functional changes
Fluorescence imaging
Confocal microscopy
Optical coherence tomography + multiphoton microscopy
Raman spectroscopy

\footnotetext{
White-light bronchoscopy

White-light bronchoscopy (WLB) is the simplest and most commonly used endoscopic imaging method. It makes use of differences in the specular reflection, back scattering and absorption properties of white light to define the structural features of the bronchial surface to discriminate between normal and abnormal tissues. Although useful when there are alterations in surface features (eg, invasive lung cancer), it is insensitive to subtle changes (eg, preinvasive lung cancer) at or below the epithelial surface.
}

\section{Narrow band imaging}

Narrow band imaging uses blue light (at $415 \mathrm{~nm}$ ) and green light (at $540 \mathrm{~nm}$ ) corresponding to the maximal hemoglobin absorption peaks. Blue light highlights superficial capillaries and green light penetrates deeper to highlight larger blood vessels in the submucosa. Narrow band imaging improves detection of dysplasia and carcinoma in situ compared with WLB (1).

\section{Autofluoescence bronchoscopy}

Autofluorescence bronchoscopy uses fluorescence to provide information about the biochemical composition and metabolic state of bronchial tissues. The most important fluorophores are structural proteins such as collagen and elastin, and those involved in cellular metabolism such as NADH and flavins. The fluorophores determine the fluorescence properties of bronchial tissue (2). As the bronchial epithelium changes from normal through to dysplastic, carcinoma in situ and invasive cancer, there is a progressive decrease in green autofluorescence with less decrease in red fluorescence intensity (2).

The spectral differences between $500 \mathrm{~nm}$ and $700 \mathrm{~nm}$ in normal, premalignant and malignant tissues are the basis for autofluorescence endoscopic imaging devices for localization of early lung cancer in the bronchial tree. In addition to multiple single center studies, there are three multicentre clinical trials and two randomized trials that showed improved detection rate with autofluorescence bronchoscopy or fluorescence-reflectance bronchoscopy compared with WLB alone (3).

\section{Confocal microendoscopy}

There are two imaging modalities that have sufficient spatial resolution and tissue depth penetration to study the bronchial epithelial and subepithelial changes associated with airway diseases. Confocal microendoscopy offers spatial resolution at the submicron range, but although the basement membrane and upper submucosa can be imaged with superb quality, the epithelial cells are not visible without contrast agents (4). The development of molecularly targeted contrast agents enables disease-specific morphological and biochemical processes to be labelled with unique optical signatures. For example, epidermal growth factor receptor expression in cells can be imaged in-vivo using epidermal growth factor receptor-gold nanoparticle conjugates and confocal microscopy to study the carcinogeneisis process (5).

\section{OCT}

OCT is a noncontact imaging method that allows rapid scanning of a larger surface area. Near infrared light allows imaging of cellular and extra-cellular structures with a spatial resolution of $2 \mu \mathrm{m}$ to $16 \mu \mathrm{m}$ and a depth penetration of approximately $2 \mathrm{~mm}$, to image through the bronchial wall for visualization of carcinoma in situ, high-grade dysplasia or invasion through the basement membrane (6). Fibre optic probes can be miniaturized to enable imaging of airways down to the terminal bronchiole beyond the range of a standard bronchoscope. Preliminary study suggests that OCT is a more sensitive tool in detecting airway wall remodelling in smokers compared with computed tomography scans, and raises the possibility that OCT could be used to study airway changes in vivo in patients with chronic obstructive pulmonary disease to assess the therapeutic potential of novel airway therapies (7). 


\section{Spectroscopy}

Spectroscopic measurements during bronchoscopy provides information regarding the physiological state and chemical composition of bronchial tissues (8). Oxygen saturation and blood volume can be measured using reflectance spectroscopy (9), and Raman spectroscopy provides information on the molecular composition and structure of a material, through inelastic scattering of light, first described in 1928 by Raman and Kirishnana (10); Raman subsequently received a Nobel prize for this work. When light strikes a molecule, most of it is scattered at the same frequency as the incident light but a small fraction is scattered at a different wavelength. The frequency difference between incident and Raman scattered light is termed the Raman shift, and can provide a molecular signature of the material. Studies in excised bronchial and lung tissue (11) as well as in vivo study (12) suggest Raman spectroscopy may differentiate premalignant from malignant lesions and from normal tissue.

\section{SUMMARY}

Recent advances in optical imaging provide unprecedented opportunities to study the biology and mechanisms of airway diseases in vivo, improve clinical diagnosis, and offer the potential to monitor the effect of therapeutic interventions.

\section{CONFLICTS OF INTEREST: None.}

\section{REFERENCES}

1. Shibuya K, Hoshino H, Chiyo M, et al. High magnification bronchovideoscopy combined with narrow band imaging could detect capillary loops of angiogenic squamous dysplasia in heavy smokers at high risk for lung cancer. Thorax 2003;58:989-95.

2. Wagnieres G, McWilliams A, Lam S. Lung cancer imaging with fluorescence endoscopy. In: Mycek M, Pogue B, eds. Handbook of Biomedical Fluorescence. New York: Marcel Dekker, 2003:361-96.

3. Lam S. The Role of autofluorescence bronchoscopy in diagnosis of early lung cancer. In: Hirsch FR, Bunn PA Jr, Kato H, Mulshine JL, eds. IASLC Textbook of Prevention and Early Detection of Lung Cancer. Informa Healthcare, 2005.

4. Thiberville L, Moreno-Swirc S, Vercauteren T, Peltier E, Cave C, Heckly GB. In vivo imaging of the bronchial wall microsctructure using fibered confocal fluorescence microscopy. Am J Respir Crit Care Med 2007;175:22-31.

5. Aaron J, Nitin N, Travis K, et al. Plasmon resonance coupling of metal nanoparticles for molecular imaging of carcinogenesis in vivo. J Biomed Opt 2007;12:034007.

6. Lam S, Standish B, Baldwin C, et al. In vivo optical coherence tomography imaging of preinvasive bronchial lesions. Clin Cancer Res 2008;14:2006-11.

7. Coxson H, Quiney B, Sin D, et al. Airway wall thickness assessed using computed tomography and optical coherence tomography. Am J Resp Crit Care Med 2008;177:1-6.

8. Zeng H, Petek M, Zorman MT, McWilliams A, Palcic B, Lam S. Integrated endoscopy system for simultaneous imaging and spectroscopy for early lung cancer detection. Optics Letters 2004:29:587-9.

9. Fawzy YS, Petek M, Tercelj M, Zeng H. In-vivo assessment and evaluation of lung tissue morphologic and physiological changes from non-contact endoscopic reflectance spectroscopy for improving lung cancer detection. J Biomedical Opt 2006;11:044003.

10. Raman C, Kirishnan K. A new type of secondary radiation. Nature $1928 ; 121: 105$

11. Huang Z, McWilliams A, Lam S, Mclean DI, Lui H, Zeng H. Nearinfrared Raman spectroscopy for optical diagnosis of lung cancers. Int J Cancer 2003;107:1047-52.

12. Short M, Lam S, McWilliams A, Zhao J, Lui H, Zeng H. Development and preliminary results of an endoscopic Raman probe for potential in-vivo diagnosis of lung cancers. Optics Letters 2008;33:711-13.

\section{Endobronchial ultrasonography: Bronchoscopy beyond the airway wall}

\author{
Alain Tremblay MDCM FRCPC FCCP \\ Division of Respiratory Medicine, Department of Medicine, \\ University of Calgary, Calgary, Alberta \\ Email alain.tremblay@ucalgary.ca
}

\section{INTRODUCTION}

$E^{n}$ ndobronchial ultrasonography (EBUS) is rapidly changing the Fproach to the diagnosis of lung disease. The balloon sheath and peripheral EBUS consists of a small $1.2 \mathrm{~mm}$ to $1.7 \mathrm{~mm}$, $20 \mathrm{MHz}$ radial ultrasound (US) probe inserted through the working channel of a standard flexible bronchoscope (Figure 1A), resulting in a radial field of view (Figure 1B), while the linear EBUS consists of a dedicated bronchoscope with a $7.5 \mathrm{MHz}$ US probe integrated into the tip of instrument (Figure 2A).
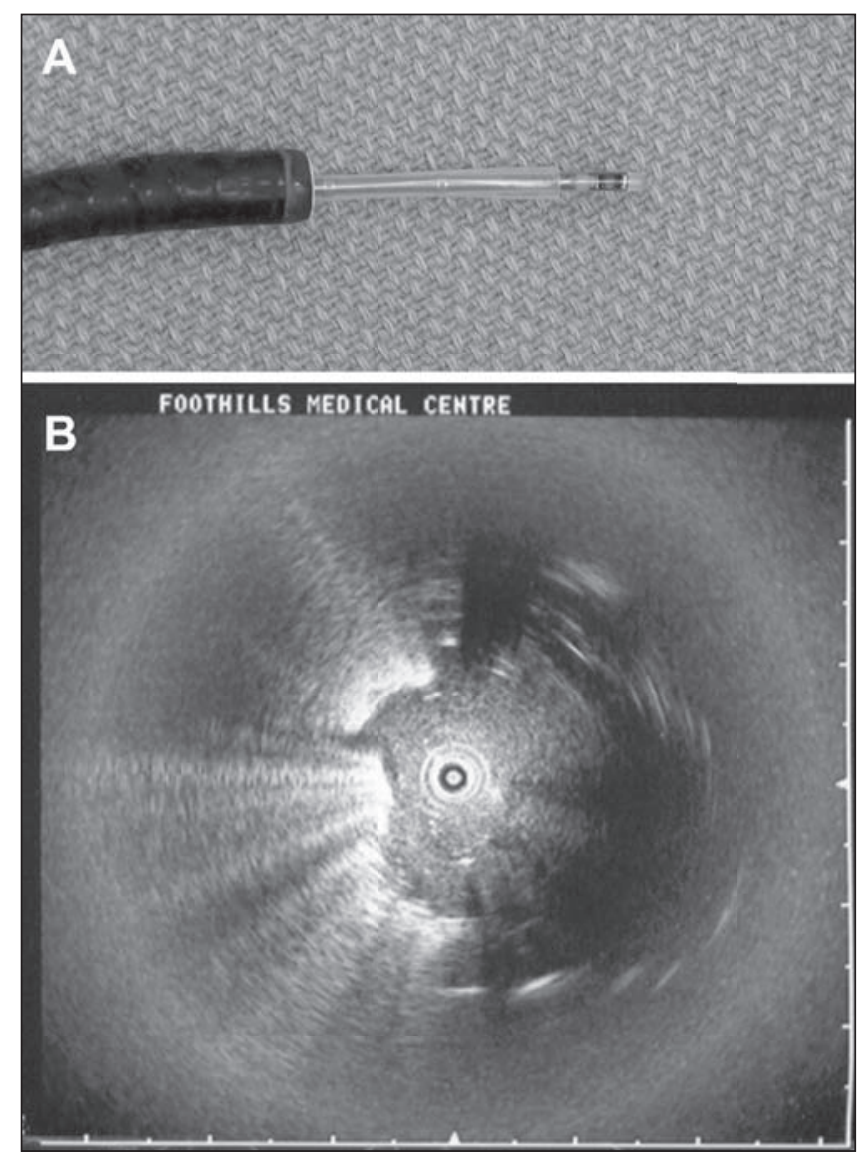

Figure 1) Peripheral endobronchial ultrasonography. A Radial ultrasound probe $(1.7 \mathrm{~mm}$ diameter) and guide sheath inserted through the working channel of a standard bronchoscope. B Ultrasound image of a peripheral lung nodule

\section{BALLOON SHEATH EBUS}

A radial probe is placed in a balloon-tipped sheath filled with saline for an air-free interface between the probe and the airway. High resolution images of the central airway allow for staging lung, esophageal and thyroid malignancies (1), as well as managing carcinoid tumours, early lung cancers or carcinoma in situ. For locating mediastinal lymph nodes before transbronchial needle aspiration (TBNA) (2), this approach has been supplanted by linear EBUS. 

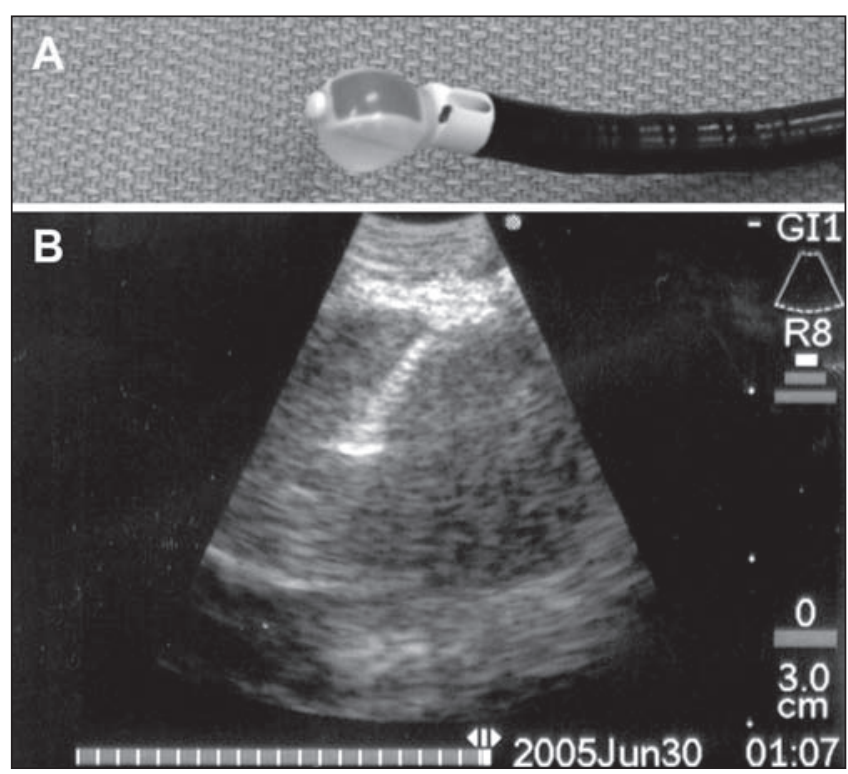

Figure 2) Linear endobronchial ultrasonography. A Dedicated endobronchial ultrasonography bronchoscope with small, salinefilled balloon over the ultrasound transducer at the distal end of instrument. Fibre optic bundle and working channel are angled at 30 degrees and situated proximal to transducer. B Approximately $2 \mathrm{~cm}$ diameter mediastinal lymph node with 22 gauge needle inserted under direct ultrasonographic visualization

\section{PERIPHERAL EBUS}

The radial probe inserted through a guide-sheath or 'extended working channel' is used to locate peripheral lung lesions beyond the usual view of the bronchoscope (Figures $1 \mathrm{~A}$ and $1 \mathrm{~B})$. The probe is then removed, leaving the guide sheath through which biopsy forceps, brushes or needles are advanced for sampling. Diagnostic yields are $60 \%$ to $80 \%$ and randomized trials have confirmed increased yields compared with standard transbronchial biopsy (3). EBUS can also be used in combination with electromagnetic guidance navigational bronchoscopy (4). The US image may suggest whether lesions are benign or malignant (5).

\section{LINEAR EBUS}

This technique allows real-time visualization and needle aspiration of mediastinal and proximal lung lesions with a dedicated 22 gauge needle (Figure 2B). Diagnostic yields are greater than $90 \%$, although randomized trials against standard TBNA are required. In patients with proven or suspected lung cancer and 'nonbulky' nodal enlargement greater than $1 \mathrm{~cm}$ on computed tomography scan, EBUS TBNA was found to have a sensitivity of $94.6 \%$ (6) with a similar sensitivity of $92.3 \%$ in a study of patients with nodes less than $1 \mathrm{~cm}$ (7). EBUS is more sensitive and more specific than positron emission tomography scanning for mediastinal staging in lung cancer (8). EBUS has been compared with mediastinoscopy for lung cancer staging (9), and EBUS TBNA is superior to blind TBNA for the investigation of sarcoidosis (10).

\section{CONCLUSION}

EBUS offers a new safe, minimally invasive and highly sensitive option for our patients. In our institution, over one-half of flexible bronchoscopies include an EBUS component.
Clinicians will need to ensure a relatively large procedure volume to ensure that they attain and maintain competency with this exciting technique.

CONFLICTS OF INTEREST: The University of Calgary has received unrestricted educational grant support from Olympus Canada for support of the Continuing Medical Education courses on endobronchial ultrasonography, as well as for support of the Interventional Pulmonary Medicine training program.

\section{REFERENCES}

1. Herth F, Ernst A, Schulz M, Becker H. Endobronchial ultrasound reliably differentiates between airway infiltration and compression by tumor. Chest 2003;123:458-62.

2. Herth F, Becker HD, Ernst A. Conventional vs endobronchial ultrasound-guided transbronchial needle aspiration: A randomized trial. Chest 2004;125:322-5.

3. Paone G, Nicastri E, Lucantoni G, et al. Endobronchial ultrasounddriven biopsy in the diagnosis of peripheral lung lesions. Chest 2005; 128:3551-7.

4. Eberhardt R, Anantham D, Ernst A, Feller-Kopman D, Herth F. Multimodality bronchoscopic diagnosis of peripheral lung lesions: A randomized controlled trial. Am J Respir Crit Care Med 2007;176:36-41

5. Kuo CH, Lin SM, Chen HC, Chou CL, Yu CT, Kuo HP. Diagnosis of peripheral lung cancer with three echoic features via endobronchial ultrasound. Chest 2007;132:922-9.

6. Yasufuku K, Chiyo M, Koh E, et al. Endobronchial ultrasound guided transbronchial needle aspiration for staging of lung cancer. Lung Cancer 2005;50:347-54.

7. Herth FJ, Ernst A, Eberhardt R, Vilmann P, Dienemann H, Krasnik M. Endobronchial ultrasound-guided transbronchial needle aspiration of lymph nodes in the radiologically normal mediastinum. Eur Respir J 2006;28:910-4.

8. Yasufuku K, Nakajima T, Motoori K, et al. Comparison of endobronchial ultrasound, positron emission tomography, and CT for lymph node staging of lung cancer. Chest 2006;130:710-8.

9. Ernst A, Anantham D, Eberhardt R, Krasnik M, Herth FJ. Diagnosis of mediastinal adenopathy real-time endobronchial ultrasound guided needle aspiration versus mediastinoscopy. J Thorac Oncol 2008;3:577-82.

10. Stather DR, Michaud G, Khalil M, Field SF, Tremblay A. Endobronchial ultrasonography in the diagnosis of sarcoidosis preliminary results of a randomized study. Chest 2007;132:465S. (Abst).

\section{End of life issues in chronic obstructive pulmonary disease}

\author{
Paul Hernandez MDCM FRCPC
}

Respirology Division, Department of Medicine, Capital District Health Authority, Dalhousie University, Halifax, Nova Scotia E-mail paul.hernandez@cdha.nshealth.ca.

Chronic obstructive pulmonary disease (COPD) is the fourth leading cause of mortality in Canada and the only leading cause of mortality on the rise, particularly among women (1). Despite recent advances in our understanding of COPD pathophysiology and management, many patients suffer considerable physical and psychological burden related to COPD. The present paper will review the prognostic factors for mortality, the determinants of quality end-of-life care, and management options to improve end-of-life care in advanced COPD.

The natural history of COPD is unpredictable in individual patients, rendering the timing of discussions about end-of-life care challenging. Many family physicians report being ill prepared for this communication task (2). Recent studies have improved our ability to predict short term survival (3-5), and 
predictors of mortality are summarized in Table 1. Patients with these risk factors should be engaged in discussions about prognosis and end-of-life care.

\section{TABLE 1}

\section{Predictors of chronic obstructive pulmonary disease} mortality

Very severe airflow obstruction (eg, forced expiratory volume in $1 \mathrm{~s}$ less than $30 \%$ predicted) and hyperinflation (eg, inspiratory capacity/total lung capacity less than $25 \%$ )

Poor functional status (eg, Medical Research Council score 4 to 5) Poor exercise tolerance (eg, 6 min walk distance less than $150 \mathrm{~m}$ ) Poor nutritional status (eg, body mass index less than $19 \mathrm{~kg} / \mathrm{m}^{2}$ )

Older age

Recurrent acute exacerbation of chronic obstructive pulmonary disease (especially requiring hospitalization and mechanical ventilation) Pulmonary hypertension

Recent studies using qualitative methodologies have assessed the experiences of patients living and dying with advanced COPD (6-9). Patients report a loss of dignity related in part to over-reliance on others, and a desire to avoid unnecessary life prolongation, to minimize the burden on their loved ones, and to have adequate time to put their affairs in order. Symptom control, particularly dyspnea, is often suboptimal. Unfortunately, these patients often spend much of their last year of life in hospital rather than at home.

A recurrent theme in research about end-of-life care is the importance of good communication. Only a minority of patients with advanced COPD discuss treatment preferences for end-of-life care with their physicians, even in supportive, multidisciplinary settings such as pulmonary rehabilitation $(10,11)$. Curtis $(12)$ has provided excellent guidance for talking about end-of-life care, prognosis and advanced care planning. Discussions should include patient preferences for life-sustaining treatment options and choice of surrogate decision makers. Patients and families should be aware that withholding life sustaining measures does not equate to withholding all care, or abandonment.

One possible solution to improve end-of-life care of COPD is to involve formal palliative-care services. Palliative care aims to relieve the suffering and improve the quality of life of persons who are living with or dying from advanced illness, or are bereaved (13). Symptom relief is an important objective of palliative care, and dyspnea is a consistently reported symptom affecting quality of life among COPD patients (14). Further research is required to improve our understanding of the mechanisms of dyspnea in COPD, and innovative palliative approaches are required in patients with severe dyspnea despite optimal pharmacological and nonpharmacological therapies.

In summary, there is an urgent need to address the quality of end-of-life care in patients with advanced COPD. Improved physician communication and symptom control are two important elements that require our attention. Ultimately, new models of care delivery involving palliative-care services offer a potential solution.

CONFLICTS OF INTEREST: None.

\section{REFERENCES}

1. O'Donnell DE, Aaron S, Bourbeau J, et al. Canadian Thoracic Society recommendations for management of chronic obstructive pulmonary disease - 2007 update. Can Respir J 2007;14(Suppl B):5B-32B.

2. Elkington H, White P, Higgs R, Pettinari C. GPs' views of discussions of prognosis in severe COPD. Fam Pract 2001;18:440-4.

3. Connors AF Jr, Dawson NV, Thomas C, et al. Outcomes following acute exacerbation of severe chronic obstructive lung disease. The SUPPORT investigators (Study to Understand Prognoses and Preferences for Outcomes and Risks of Treatments). Am J Respir Crit Care Med 1996;154:959-67.

4. Soler-Cataluña JJ, Martínez-García MA, Román Sánchez P, et al. Severe acute exacerbations and mortality in patients with chronic obstructive pulmonary disease. Thorax 2005;60:925-31.

5. Celli BR, Cote CG, Marin JM, et al. The body-mass index, airflow obstruction, dyspnea, and exercise capacity index in chronic obstructive pulmonary disease. N Engl J Med 2004;350:1005-12.

6. Seamark DA, Blake SD, Seamark CJ, Halpin DM. Living with severe chronic obstructive pulmonary disease (COPD): Perceptions of patients and their carers. An interpretative phenomenological analysis. Palliat Med 2004;18:619-25.

7. Lynn J, Ely EW, Zhong Z, et al. Living and dying with chronic obstructive pulmonary disease. J Am Geriatr Soc 2000;48(5 Suppl):S91-S100.

8. Guthrie SJ, Hill KM, Muers ME. Living with severe COPD. A qualitative exploration of the experience of patients in Leeds. Respir Med 2001;95:196-204.

9. Heyland DK, Dodek P, Rocker G, et al. What matters most in end-oflife care: Perceptions of seriously ill patients and their family members. CMAJ 2006;174:627-33.

10. Heffner JE, Fahy B, Hilling L, Barbieri C. Attitudes regarding advance directives among patients in pulmonary rehabilitation. Am J Respir Crit Care Med 1996;154:1735-40.

11. Heffner JE, Fahy B, Barbieri C. Advance directive education during pulmonary rehabilitation. Chest 1996;109:373-9.

12. Curtis JR. Palliative and end-of-life care of patients with severe COPD. Eur Respir J 2008;32:796-803.

13. Palliative Care: A Fact Sheet for Seniors. May 1997. Canadian Hospice Palliative Care Association. <www.chpca.net> (Version current at November 7, 2008).

14. O’Donnell DE, Banzett RB, Carrieri-Kohlman V, et al. Pathophysiology of dyspnea in chronic obstructive pulmonary disease: A roundtable. Proc Am Thorac Soc 2007;4:145-68.

\section{Anxiety and depression in end-stage chronic obstructive pulmonary disease}

\author{
Yves Lacasse MD MSc FRCP \\ Unité de recherche en pneumologie, Centre de recherche de \\ I'Hôpital Laval, Institut universitaire de cardiologie et de pneu- \\ mologie de l'Université Laval, Québec \\ E-mail Yves.Lacasse@med.ulaval.ca
}

1though feelings of anxiety and depression are common in Apatients with chronic obstructive pulmonary disease (COPD), estimates of their prevalence vary considerably (1). This likely reflects the variety of scales and methods used to measure such symptoms. Regardless of whether anxiety and depression are considered separately or as a single construct, their impact on COPD patients is important.

Some of the specific anxiety-related disorders include generalized anxiety disorder, panic attacks and panic disorder. A heightened experience of dyspnea is likely to be a contributing factor to anxiety. Feelings of depression in COPD have been described as reactive to the condition and symptoms may range from an 'adjustment disorder with depressed mood' to 'major depression'. Depression may be precipitated by the loss and grief associated with the disability of COPD. Smoking has been associated with nicotine addiction and the factors that contribute to 
smoking may also predispose to anxiety and depressive disorders.

With the increasing awareness of the high prevalence and impact of anxiety- and depression-related symptoms in patients with COPD, it is interesting to note that these psychological manifestations are treated in a minority of patients. Randomized controlled trials indicate that exercise training and carefully selected pharmacology are often effective in ameliorating anxiety and depression.

When depressive symptoms are identified in hospitalized patients, the prognosis is usually good, with these symptoms usually remitting within 12 weeks. However, only one-quarter of those with major depression remit by 12 weeks and only onehalf by 24 weeks.

Every clinician caring for patients with COPD must have a high level of suspicion regarding the presence of anxiety and depressive symptoms as well as the possibility of a major anxiety or depressive disorder. Although respiratory specialists usually focus on the physiological aspects of the disease, they often have access to rehabilitation programs in which a psychological assessment can be conducted. Referral to a mental health professional is indicated when high levels of anxiety or depression are suspected using simple diagnostic screening instruments; anxiety or depression are refractory to pharmacological or nonpharmacological therapy; the choice of anxiolytic or antidepressant drug is complicated by concurrent medications or comorbidities; or the patient presents with suicidal ideation.

An understanding of the patient's psychological history and coping mechanisms and the role of anxiety and depressive reactions to illness may enable clinicians to reduce these symptoms and to improve quality of life among patients with COPD.

\section{CONFLICTS OF INTEREST: None.}

\section{REFERENCES}

1. Hill K, Geist R. Goldstein RS, Lacasse Y. Anxiety and depression in end-stage COPD. Eur Respir J 2008;31:667-77.

\section{Is chronic obstructive pulmonary disease really a cardiac disease?}

\author{
Don D Sin MD \\ The University of British Columbia (Respiratory Division), The \\ Providence Heart and Lung Institute \& The James Hogg \\ iCAPTURE Center for Cardiovascular and Pulmonary Research \\ (St. Paul's Hospital), Vancouver, British Columbia \\ Emaildsin@mrl.ubc.ca
}

\section{EPIDEMIOLOGY}

C ardiovascular diseases (CVDs) such as ischemic heart disease, sudden deaths, and heart failure are common causes of hospitalization and mortality in patients with chronic obstructive pulmonary disease (COPD). In patients with mild to moderate severity, CVDs are the leading cause of hospitalization (50\% of hospital admissions) and the second leading cause of mortality, after lung cancer (1). COPD patients have twice the risk of CVD hospitalization and mortality than subjects without COPD (2). The risk is increased in a dose-dependent way within the range of forced expiratory volume in $1 \mathrm{~s}$ values that are considered in the 'normal' range (ie, between $80 \%$ to $100 \%$ predicted) (2).
In severe and very severe COPD, respiratory failure and pneumonia are the leading causes of morbidity and mortality (3). However, even in these patients, CVDs are a significant concern. Approximately $20 \%$ to $25 \%$ of all deaths in patients with GOLD stages 3 and 4 disease are principally related to a cardiovascular event (3). Having a previous history of CVD increases the risk of mortality by 2.5 -fold and the risk of a COPD hospitalization by $35 \%$, independent of other risk factors. In the general population, reduced lung function is a major risk factor for CVD mortality and may contribute up to $25 \%$ of the total attributable risk for ischemic heart disease mortality (4).

\section{MECHANISM}

Inflammation plays a central role in the pathophysiology of COPD (5). Although cigarette smoking causes inflammation in the small airways of all smokers, most do not develop clinically relevant COPD (5). Once COPD becomes established, airway inflammation persists even after smoking cessation (5). COPD patients also have systemic inflammation, characterized by elevated plasma C-reactive protein (CRP) and fibrinogen (6). This rise in biomarkers parallels the rise in airway inflammation, suggesting a link between them.

Elevated plasma CRP has been associated with CVD morbidity and mortality in patients with COPD as well as in the general population. In a large group of smokers with mild to moderate COPD (Lung Health Study [6]), serum CRP levels predicted the risk of all-cause and CVD mortality. The highest compared with the lowest quintile of CRP was associated with a $51 \%$ increase in fatal and nonfatal CVD (6).

Hemostatic and thrombotic factors also play a role in CVD morbidity and mortality of COPD patients, with increased thrombin, tissue plasminogen activator-plasminogen activator inhibitor complex and beta-thromboglobulin (a marker of platelet activation). A large meta-analysis has shown that for every $1 \mathrm{~g} / \mathrm{L}$ increase in plasma fibrinogen, the risk of COPDspecific and CVD-specific mortality increase by fourfold and 2.4-fold, respectively (7). During exacerbations, plasma fibrinogen increases further, which contributes to the abnormal hemostasis and thrombosis.

Increased sympathetic tone in COPD increases the risk of CVDs by increasing arterial pressure, inducing endothelial dysfunction, and promoting cardiac remodelling. In advanced COPD, patients demonstrate excess adrenergic tone, which appears to be related to the patients' oxyhemoglobin saturation.

\section{TREATMENT}

Smoking cessation is the most important intervention in reducing CVD mortality (1). Compared with continuing smokers, sustained quitters have a $65 \%$ reduction in the risk of death from CVD. Even intermittent quitters experience a large reduction in the risk of death from CVD (Approximately 54\% relative reduction compared with continuing smokers). Whether drug treatments modify CVD risk in COPD is controversial. Observational studies and one post hoc analysis suggests that inhaled corticosteroids (ICSs) reduce CVD, and a recent trial noted a lower all-cause mortality among patients treated with a ICS/long-acting beta-2 agonist combination compared with a long-acting anticholinergic bronchodilator 
(9), driven by lower rates of CVD events in the ICS/long-acting beta- 2 agonist group although mortality rates were low in both groups.

\section{CONCLUSION}

COPD patients have twice the risk of CVD events compared with the general population. Smoking cessation reduces CVD risks and certain pharmacological therapies may modulate risk, pending results from large clinical trials.

ACKNOWLEDGEMENTS: DDS is a Senior Scholar with the Michael Smith Foundation for Medical Research and a Canadian Research Chair in COPD. The work is supported in part by the Canadian Institutes of Health Research and the GlaxoSmithKline/ St Paul's Hospital Foundation Professorship in COPD.

CONFLICT OF INTEREST: DDS has received research funding and honoraria for speaking engagements form GlaxoSmithKline and AstraZeneca, makers of ICS/long-acting beta-2 agonist drugs.

\section{REFERENCES}

1. Anthonisen NR, Connett JE, Kiley JP, et al. Effects of smoking intervention and the use of an inhaled anticholinergic bronchodilator on the rate of decline of $\mathrm{FEV}_{1}$. The Lung Health Study. JAMA 1994;272:1497-505.

2. Sin DD, Wu L, Man SF. The relationship between reduced lung function and cardiovascular mortality: A population-based study and a systematic review of the literature. Chest 2005;127:1952-9.

3. McGarvey LP, John M, Anderson JA, Zvarich M, Wise RA. Ascertainment of cause-specific mortality in COPD: Operations of the TORCH Clinical Endpoint Committee. Thorax 2007;62:411-5.

4. Hole DJ, Watt GC, Davey-Smith G, Hart CL, Gillis CR, Hawthorne VM. Impaired lung function and mortality risk in men and women: Findings from the Renfrew and Paisley prospective population study. BMJ 1996;313:711-5; discussion 5-6.

5. Hogg JC. Pathophysiology of airflow limitation in chronic obstructive pulmonary disease. Lancet 2004;364:709-21.

6. Man P, Connett JE, Anthonisen NR, Wise RA, Tashkin DP, Sin DD. C-reactive protein and mortality in mild to moderate chronic obstructive pulmonary disease. Thorax 2006;61:849-53.

7. Danesh J, Lewington S, Thompson SG, et al. Plasma fibrinogen level and the risk of major cardiovascular diseases and nonvascular mortality: An individual participant meta-analysis. JAMA 2005;294:1799-809.

8. Heindl S, Lehnert M, Criee CP, Hasenfuss G, Andreas S. Marked sympathetic activation in patients with chronic respiratory failure. Am J Respir Crit Care Med 2001;164:597-601.

9. Wedzicha JA, Calverley PM, Seemungal TA, Hagan G, Ansari Z, Stockley RA. The prevention of chronic obstructive pulmonary disease exacerbations by salmeterol/fluticasone propionate or tiotropium bromide. Am J Respir Crit Care Med 2008;177:19-26.

\section{Action plans in asthma: Knowledge, confusion and controversy}

\author{
Lisa Cicutto PhD CAE \\ National Jewish Health, Denver, Colorado, USA \\ E-mail lisa.cicutto@utoronto.ca
}

Since 1980, written asthma action plans have been discussed and evaluated as an important element of asthma care (1). Currently, provision of an action plan is a core recommendation of asthma practice guidelines $(2,3)$, although usage rates remain between only $2 \%$ and $11 \%(4-6)$.

The definition and concept of written asthma action plans has evolved over the past 20 years. Earlier action plans were described as "written instructions for what to do and when for the treatment of asthma" (7), focusing primarily on identifying warning signs of worsening asthma and the appropriate pharmacological approach to their treatment. More recently, the Alberta Asthma Action Plan Task Force defined an asthma action plan as "written pharmacologic and non-pharmacologic instructions that are guided by action points, developed collaboratively between the patient and health professionals" (4). In general, written asthma action plans consist of zones to indicate various levels of asthma control with corresponding action points or steps that the patient needs to follow. The most common format is a three-zone plan that uses a traffic control analogy, where the green zone indicates stability, the yellow zone indicates caution and a need to increase therapy, and the red zone indicates danger and a need for urgent medical assistance.

Several systematic reviews of studies of action plans have identified areas of strong evidence as well as areas of controversy. Gibson et al's original systematic review (8) and subsequent updates indicate that those who receive asthma self-management education, visit the doctor regularly and have a written action plan experience fewer urgent visits to the emergency room and physician, hospital admissions, nocturnal awakenings and missed days of work. However, a systematic review by Toelle et al (9) observed that action plans alone do not improve adherence to maintenance therapy and do not consistently produce better patient outcomes than no written plan at all. The authors concluded that the contribution of an action plan to the known beneficial effects of a comprehensive asthma care program (self-management education and regular review) is unknown. However, a recent review in children (10) suggests that a written action plan compared with no written action plan can lead to fewer acute care visits, school absences and nocturnal awakenings, although this was based on a single randomized controlled trial.

Systematic reviews have also focused on identifying key characteristics of the most effective asthma action plans. In adults, current evidence suggests that action plans based only on symptoms perform similarly to those that include peak expiratory flow $(10,11)$. However, in children, symptom-based plans lowered the risk of an exacerbation requiring an acute care visit, and children preferred these type of plans (10). The most effective action plans use two to four action points and recommend inhaled and oral corticosteroids for treatment of exacerbations (12).

Overall, evidence suggests that action plans supported by self-management education and regular follow-up improve clinical outcomes $(8,9,11)$. However, there are many areas that require future research, such as assessing the actual use and timing of behaviours in action plans; exploring action plans in various subgroups (according to gender, culture, language, literacy level) and settings (schools, daycares, emergency departments); and identifying interventions to improve the uptake of written action plans by practitioners and patients.

\section{CONFLICTS OF INTEREST: None.}

\section{REFERENCES}

1. Clark NM, Feldman CH, Freudenberg N, Millman EJ, Wasilewski Y, Valle I. Developing education for children with asthma through study of self-management behavior. Health Education 1980;7:278-97.

2. Becker A, Lemière C, Bérubé D, et al; Asthma Guidelines Working Group of the Canadian Network For Asthma Care.Summary of 
recommendations from the Canadian Asthma Consensus guidelines, 2003. CMAJ 2005;13;173(6 Suppl):S3-11.

3. Bateman ED, Hurd SS, Barnes PJ, et al. Global strategy for asthma management and prevention: GINA executive summary. Eur Respir J 2008;31:143-78.

4. Tsuyuki RT, Sin DD, Sharpe HM, Cowie RL, Nilsson C, Man SF; Alberta Strategy to Help Manage Asthma (ASTHMA) Investigators. Management of asthma among community-based primary care physicians. J Asthma 2005;42:163-7.

5. FitzGerald JM, Boulet LP, McIvor RA, Zimmerman S, Chapman KR. Asthma control in Canada remains suboptimal: The Reality of Asthma Control (TRAC) study. Can Respir J 2006;13:253-9.

6. Cicutto LC, Ashby M. A toll free asthma helpline: Service provision and impact. J Asthma 2007:44:705-10.

7. Charlton I, Charlton G, Broomfield J, Mullee MA. Evaluation of peak flow and symptoms only self management plans for control of asthma in general practice. Br Med J 1990;301:1355-9.

8. Gibson PG, Powell H, Coughlan J, et al. Self-management education and regular practitioner review for adults with asthma. Cochrane Database of Systematic Reviews 2002, Issue 3. Art. No.: CD001117. DOI: $10.1002 / 14651858 . C D 001117$.

9. Toelle BG, Ram FS. Written individualised management plans for asthma in children and adults. Cochrane Database of Systematic Reviews 2004, Issue 1. Art. No.: CD002171. DOI: 10.1002/14651858. CD002171.pub2.T

10. Zemek RL, Bhogal SK, Ducharme FM. Systematic review of randomized controlled trials examining written action plans in children. Arch Pediatr Adolesc Med 2008;162:157-63.

11. Powell H, Gibson PG. Options for self-management education for adults with asthma. Cochrane Database of Systematic Reviews 2002, Issue 3. Art. No.: CD004107.

12. Gibson PG, Powell H. Written action plans for asthma: An evidencebased review of the key components. Thorax 2004;59:94-99.

\section{Preliminary results of a home telecare project for patients with chronic obstructive pulmonary disease}

\author{
Antonia Arnaert PhD MPA MSC RN ${ }^{1}$, Megan Wainwright BA ${ }^{2}$ \\ ${ }^{1}$ School of Nursing; ${ }^{2}$ Department of Oncology, McGill University, \\ Montreal, Quebec \\ E-mail antonia.arnaert@mcgill.ca
}

Opros hronic obstructive pulmonary disease (COPD) is a major public health problem $(1,2)$, particularly in older patients $(3,4)$. Although reasons for hospitalizations vary due to comorbidities (5), acute exacerbations are the main cause, and result in poor quality of life (6) and increased costs $(7,8)$. Studies have found that increased nursing homecare can help COPD patients to cope better and, in some cases, can reduce hospital admissions (9). One strategy to improve homecare services while reducing costs is 'home telecare' (HTC), which is defined as "the use of information and communication technologies to evaluate health status and deliver care from a distance to patients at home" (10).

This three-month feasibility study was the first in Quebec to use remote monitoring coupled with video visits. The aim was to test the HTC technology, become familiar with the needs of COPD patients, evaluate our methods, and explore nurse and patient perspectives. In January 2008, three female patients (mean age 70 years) with severe COPD were recruited while hospitalized at the McGill University Health Centre for an acute exacerbation. Approximately one week following discharge, they began receiving HTC visits from a trained telenurse. The HTC system is a Web-based application that runs on desktop computers (Figure 1). Most aspects of the system are controlled remotely by the nurse, including the devices for monitoring patients' vital signs, such as blood pressure and blood oxygen. During the first two months, patients were each scheduled for a daily visit, and the third and final month was used to wean them off the HTC system. The Living Well with $\mathrm{COPD}^{\mathrm{TM}}$ action plan (11), for which the nurses received training, guided the nurses' care plan.

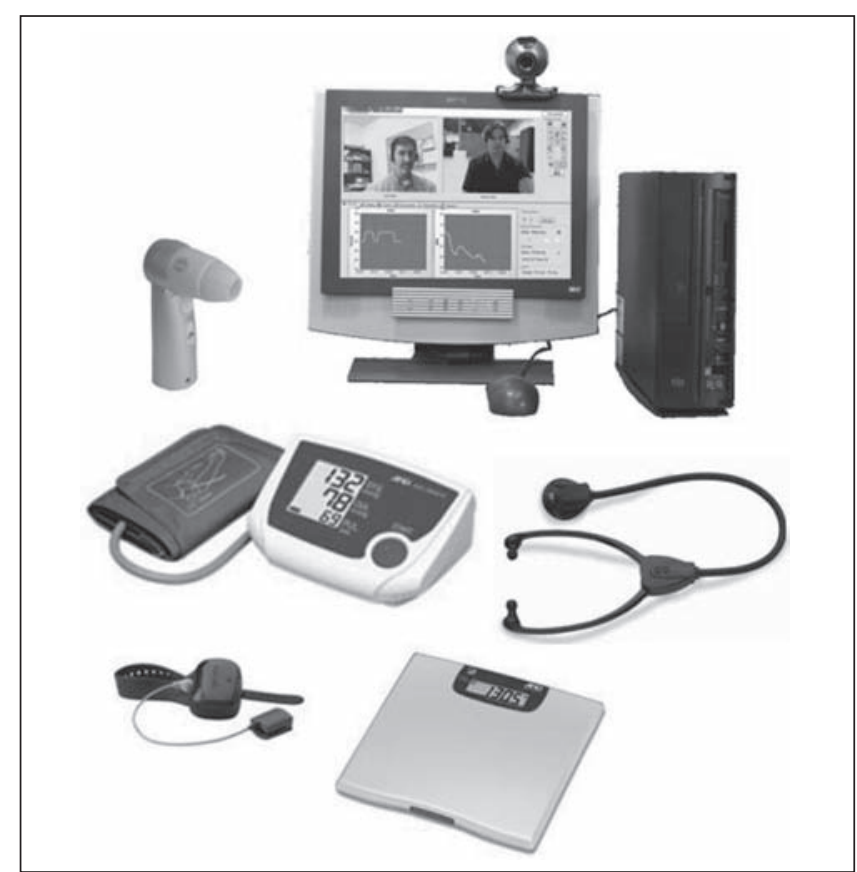

Figure 1) Home telecare patient station: desktop computer, Webcam, blood-pressure cuff, microscope, stethoscope, blood oxymeter, scale and PHD Medical's (Canada) Televisit software. Not included in image: thermometer

The total number of HTC visits made during the study was 161 , lasting on average 15.1 mins, which is consistent with other HTC studies (12). Nurses' and patients' experiences were extremely positive; however, the primary challenge in the first weeks of the study was helping the patients to adapt to and become comfortable with the technology. With regard to HTC's potential to encourage self-management, the following statement summarizes the point of view of the nurses:

"Theoretically they [patients] did understand...however once they started to have symptoms...the theory I thought sometimes went out the window and the emotions took over... and then they got a bit lost 'what should I do, I think I should wait'...That's where I thought our intervention was helpful because they started to make the connection between what they knew and the emotions. After about six weeks receiving HTC, all of a sudden we [nurses] didn't have to remind them so much 'maybe I should start my action plan', there you go, that is a good idea! And then you reinforce it."

All patients said that they greatly enjoyed the daily contact and support from the nurses and that it reassured them to have their vitals checked. One patient said:

"I found it [HTC] fantastic! It helped me know myself and to no longer wait before going to the hospital. It 
helped me have more confidence in myself, and control my fears, my breathlessness and my exacerbations, it was incredible for me...the nurses would advise me first 'don't you think you should call your doctor?' and after a while I learned to know myself, to know it's faster than I thought. I had a tendency of waiting, waiting...it will pass, it will pass, and it doesn't".

The present study demonstrates HTC's potential for monitoring exacerbations and for assisting patients in applying the skills and techniques learned for managing their disease at home. It is our belief that HTC may very well be the missing link for COPD self-management education.

ACKNOWLEDGEMENTS: We would like to thank Ms Donna Byrne MscN, the President of the private homecare company Health Access Santé in Beaconsfield, Quebec, for her tremendous infrastructural and financial support and thank her homecare nurses for participating in this study. We also thank the COPD network case manager of the referring hospital, the COPD nurse of the pulmonary rehabilitation clinic and the technology provider PHD Medical for their collaboration and contribution. The research was funded by GRISIM (Groupe de recherché interuniversitaire en science infirmière de Montréal) and Training and Human Resources Development Project, Health Canada.

\section{CONFLICTS OF INTEREST: None.}

\section{REFERENCES}

1. Bourbeau J, Julie M, Maltais F, et al. Reduction of hospital utilization in patients with chronic obstructive pulmonary disease. Arch Intern Med 2003;163:585-591.

2. Cote CG, Bartolome RC. Predictors of mortability in chronic obstructive pulmonary disease. Clin Chest Med 2007;28:515-24.

3. Mannino DM. COPD: Epidemiology, prevalence, morbidity and mortality, and disease heterogeneity. Chest 2002;121(S5):121S-6S.

4. Lee DT, Lee Iris FK, Mackenzie AE, Ho RN. Effects of a care protocol on care outcomes in older nursing home patients with chronic obstructive pulmonary disease. J Am Geriatr Soc 2002;50:870-6.

5. Crockett AJ, Cranston JM, Moss JR, Alpers JH. An association between length of stay and co-morbidity in chronic airflow limitation. Int J Qual Health Care 2000;12:41-6.

6. Aaron SD, Fergusson D, Marks GB, et al. Counting, analyzing and reporting exacerbations of COPD in randomized controlled trial. Thorax 2008;63:122-8.

7. Miravitlles M, Murio C, Guerrero T. Pharmacoeconomic evaluation of acute exacerbations of chronic bronchitis and COPD. Chest 2002;121:1449-55.

8. O'Reilly JF, Williams AE, Holt K, Rice L. Defining COPD exacerbations: Impact on estimation of incidence and burden in primary care. Prim Care Respir J 2006;15:346-53.

9. Barnett M. Providing anticipatory care for patients with chronic obstructive pulmonary disease. Nurs Stand 2006;21:41-6.

10. Celler BG, Lovel NH, Chan DK. The potential impact of home telecare on clinical practice. Med J Aust 1999;171:518-21.

11. Living Well with COPD ${ }^{\mathrm{TM}}$. < http://www.livingwellwithcopd.com> (Version current at February 23, 2008).

12. Johnston B, Wheeler L, Deuser J. Kaiser Permanente Medical Center's pilot tele-home health project. Telemed Today 1997;4:16-9.

\section{Does obstructive sleep apnea cause cardiovascular disease?}

\author{
Najib T Ayas MD MPH, Joshua Wenner BA \\ Respiratory Division and Sleep Disorders Program, University of \\ British Columbia, Vancouver, British Columbia \\ Email Najib.ayas@vch.ca
}

$\mathrm{O}$

bstructive sleep apnea (OSA) is a respiratory disorder characterized by reduced upper airway patency during sleep leading to recurrent episodes of airflow cessation (apnea) or reduction (hypopnea), resulting in sleep fragmentation and hypoxemia. There is accumulating evidence that OSA is a cause of cardiovascular disease.

First, there are a number of animal studies that have demonstrated a potential link between experimentally induced intermittent hypoxia and the development of cardiovascular disease. For example, in a recent study, investigators exposed 40 mice to one of four conditions for 12 weeks: intermittent hypoxia and a high cholesterol diet; intermittent hypoxia and a normal diet; intermittent air and a high cholesterol diet; and intermittent air and a normal diet (1). Aortic plaques were identified in nine of 10 mice in the intermittent hypoxia and high cholesterol group, but in none of the mice in the other groups. Furthermore, increased levels of lipids and markers of hepatic inflammation were found in this group, suggesting that inflammation may be a potential pathogenic mechanism.

Second, OSA is strongly and independently associated with cardiovascular disease in a number of prospective cohorts. For example, Marin et al (2) followed five groups of men (healthy men, snorers without OSA, untreated patients with mild/moderate OSA, untreated patients with severe OSA, and treated patients) for 10 years to track the incidence of cardiovascular disease (stroke, myocardial infarction, percutaneous coronary intervention, coronary artery bypass). Compared with healthy controls, untreated men with severe OSA had a threefold increased risk of fatal $(\mathrm{OR}=2.87,95 \% \mathrm{CI} 1.17$ to 7.51$)$ and nonfatal $(\mathrm{OR}=3.17,95 \% \mathrm{CI} 1.12$ to 7.51$)$ cardiovascular events, even after controlling for a variety of potential confounders. Interestingly, the OR was not significantly increased in patients treated for OSA, suggesting that treatment may substantially mitigate the increased risks associated with the disease. A number of other prospective cohorts have also demonstrated independent associations between OSA and a variety of cardiovascular and cerebrovascular outcomes (3-7). However, a major problem with these studies is the influence of potential confounding variables.

Third, experimental studies of patients with OSA treated with continuous positive airway pressure (CPAP) have demonstrated reductions in a variety of cardiovascular risk markers including blood pressure, systemic inflammation and endothelial dysfunction (8-10). A recent small preliminary report (11) suggested improvements in carotid intima and media thickness with CPAP.

Animal studies, prospective epidemiological studies, and short-term CPAP intervention studies have provided compelling data implicating OSA in the pathogenesis of cardiovascular disease. However, large, long-term, randomized controlled trials of CPAP therapy are needed to understand whether therapy reduces risks of cardiovascular disease in patients with OSA. These types of studies will be crucial to our understanding of the 
links between OSA and cardiovascular disease, and to help guide the management of our patients.

CONFLICTS OF INTEREST: Dr Ayas has received a research grant from Respironics Inc.

\section{REFERENCES}

1. Savransky V, Nanayakkara A, Li J, et al. Chronic intermittent hypoxia induces atherosclerosis. Am J Respir Crit Care Med 2007;175:1290-7.

2. Marin JM, Carrizo SJ, Vicente E, et al. Long-term cardiovascular outcomes in men with obstructive sleep apnoea-hypopnoea with or without treatment with continuous positive airway pressure: an observational study. Lancet 2005;365:1046-53.

3. Peppard PE, Young T, Palta M, et al. Prospective study of the association between sleep-disordered breathing and hypertension. N Engl J Med 2000;342:1378-84.

4. Arzt M, Young T, Finn L, Skatrud JB, Bradley TD. Association of sleep-disordered breathing and the occurrence of stroke. Am J Respir Crit Care Med 2005;172:1447-51.

5. Yaggi HK, Concato J, Kernan WN, Lichtman JH, Brass LM, Mohsenin V. Obstructive sleep apnea as a risk factor for stroke and death. N Engl J Med 2005;353:2034-41.

6. Gami AS, Howard DE, Olson EJ, Somers VK. Day-night pattern of sudden death in obstructive sleep apnea. N Engl J Med 2005;352:1206-14.

7. Peker Y, Carlson J, Hedner J. Increased incidence of coronary artery disease in sleep apnoea: A long-term follow-up. Eur Respir J 2006;28:596-602.

8. Haentjens P, Van Meerhaeghe A, Moscariello A, et al. The impact of $\mathrm{CPAP}$ on blood pressure in patients with obstructive sleep apnea syndrome: Evidence from a meta-analysis of placebo-controlled randomized trials. Arch Intern Med 2007;167:757-64.

9. Cross MD, Mills NL, Al-Abri M, et al. Continuous positive airway pressure improves vascular function in obstructive sleep apnoea/ hypopnoea syndrome: a randomised controlled trial. Thorax 2008;63:578-83.

10. Yokoe T, Minoguchi K, Matsuo H, et al. Elevated levels of C-reactive protein and interleukin- 6 in patients with obstructive sleep apnea syndrome are decreased by nasal continuous positive airway pressure. Circulation 2003;107:1129-34.

11. Drager LF, Bortolotto LA, Figueiredo AC, Krieger EM, Lorenzi GF. Effects of continuous positive airway pressure on early signs of atherosclerosis in obstructive sleep apnea. Am J Respir Crit Care Med 2007;176:706-12.

\section{Diagnostic strategies for patients with suspected sleep-disordered breathing}

\author{
$R$ John Kimoff MD FRCP \\ Respiratory Division, McGill University Health Centre and \\ Meakins-Christie Laboratories, McGill University, Montreal, \\ Quebec \\ E-mail john.kimoff@mcgill.ca
}

$\mathrm{O}$ bstructive sleep apnea (OSA) is estimated to affect $4 \%$ of adult women and $9 \%$ of adult men, based on data gathered in the early 1990s (1). With the dramatic increase in obesity over the past two decades in North America (2), the true prevalence of OSA is likely now even higher. OSA is associated with considerable morbidity and likely increased mortality, representing a major public health issue.

Traditionally, the gold standard approach to diagnosis of OSA has been sleep laboratory-based polysomnography (3), with subsequent polysomnographic recording to manually titrate nasal continuous positive airway pressure (CPAP), the proven treatment of choice for OSA (4). However, polysomnography is an expensive procedure with limited availability in many parts of Canada, and there is growing evidence that alternative, lower-cost strategies such as portable monitors can play a role in OSA management $(5,6)$. In patients with a moderate to high pretest probability of OSA, such devices can often establish the presence and severity of disease and inform the selection of treatment. A major evidence review (6) concluded that the increased accuracy of polysomnographic apneahypopnea index measurements, compared with ambulatory monitors, does not provide superior prediction of clinically relevant outcomes such as CPAP response or compliance, among patients with a high probability of OSA.

However, even once a diagnosis of OSA is made, access to nasal CPAP is limited. Only Ontario, Manitoba and Saskatchewan have universal CPAP coverage programs, and requirements for polysomnographic CPAP titration may still result in long waiting times. Other provinces and territories have widely varying degrees of support for and access to CPAP. Several studies have demonstrated that autotitrating CPAP can guide initiation of effective treatment on an ambulatory basis as reliably as polysomnographic CPAP titration in moderate to severe OSA $(7,8)$. Recently, Mulgrew et al (9) demonstrated that in patients with a high probability of OSA, ambulatory diagnosis and treatment with autotitrated CPAP produced equal or superior treatment compliance and improvements in excessive daytime sleepiness to conventional polysomnography. These studies suggest that ambulatory disease management with portable diagnostic testing and auto-CPAP titration can be effective in moderate to severe OSA.

Generalizability is limited by the fact that the majority of studies to date have focussed on middle-aged Caucasian males without major medical comorbidities presenting with a strong clinical history for OSA. There is a need for further research among diverse ethnic groups, women, the elderly, patients with major comorbidities, and in screening and prevention in the general population. A Workshop on Research Priorities in Ambulatory Management of OSA was held in October 2007, and its key findings and recommendations will be published in the Proceedings of the American Thoracic Society. This document should serve as a blueprint for the generation of new knowledge in this area.

It is now clear that 'uncomplicated' moderate to severe OSA does not absolutely require, and due to sheer volume, cannot solely be managed by, tertiary medical centres. However, practical impediments remain to the translation of even current knowledge on ambulatory management of OSA into widespread, effective use in primary care and other settings. Clinical guidelines on the role of portable monitors in OSA management (10) emphasize the need for trained, expert medical and technical staff to ensure competent clinical evaluation and high-quality recording, data analysis and interpretation. Currently, there is a major lack of such skilled personnel in Canada. However, partnerships between specialized and primary centres may enable training and protocols for quality assurance in OSA diagnosis and management. Ambulatory technology could then be provided in the primary setting, with referrals to specialized centres for more complex cases. While considerable further work is needed to identify optimal, costeffective methodologies, it will only be through the development of integrated networks of this nature that high-quality care for OSA will become accessible to all Canadians. 
CONFLICTS OF INTEREST: Dr Kimoff has received speaker fees for presentations on sleep apnea from GlaxoSmithKline and VitalAire Inc.

\section{REFERENCES:}

1. Young T, Peppard PE, Gottlieb DJ. Epidemiology of obstructive sleep apnea: a population health perspective. Am J Respir Crit Care Med 2002;165:1217-39.

2. Katzmarzyk PT, Mason C. Prevalence of class I, II and III obesity in Canada. CMAJ 2006;174:156-7.

3. Fleetham J, Ayas N, Bradley D, et al. Canadian Thoracic Society guidelines: Diagnosis and treatment of sleep disordered breathing in adults. Can Respir J 2006;13:387-92.

4. Giles TL, Lasserson TJ, Smith BH, White J, Wright J, Cates CJ. Continuous positive airways pressure for obstructive sleep apnoea in adults. Cochrane Database Syst Rev 2006;3:CD001106.

5. Flemons WW, Littner MR, Rowley JA, et al. Home diagnosis of sleep apnea: a systematic review of the literature. An evidence review cosponsored by the American Academy of Sleep Medicine, the American College of Chest Physicians, and the American Thoracic Society. Chest 2003;124:1543-79.

6. Trikalinos TA, Ip S, Raman G, et al. Home diagnosis of obstructive sleep apnea-hypopnea syndrome. <www.cms.hhs.gov/determinationprocess/ downloads/id48TA.pdf $>$. (Version current at August 8, 2007).

7. Masa JF, Jiménez A, Durán J, et al. Alternative methods of titrating continuous positive airway pressure: a large multicenter study. Am J Respir Crit Care Med 2004;170:1218-24.

8. West SD, Jones DR, Stradling JR. Comparison of three ways to determine and deliver pressure during nasal CPAP therapy for obstructive sleep apnoea. Thorax 2006;61:226-31.

9. Mulgrew AT, Fox N, Ayas NT, Ryan CF. Diagnosis and initial management of obstructive sleep apnea without polysomnography: A randomized validation study. Ann Intern Med 2007;146:157-66.

10. Collop NA, Anderson WM, Boehlecke B, et al. Clinical guidelines for the use of unattended portable monitors in the diagnosis of obstructive sleep apnea in adult patients. Portable Monitoring Task Force of the American Academy of Sleep Medicine. J Clin Sleep Med 2007;3:737-47.

\section{Canadian Thoracic Society guidelines for sleep disordered breathing}

John A Fleetham

Respiratory Division, University of British Columbia, Vancouver, British Columbia

E-mail John.Fleetham@vch.ca

Sleep disordered breathing (SDB) is associated with reduced quality of life, decreased cardiovascular health, and increased health care utilization, motor vehicle crashes and mortality. There are several well tolerated and effective treatments that have been shown to improve these various outcomes. Despite this, the majority of Canadians with SDB remain undiagnosed and untreated. There is considerable variability in access to diagnosis and treatment for SDB across Canada, which has led to a heterogeneous approach across provinces and territories. In an attempt to address this, the Canadian Thoracic Society has developed national guidelines for the diagnosis and treatment of $\operatorname{SDB}(1,2)$. These guidelines include recommendations concerning patient triage (Table 1 ) and maximum wait times for assessment (Table 2). Patients with suspected SDB should be triaged based on the degree of subjective sleepiness and the presence of comorbid disease, a safety critical occupation, risk of a motor vehicle crash and sleep arterial oxygen desaturation. Urgent patients should have a medical specialist assessment and/or polysomnography arranged and completed within two to four weeks, and all patients, within six months.
TABLE 1

Triage criteria for patients referred for assessment of sleep disordered breathing (SDB)

\begin{tabular}{l} 
Urgent \\
\hline Patients with: \\
suspected SDB; \\
major daytime sleepiness (ESS 15 or greater); and \\
a safety-critical occupation ${ }^{\dagger}$ \\
Or \\
suspected SDB plus one or more of the following: \\
• comorbid disease* or pregnancy \\
• overnight home oximetry that reveals $>30 / h 4 \%$ desaturations \\
Semiurgent \\
\hline Patients with: \\
suspected SDB; \\
major daytime sleepiness (ESS 15 or greater); and \\
no comorbid disease ${ }^{*}$, pregnancy or safety-critical occupation ${ }^{\dagger}$ \\
Elective \\
\hline Patients with: \\
suspected SDB; \\
no major daytime sleepiness (ie, ESS <15); \\
no comorbid diseases or pregnancy; and \\
no safety-critical occupation ${ }^{\dagger}$. \\
${ }^{*}$ Comorbid disease: ischemic heart disease, cerebrovascular disease, con- \\
gestive heart failure, obstructive/restrictive lung disease, pulmonary hyperten- \\
sion, hypercapnic respiratory failure. ${ }^{\dagger}$ Safety critical occupations or at high risk \\
of a motor vehicle crash: Individuals working with machinery, or employed in \\
hazardous occupations; truck, taxi, bus drivers; railway engineers, airline \\
pilots, ship captains; car drivers who admit to have fallen asleep while driving \\
within the last two years. ESS Epworth Sleepiness score
\end{tabular}

TABLE 2

Maximum wait times for medical specialist assessment and/or polysomnography

Urgent cases: within 2 to 4 weeks

Semi-urgent cases: within 2 months

Elective cases: within 6 months.

As with any medical condition, the diagnosis of SDB starts with history and physical examination. Sleep monitoring is required to confirm the diagnosis and to determine the type and severity of SDB. There is much debate about the most appropriate form of sleep monitoring. Level I (complete laboratory polysomnography) remains the accepted standard for evaluation of SDB and is the test of choice. There is, however, quite variable access to polysomnography across Canada. Level II (full ambulatory polysomnography) and Level III (portable monitoring with multichannel cardiorespiratory recording devices) can be used to confirm the diagnosis of obstructive sleep apnea/hypopnea syndrome (OSAHS) in patients with a moderate to high pretest probability, but are of more limited use in patients with comorbid disease and for the diagnosis of other forms of SDB. Studies using Level IV portable monitoring (oximetry) may have a role in the initial assessment of SDB; however' their significant limitations in distinguishing different types of SDB must be fully appreciated before using them to make diagnostic and therapeutic decisions. Although access to polysomnography across Canada is improving, it is unlikely to increase sufficiently to provide timely access to diagnosis of SDB for all Canadians. A diagnostic approach 
based on disease probability and use of Level I, II, III and IV monitoring needs to be developed and validated. As with all diagnostic tests, the level of experience and training available to interpret the results is as important as the type of sleep monitoring.

All symptomatic patients with OSAHS should have a therapeutic trial of continuous positive airway pressure (CPAP) to improve their symptoms. The indications for treatment of asymptomatic patients with abnormal sleep monitoring are unclear. Treatment may be considered in asymptomatic patients with significant comorbid illness, patients who work in a safety critical occupation, or those who have an apnea/hypopnea index of greater than 30 events/h. CPAP at a fixed pressure is the primary treatment for patients with OSAHS. Oral appliances are an appropriate therapy for patients with mild to moderate OSAHS with minimal daytime symptoms. Corrective upper airway surgery may be considered in selected patients with OSAHS who have failed CPAP and/or oral appliance treatment. There is variable provincial medical plan and extended health insurance coverage for CPAP, oral appliances and surgery for OSAHS.

Similar to other common chronic disorders such as asthma and diabetes, there needs to be a national patient awareness program regarding the symptoms and consequences of SDB that includes information about maximum recommended wait times for diagnosis and treatment. This should be complemented by a national strategy that provides timely access to the diagnosis and treatment of SDB for all Canadians. Governments, transportation agencies, industry and insurance companies must be educated about the economic impact of untreated SDB.

\section{CONFLICTS OF INTEREST: None.}

\section{REFERENCES}

1. Fleetham J, Ayas N, Bradley D, et al; for the the CTS Sleep Disordered Breathing Committee. Canadian Thoracic Society Guidelines: Diagnosis and treatment of sleep disordered breathing in adults. Can Respir J 2006;13:387-92.

2. Fleetham J, Ayas N, Bradley D, et al. Directives de la Société canadienne de thoracologie: Diagnostic et traitement des troubles respiratoires du sommeil de l'adulte. Can Respir J 2007;14:31-6.

\section{Inflammatory response to viral infection in children: Focus on respiratory syncytial virus}

\author{
Brenda-Louise Giles \\ University of Manitoba Children's Hospital, Winnipeg, Manitoba \\ E-mail gilesbl@cc.umanitoba.ca
}

$\mathrm{R}$ espiratory syncytial virus (RSV) is responsible for the majority of lower respiratory track infections in infancy. Infection with RSV is seasonal in temperate climates close to the poles, is yearly in equatorial regions, and has a worldwide distribution. In Canada, RSV disease typically occurs during the winter months, in a predictable fashion. Most children acquire their primary RSV infection by one year of age, and almost all children have been infected by their second birthday.

RSV is the most common pathogen leading to hospitalization in infancy, despite the presence of maternally derived circulating antibodies. Furthermore, humoral antibody-derived immunity is incomplete, rendering one susceptible to repeated infections over a lifetime.

\section{RSV}

RSV is a pleomorphic, cytoplasmic, negative-stranded nonsegmented RNA virus named pneumovirus. It belongs to the Paramyxoviridae family, which also includes Parainfluenzae, mumps, morbillivirus and human metapneumonovirus. The nucleocaspid of RSV is enclosed within a lipid envelope that can facilitate fusion with the cell membrane. There are two subtypes (A and B), but a relationship between RSV subtype and severity of disease has not been established. RSV predominantly infects airway epithelial cells.

\section{RSV INFECTION AND RESPONSE}

Primary infection occurs once the virus invades the airway epithelium of a susceptible host. It is the host response that leads to RSV disease in a predictable fashion including initial innate responses, followed by cellular-specific responses and, finally, humoral immunity. The timing of the host immune response is important; the innate response, including release of chemokines and cytokines, occurs within the first three days. During this time, T-cells, neutrophils, monocytes and in some, eosinophils, are attracted, along with upregulation of adhesion molecules and dendritic cell activation. Following this, cellmediated responses occur with either a T helper cell (Th) 1 or a Th2 response. Most infants and children will mount a Th1type response to RSV infection and have resolution of disease. However, in predisposed individuals, a Th2 response to RSV infection may occur, leading to enhanced disease and severe bronchiolitis and in some, subsequent long term sequelae.

\section{RSV DISEASE}

Even though most children are infected by their first birthday, some infants are at risk for significant disease: those born prematurely, those with either pulmonary or cardiac disease, and those with immune impairment. Approximately 3\% of children with RSV disease are admitted to hospital and of those, $10 \%$ die. It is important to realize that RSV infection does not correlate with disease severity or progression; often, the virus is cleared at the height of maximal symptoms. The symptoms are clearly related to the individual host response and ensuing airway pathology: mucosal edema, mucus production, bronchospasm, airway blockage leading to patchy atelectasis and compensatory emphysema. The younger infant is at higher risk for disease; an immature immune system despite maternally derived antibodies does not confer full protection, humoral responses are often inconsistent, and the youngest infants may actually mount a Th2 rather than a Th1 response to infection, resulting in increased morbidity in this population.

\section{SUMMARY}

RSV is common in infancy and the disease is associated with host response rather than viral load. Immaturity of the infant response to infection may lead to a Th2 cell mediated response (instead of a Th1 response), which leads to increased morbidity and long term sequelae.

CONFLICTS OF INTEREST: None.

\section{SUGGESTED READING}

1. Piedimonte G. Origins of reactive airways disease in early life: Do viral infections play a role? Acta Paediatr Suppl 2002;91:6-11. 
2. Kato M, Hayashi Y, Kimura H. Oxygen radicals in inflammation and allergy related to viral infections. Curr Drug Targets Inflamm Allergy 2005:4:497-501.

3. Smyth RL. Innate immunity in respiratory syncytial virus bronchiolitis. Exp Lung Res 2007;33:543-7.

4. Becker S, Soukup JM. Airway epitheliol cell-induced activation of monocytes and eosinophils in respiratory syncytial viral infection. Immunobiology 1999;201:88-106.

5. Hacking D, Hull J. Respiratory syncytial virus - viral biology and the host response. J Infect 2002;45:18-24.

6. Boukhvalova MS, Yim KC, Kuhn KH, et al. Age-related differences in pulmonary cytokine response to respiratory syncytial virus infection: Modulation by anti-inflammatory and antiviral treatment. J Infect Dis 2007;195:511-8.

7. Silvestri M, Sabatini F, Defilippi AC, Rossi GA. The wheezy infant immunological and molecular considerations. Paediatr Respir Rev 2004;5(Suppl A):S81-7.

8. Mejias A, Chavez-Bueno S, Jafri HS, Ramilo O. Respiratory syncytial virus infections: Old challenges and new opportunities. Pediatr Infect Dis J 2005;24(11 Suppl):S189-96.

9. Openshaw PJM. Antiviral immune responses and lung inflammation after respiratory syncytial virus infection. Proc Am Thorac Soc 2005;2:121-5.

10. Grell SN, Riber U, Tjørnehøj K, Larsen LE, Heegaard PM. Agedependent differences in cytokine and antibody responses after experimental RSV infection in a bovine model. Vaccine 2005;23:3412-23.

11. Peebles Jr RS, Hashimoto K, Graham BS. The complex relationship between respiratory syncytial virus and allergy in lung disease. Viral Immunol 2003;16:25-34.

\section{Inflammatory response to viral infections in adults}

\author{
David Proud PhD \\ Airway Inflammation Group, Institute of Infection Immunity and \\ Inflammation, University of Calgary, Calgary, Alberta \\ E-mail dproud@ucalgary.ca
}

U pper respiratory viral infections are a major trigger for acute exacerbations of asthma and chronic obstructive pulmonary disease. Although several viral types have been associated with exacerbations of these diseases, in both adolescents and adults human rhinovirus (HRV) is the dominant pathogen detected (1). The epithelial cell is the primary site for HRV infection, and there is now strong evidence that infections from the upper airway can spread to lower airway epithelial cells (2). HRV does not induce overt cytotoxicity in epithelial cells. Thus, it is generally assumed that an over-exuberant host inflammatory response to viral infection, initiated by alterations of epithelial cell biology, triggers disease exacerbations. To examine this concept, investigators have combined in vitro studies of cultured human airway epithelial cells with in vivo studies in experimental, or naturally acquired, HRV infections. Infection of cultured human epithelial cells with HRV has been shown to lead to generation of a variety of proinflammatory chemokines, including interleukin (IL)-8 (CXCL8), epithelial-neutrophil activating peptide (ENA)-78 (CXCL5), and interferon- $\gamma$-inducible protein of $10 \mathrm{kd}$ (IP-10, CXCL10), as well as cytokines, such as IL-1 $\beta$, IL-6, granulocyte monocyte colonystimulating factor and IL-11 (1,3). Importantly, several of these products also are detected in airway secretions during HRV infections in vivo, suggesting that they may contribute to recruitment and activation of inflammatory cells $(1,3)$. Viral exacerbations of asthma and chronic obstructive pulmonary disease are characterized primarily by increased numbers of neutrophils and lymphocytes (Figure 1). The chemokines IL-8 and ENA-78 are potent recruiters of neutrophils, and IL-8 levels correlate with neutrophil counts in both adults and children (4). Similarly, IP-10 is a potent chemoattractant for natural killer cells and type 1 lymphocytes, and IP-10 levels correlate with lymphocyte numbers during in vivo $H R V$ infections. HRV infections also stimulate epithelial production of human $\beta$-defensin 2 , which could serve as a link between the innate and adaptive immune responses by recruiting immature dendritic cells to sites of infection (5).

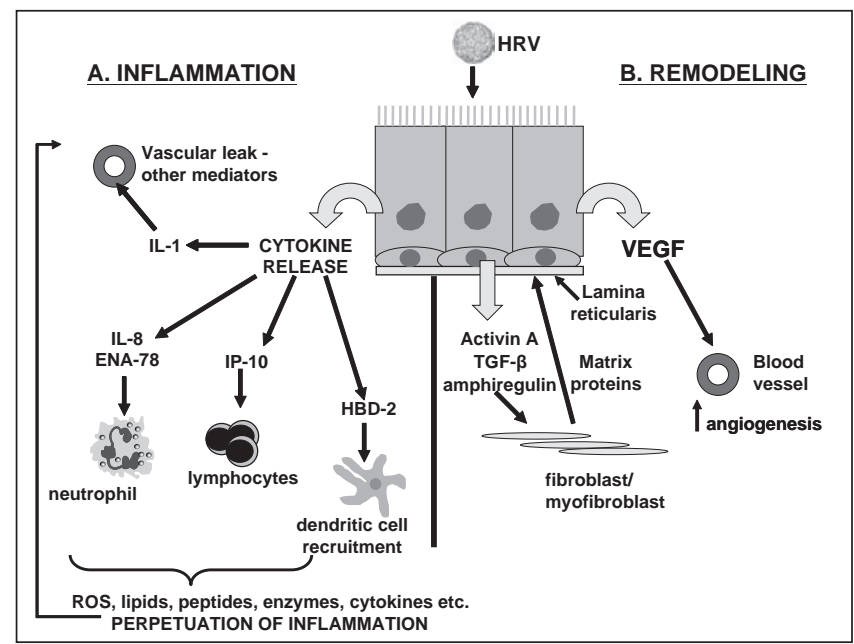

Figure 1) Infection of epithelial cells with human rhinovirus (HRV) may induce both inflammation and remodeling. Production of interleukin (IL)-1 will activate vascular endothelium, increasing vascular permeability and the generation of 'secondary' mediators. Release of chemokines such as IL-8 and epithelial-neutrophil activating peptide-78 (ENA-78) will recruit and activate neutrophils, while interferon- $\gamma$-inducible protein of $10 \mathrm{kd}(\mathrm{IP}-10)$ will recruit type 1 lymphocytes. Mediators released from the cells can contribute to perpetuation of inflammation. Production of human $\beta$-defensin-2 (HBD-2) can recruit and activate dendritic cells and could initiate antigen presentation. On the other hand, production of mediators such as transforming growth factor- $\beta$ (TGF- $\beta$ ), activin A and amphiregulin may stimulate matrix protein production from fibroblasts and myofibroblasts, while vascular endothelial growth factor (VEGF) may contribute to angiogenesis

Although production of cytokines and chemokines from epithelial cells may be the initial trigger for enhanced inflammation, cytokines such as IL- $1 \beta$ would be expected to cause vascular activation and release of plasma mediators (Figure 1). Indeed, bradykinin and lysyl-bradykinin are produced during HRV infections and correlate with symptoms, but defining the role of these peptides needs specific intervention studies. Similarly, recruited inflammatory cells can release a 'second wave' of mediators that may contribute to airway inflammation and mucus production. In children, infection with respiratory syncytial virus (RSV) induces production of leukotrienes (6). These likely contribute to airway symptoms, because infants hospitalized for RSV bronchiolitis showed a small but significant inhibition of postbronchiolitis lower airway symptoms in response to montelukast. Moreover, montelukast reduced the number of virally induced asthma exacerbations in young children with intermittent asthma (7). In adults, modest leukotriene production has been reported in subjects infected with RSV or influenza, but not during HRV infections. 
In addition to the role of HRV-infected epithelial cells in airway inflammation, recent evidence suggests that they also produce a range of growth factors that may be expected to contribute to airway remodelling (8). Given that children get multiple infections annually in early life, these may contribute to remodelling seen in young children, while in adults, viral infections may contribute to continued progression of remodelling (Figure 1). Finally, epithelial cells may help regulate susceptibility to development of disease exacerbations via their ability to release antiviral agents, such as nitric oxide, that reduce viral inflammation and viral replication (9). This raises the possibility that boosting such antiviral defenses may be of therapeutic potential.

\section{CONFLICTS OF INTEREST: None.}

\section{REFERENCES}

1. Proud D, Chow C-W. Role of viral infections in asthma and chronic obstructive pulmonary disease. Am J Respir Cell Mol Biol 2006;35:513-8.

2. Mosser AG, Brockman-Schneider R, Amineva S, et al. Similar frequency of rhinovirus-infectable cells in upper and lower airway epithelium. J Infect Dis 2002;185:734-43.

3. Traves SL, Proud D. Viral-associated exacerbations of asthma and COPD. Curr Opin Pharmacol 2007;7:252-8.

4. Teran LM, Johnston SL, Schröder J-M, Church MK, Holgate ST. Role of nasal interleukin-8 in neutrophil recruitment and activation in children with virus-induced asthma. Am J Respir Crit Care Med 1997;155:1362-6.

5. Proud D, Sanders SP, Wiehler S. Human rhinovirus infection induces airway epithelial cell production of human $\beta$-defensin- 2 both in vitro and in vivo. J Immunol 2004;172:4637-45.

6. Volovitz B, Welliver RC, De Castro G, Krstofik DA, Ogra PL. The release of leukotrienes in the respiratory tract during infection with respiratory syncytial virus: role in obstructive airway disease. Pediatr Res 1988;24(4):504-7.

7. Bisgaard H, Zielen S, Garcia-Garcia ML, et al. Montelukast reduces asthma exacerbations in 2-to 5-year-old children with intermittent asthma. Am J Respir Crit Care Med 2005;171:315-22.

8. Leigh R, Oyelusi W, Wiehler S, et al. Human rhinovirus infection enhances airway epithelial cell production of growth factors invovled in airway remodeling. J Allergy Clin Immunol 2008;121:1238-45.

9. Proud D. Nitric oxide and the common cold. Curr Opin Allergy Clin Immunol 2005;5:37-42.

\section{Limb muscle dysfunction in chronic obstructive pulmonary disease}

\author{
François Maltais MD \\ Centre de pneumologie, Hôpital Laval, Sainte Foy, Quebec City, \\ Quebec \\ E-mail francois.maltais@med.ulaval.ca
}

\section{HIGHLIGHTING THE IMPACT OF LOWER LIMB MUSCLE DYSFUNCTION ON EXERCISE TOLERANCE IN CHRONIC OBSTRUCTIVE PULMONARY DISEASE AND HOW THIS MAY APPLY TO PHARMACOTHERAPY AND REHABILITATION}

Bronchodilation and exercise tolerance

Clinical trials confirm the efficacy of long-acting bronchodilators in reducing operational lung volumes during exercise, reducing dyspnea and increasing exercise tolerance (1-3). However, improvement in lung function correlates weakly with changes in exercise capacity and for some patients, exercise capacity does not change (4).

\section{Leg fatigue during exercise}

Leg fatigue is the predominant limitation at peak cycling exercise in one-third of patients with chronic obstructive pulmonary disease (COPD) (5), and contractile fatigue of the quadriceps with cycle-based exercise has been demonstrated (6). Contractile fatigue occurs at a much lower exercise intensity in COPD compared with healthy individuals (7). Such patients are vulnerable to fatigue, even during mild exercise.

To evaluate whether contractile fatigue of the quadriceps could influence exercise tolerance, 18 patients with COPD exercised at a constant work rate to exhaustion on two separate days (7). Exercise was preceeded by nebulized placebo or ipratropium bromide. Using magnetic stimulation of the femoral nerve, the strength of the quadriceps was measured before and after exercise. One-half of the 18 patients developed contractile fatigue of the quadriceps, with reduced muscle strength greater than $15 \%$. In patients who did not develop fatigue, a $13 \%$ improvement in forced expiratory volume in $1 \mathrm{~s}$ after bronchodilation translated into better exercise endurance. A similar improvement in forced expiratory volume in $1 \mathrm{~s}$ did not influence exercise in patients who developed quadriceps fatigue. Therefore, leg fatigue modulates the exercise-response to bronchodilation.

This observation is supported by a pooled analysis of three studies $(5,8,9)$ of exercise response to bronchodilation in patients with COPD. In this analysis, the improvement in exercise was smaller in those limited by leg fatigue than those limited by dyspnea.

\section{Susceptibility to muscle fatigue}

Muscle weakness commonly contributes to muscle fatigue in COPD $(10,11)$ and the perception of leg fatigue for a given power output is greater in weak compared with strong individuals. Quadriceps strength is a determinant of exercise capacity independent of the impairment in lung function.

Morphometric changes, such as a reduction in highly oxidative type I fibres in favour of fatigue-susceptible type IIx fibres, predispose patients to fatigue $(8,12)$, and quadriceps mitochondrial enzyme activity is diminished in COPD compared with healthy controls (13). Muscle capillarization is also affected (14).

\section{Treating peripheral muscle dysfunction in COPD}

Peripheral muscle dysfunction is improved with exercise training, with both aerobic and strengthening exercises $(15,16)$ reported to increase mid-thigh muscle area and muscle strength (15). The aerobic capacity of the quadriceps improved following a 12-week training program of three weekly $30 \mathrm{~min}$ to 40 min exercise sessions (17). Other benefits included a slower rise in blood lactate during exercise (18) and a reduced susceptibility to fatigue (19).

Exercise training also alleviates the central component of exercise intolerance in COPD. In fact, a reduced ventilatory requirement at a given exercise level was one of the first physiological adaptations following exercise training in COPD to be reported (18). As a result, exercise-induced dynamic hyperinflation is diminished (20).

An example of the synergistic interactions between pharmacotherapy and rehabilitation was noted when patients with COPD were randomized to receive tiotropium or placebo before undertaking an eight-week exercise training program (21). The 
combined treatment group had a larger improvement in exercise endurance during the training program compared with the group randomized to exercise training alone, perhaps because optimal bronchodilation enabled higher training intensities.

\section{How to optimize the benefits of pulmonary rehabilitation} As high training intensity is unrealistic for many patients limited by severe dyspnea, adjunct approaches include oxygen supplementation (22), heliox (23), noninvasive ventilation (24) and interval training (25), although their long-term implications on exercise, functional status and quality of life remain to be defined.

Treatment of muscle wasting by combining strengthening exercises with high doses of anabolic steroids in men with COPD and low testosterone levels was associated with a striking gain of $3.3 \mathrm{~kg}$ in limb muscle mass over a 12-week period (26). The longer term relevance of this approach, as well as other anabolic substances, is unclear.

\section{Implications of limb muscle dysfunction for the choice of exercise testing}

Because quadriceps fatigue during exercise is worse after cycling than after walking $(5,27)$, tests such as the endurance shuttle walk should be appropriate to assess the effect of bronchodilation on exercise performance. These outcome measures will inform future clinical trials of the impact of bronchodilation on functional status (28).

\section{CONCLUSIONS}

Limb muscle dysfunction has implications for exercise intolerance and the exercise response to bronchodilation. It constitutes an important mechanism through which exercise training improves exercise tolerance in COPD.

\section{CONFLICTS OF INTEREST: None.}

\section{REFERENCES}

1. O'Donnell DE, Fluge T, Gerken F, et al. Effects of tiotropium on lung hyperinflation, dyspnoea and exercise tolerance in COPD. Eur Respir J 2004;23:832-40.

2. Maltais F, Hamilton A, Marciniuck D, et al. Improvements in symptom-limited exercise performance over eight hours with oncedaily tiotropium in patients with COPD. Chest 2005;128:1168-78.

3. O'Donnell DE, Sciurba F, Celli B, et al. Effect of fluticasone propionate/salmeterol on lung hyperinflation and exercise endurance in COPD. Chest 2006;130:647-56.

4. O'Donnell DE, Lam M, Webb KA. Spirometric correlates of improvement in exercise performance after anticholinergic therapy in chronic obstructive pulmonary disease. Am J Respir Crit Care Med 1999; 160:542-9.

5. Pepin V, Saey D, Whittom F, LeBlanc P, Maltais F. Walking versus cycling: Sensitivity to bronchodilation in chronic obstructive pulmonary disease. Am J Respir Crit Care Med 2005;172:1517-22.

6. Saey D, Debigaré R, LeBlanc P, et al. Contractile leg fatigue after cycle exercise: A factor limiting exercise in patients with COPD. Am J Respir Crit Care Med 2003;168:425-30.

7. Mador MJ, Bozkanat E, Kufel TJ. Quadriceps fatigue after cycle exercise in patients with copd compared with healthy control subjects. Chest 2003;123:1104-11.

8. Saey D, Michaud A, Couillard A, et al. Contractile fatigue, muscle morphometry, and blood lactate in chronic obstructive pulmonary disease. Am J Respir Crit Care Med 2005;171:1109-15.

9. Pepin V, Brodeur J, Lacasse Y, et al. Six-minute walking versus shuttle walking: Responsiveness to bronchodilation in chronic obstructive pulmonary disease. Thorax 2007;63:291-8.
10. Bernard S, Leblanc P, Whittom F, et al. Peripheral muscle weakness in patients with chronic obstructive pulmonary disease. Am J Respir Crit Care Med 1998;158:629-34.

11. Hamilton AL, Killian KJ, Summers E, Jones NL. Muscle strength, symptom intensity and exercise capacity in patients with cardiorespiratory disorders. Am J Respir Crit Care Med 1995;152:2021-31.

12. Allaire J, Maltais F, Doyon JF, et al. Peripheral muscle endurance and the oxidative profile of the quadriceps in patients with copd. Thorax 2004;59:673-8.

13. Maltais F, Simard AA, Simard C, Jobin J, Desgagnés P, Leblanc P. Oxidative capacity of the skeletal muscle and lactic acid kinetics during exercise in normal subjects and in patients with COPD. Am J Respir Crit Care Med 1996;153:288-93.

14. Whittom F, Jobin J, Simard PM, et al. Histochemical and morphological characteristics of the vastus lateralis muscle in COPD patients. Comparison with normal subjects and effects of exercise training. Med Sci Sports Exer 1998;30:1467-74.

15. Bernard S, Whittom F, Leblanc P, et al. Aerobic and strength training in patients with COPD. Am J Respir Crit Care Med 1999;159:896-901.

16. Mador MJ, Bozkanat E, Aggarwal A, Shaffer M, Kufel TJ. Endurance and strength training in patients with copd. Chest 2004;125:2036-45.

17. Maltais F, Leblanc P, Simard C, et al. Skeletal muscle adaptation to endurance training in patients with chronic obstructive pulmonary disease. Am J Respir Crit Care Med 1996;154:442-7.

18. Casaburi R, Patessio A, Ioli F, Zanaboni S, Donner CF, Wasserman K. Reductions in exercise lactic acidosis and ventilation as a result of exercise training in patients with obstructive lung disease. Am Rev Respir Dis 1991;143:9-18.

19. Mador MJ, Kufel TJ, Pineda LA, et al. Effect of pulmonary rehabilitation on quadriceps fatiguability during exercise. Am J Respir Crit Care Med 2001;163:930-5.

20. Porszasz J, Emtner M, Goto S, Somfay A, Whipp BJ, Casaburi R. Exercise training decreases ventilatory requirements and exerciseinduced hyperinflation at submaximal intensities in patients with COPD. Chest 2005;128:2025-34.

21. Casaburi R, Kukafka D, Cooper CB, Witek TJ Jr, Kesten S. Improvement in exercise tolerance with the combination of tiotropium and pulmonary rehabilitation in patients with COPD. Chest 2005;127:809-17.

22. Emtner M, Porszasz J, Burns M, Somfay A, Casaburi R. Benefits of supplemental oxygen in exercise training in nonhypoxemic chronic obstructive pulmonary disease patients. Am J Respir Crit Care Med 2003;168:1034-42.

23. Palange P, Valli G, Onorati P, et al. Effect of heliox on lung dynamic hyperinflation, dyspnea, and exercise endurance capacity in COPD patients. J Appl Physiol 2004;97:1637-42.

24. Ambrosino N, Strambi S. New strategies to improve exercise tolerance in chronic obstructive pulmonary disease. Eur Respir J 2004;24:313-22.

25. Vogiatzis I, Terzis G, Nanas S, et al. Skeletal muscle adaptations to interval training in patients with advanced COPD. Chest 2005;128:3838-45.

26. Casaburi R, Bhasin S, Cosentino L, et al. Effects of testosterone and resistance training in men with chronic obstructive pulmonary disease. Am J Respir Crit Care Med 2004;170:870-8.

27. Man WD, Soliman MG, Gearing J, et al. Symptoms and quadriceps fatigability after walking and cycling in chronic obstructive pulmonary disease. Am J Respir Crit Care Med 2003;168:562-7.

28. Brouillard C, Pepin V, Milot J, Lacasse Y, Maltais F. Endurance shuttle walking test: Responsiveness to salmeterol in COPD. Eur Respir J 2008;31:579-84. 


\section{Obstructive sleep apnea across the life span: Adult perspective}

\author{
John A Fleetham \\ Respiratory Division, University of British Columbia, Vancouver, \\ British Columbia \\ E-mail John.Fleetham@vch.ca
}

S leep disordered breathing (SDB) is associated with important health and economic consequences. SDB consists of four distinct clinical syndromes, namely, obstructive sleep apnea-hypopnea syndrome (OSAHS), central sleep apneahypopnea syndrome (which includes Cheyne-Stokes breathing syndrome), sleep hypoventilation syndrome and complex sleep apnea-hypopnea. Each syndrome has diagnostic and severity criteria. OSAHS is a clinical syndrome with symptoms, associated features and a differential diagnosis, and is characterized by recurrent episodes of partial or complete upper airway obstruction during sleep (1). In adults, OSAHS and Cheyne-Stokes breathing syndrome are common, whereas central sleep apnea-hypopnea syndrome (other forms of central), sleep hypoventilation syndrome and complex sleep apnea-hypopnea are rare. OSAHS is present in $4 \%$ of adult men and $2 \%$ of adult women, and becomes more common after menopause (2).

Excessive daytime sleepiness is the hallmark symptom of OSAHS in adults. Other symptoms include nocturnal choking, recurrent nocturnal awakenings, unrefreshing sleep and impaired concentration. OSAHS can be an exacerbating factor for systemic hypertension, cardiac arrhythmias, depression and diabetes, which are frequently present in adult patients. The majority of adult patients with OSAHS have no specific upper airway abnormality, although macroglossia, retrognathia and upper airway neuromuscular disorders are present in some patients (Table 1). Upper body obesity results in fat deposition both in and around the airway, and is a major risk factor for OSAHS. Furthermore, OSAHS is present in 10\% to $20 \%$ of the first-degree relatives of patients with OSAHS. Excessive daytime sleepiness results in a higher rate of motor vehicle crashes and work-related accidents. Patients with OSAHS and an apnea/hypopnea index of greater than 15 events/h are seven times more likely to have multiple motor vehicle crashes over a five-year period than individuals without OSAHS $(3,4)$. These crash rates return to normal with effective treatment (5). The majority of the evidence implicating OSAHS as a cause of both cardiovascular and cerebrovascular disease is indirect, due to limited availability of long-term data. Fatal and nonfatal cardiovascular events are much more common in patients with severe OSAHS than in control subjects or in patients with OSAHS treated with continuous positive airway pressure (CPAP) (Figure 1) (6). Robust clinical trial data now show that OSAHS is independently associated with systemic hypertension, and that blood pressure falls when severe OSAHS is treated with CPAP (7). Patients with OSAHS have increased health care expenditures and before diagnosis, patients with SDB use health care services at approximately twice the rate of control subjects (8).
TABLE 1

Obstructive sleep apnea-hypopnea syndrome high-risk groups (adults)

Upper body obesity
Craniofacial abnormality
Rheumatoid arthritis
Macroglossia
Acromegaly
Amyloidosis
Neurological disorders
Amyotrophic lateral sclerosis
Muscular dystrophy
Multiple sclerosis
Spinal cord injury
Black race
Familial

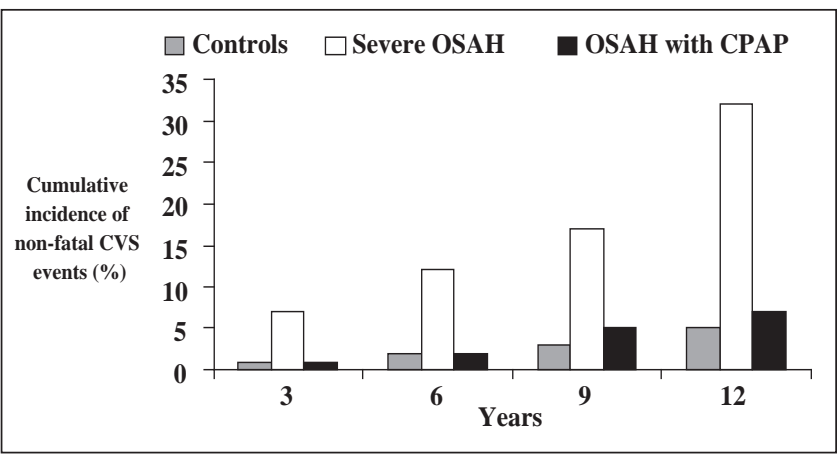

Figure 1) Nonfatal cardiovascular (CVS) events in the control group, patients with severe obstructive sleep apnea-hypopnea (OSAH) and OSAH patients treated with continuous positive airway pressure $(\mathrm{CPAP})$. Adapted from reference 6

Weight loss should be encouraged in all obese patients with OSAHS. CPAP at a fixed pressure is the primary treatment for patients with OSAHS, although an oral appliance is an appropriate therapy for patients with mild to moderate OSAHS with minimal daytime symptoms. Although uncommon, the presence of large tonsils in a patient with OSAHS should prompt referral to an otolaryngologist for consideration of tonsillectomy. Treatment of OSAHS is a cost-effective use of healthcare resources. CPAP treatment decreases health care expenditures during the first two years after diagnosis of OSAHS (9).

There are important differences in OSAHS between children and adults (Table 2). Excessive daytime sleepiness is common in adults, whereas in children it is less common and should raise the possibility of another sleep disorder such as narcolepsy. The majority of children with OSAHS have enlarged tonsils, whereas most adults have no specific upper airway abnormality. Diagnostic criteria also differ between adults and children. Neurocognitive consequences are predominant in children, whereas cardiovascular consequences are predominant in adults. Adult patients also face the additional risk of a motor vehicle crash. Adenotonsillectomy is the primary treatment for OSAHS in the majority of children, whereas CPAP is the primary treatment in adults. 
TABLE 2

Comparison of the important differences between obstructive sleep apnea hypopnea in children and adults

\begin{tabular}{lll}
\hline Children & & Adults \\
\hline Less sleepy & Symptoms & More Sleepy \\
Large tonsils & Signs & Narrow Upper Airway \\
AHI $>1.5$ & Diagnosis & AHI $>5$ \\
Cardiac/metabolic & Consequences & Cardiac/metabolic \\
Neurocognitive/behaviour & & Motor vehicle crashes \\
Adenotonsillectomy & Treatment & CPAP \\
\hline
\end{tabular}

AHI Apnea-hypopnea index; CPAP Continuous positive airway pressure

\section{CONFLICT OF INTEREST: None.}

\section{REFERENCES}

1. Fleetham J, Ayas N, Bradley D, et al. Canadian Thoracic Society Guidelines: Diagnosis and treatment of sleep disordered breathing in adults. Can Respir J 2006;13:317-92.

2. Young T, Palta M, Dempsey J, Skatrud J, Weber S, Badr S. The occurrence of sleep-disordered breathing among middle-aged adults. New Engl J Med 1993;328:1230-5.

3. Young T, Blustein J, Finn L, Palta M. Sleep-disordered breathing and motor vehicle accidents in a population-based sample of employed adults. Sleep 1997;20:608-13.

4. Mulgrew AT, Nasvadi G, Butt A, et al. Risk and severity of motor vehicle crashes in patients with obstructive sleep apnea hypopnea. Thorax 2008;63:536-41.

5. George CF. Reduction in motor vehicle collisions following treatment of sleep apnoea with nasal CPAP. Thorax 2001;56:508-12.

6. Marin JM, Carrizo SJ, Vicente E, Agusti AG. Long-term cardiovascular outcomes in men with obstructive sleep apnoeahypopnea with or without treatment with continuous positive airway pressure: an observational study. Lancet 2005;365:1046-53.

7. Alajmi M, Mulgrew AT, Fox J, et al. The impact of continuous positive airway pressure therapy on blood pressure in patients with obstructive sleep apnea hypopnea: A meta-analysis of randomized controlled trials. Lung 2007;185:67-72.

8. Smith R, Ronald J, Delaive K, Walld R, Manfreda J, Kryger MH. What are obstructive sleep apnea patients being treated for prior to this diagnosis? Chest 2002;121:164-72.

9. Tan MCY, Ayas NT, Mulgrew AT, et al. Cost-effectiveness of CPAP therapy for obstructive sleep apnea hypopnea in British Columbia. Can Resp J 2008;15:159-65.

\section{Obstructive sleep apnea across the life span: Pediatrics perspective}

\author{
Valerie Gail Kirk MD FRCPC \\ Alberta Children's Hospital, Calgary, Alberta \\ Emailval.kirk@calgaryhealthregion.ca
}

I n 1889, Dr William Hill published an account of "the stupid adenoid physiognomy" in an article in the British Medical Journal entitled "On some causes of backwardness and stupidity in children" (1). The paper clearly described children suffering from what we now recognize as obstructive sleep apnea (OSA), with a focus on the behavioural and learning effects in the developing child. The present paper provides a brief review and update on the current state of knowledge regarding the presentation, effects and treatment options for children with OSA.

\section{DEFINITION}

OSA in children is "a disorder of breathing during sleep characterized by prolonged partial upper airway obstruction and/or intermittent complete obstruction that disrupts normal ventilation during sleep and normal sleep patterns" (2). Snoring alone is present in $7 \%$ to $9 \%$ of otherwise healthy children, and OSA in $2 \%$ to $3 \%(3,4)$. Due to the decreased collapsibility of upper airway structures in children, airway obstruction during sleep is uncommon in this population (5), and cut-off values indicating disease are much lower. There is also a higher incidence of partial airway obstruction with concomitant hypercapnea in children younger than 18 years of age $(6,7)$ (Table 1 ).

\section{TABLE 1}

Normative data for polysomnography in children

\begin{tabular}{lc}
\hline Parameter & Normal value \\
\hline Apnea-hypopnea index & $<1.5 / \mathrm{h}$ \\
Minimum oxygen saturation & $\geq 93 \%$ \\
Maximum carbon dioxide & $\leq 53 \mathrm{~mm} \mathrm{Hg}$ \\
Sleep efficiency & $>85 \%$ \\
Arousal index & $<11 / \mathrm{h}$ \\
\hline
\end{tabular}

Data from references 6, 7, 21 and 22

\section{CRITERIA}

Given that the clinical significance of abnormal polysomnographic findings is not yet well defined in pediatrics, recommendations are based on a combination of clinical findings, history, and polysomnography. The most common clinical presentations in children are different than those in adults, although there is a rising frequency of obesity-related sleep disordered breathing in North American children (4) (Table 2).

\section{TABLE 2}

Common presenting signs and symptoms of obstructive sleep apnea in children

Daytime
Hyperactivity
Learning problems
Difficulty concentrating
Mood/behaviour control
Mouth-breathing
Poor growth
Excessive daytime sleepiness
Pulmonary hypertension
Nighttime
Snoring, noisy breathing
Difficulty breathing
Witnessed apnea

*Excessive daytime sleepiness is less common in children with obstructive sleep apnea and should increase suspicion for narcolepsy

\section{RISK GROUPS}

Although OSA most often occurs in otherwise healthy children, those with the following abnormalities are at higher risk and may warrant screening: adenotonsillary hypertrophy, craniofacial abnormalities (eg, Down syndrome), neurological disorders (eg, cerebral palsy) and obesity $(8,9)$.

\section{EFFECTS}

Untreated OSA has well-documented effects on learning, behaviour, school performance and mood (10-12). Studies of the metabolic and cardiovascular effects of OSA in this age group have had mixed results. Affected children can develop 
ventricular dysfunction and/or hypertension, but it is not yet clear what role obesity plays in this relationship. Recent reports of increased serum levels of interleukin-6, C-reactive protein and endothelial markers as well as an increased density of leukotriene receptors in the tonsil and adenoid tissue in children with OSA suggest a role for inflammation in the pathogenesis (13-15).

\section{TREATMENT}

The majority of children with OSA will have a successful outcome with routine adenotonsillectomy ( $80 \%$ to $95 \%$ cure rate) (16). Among those with complicating disorders such as Down syndrome and/or obesity, approximately 50\% require additional treatment with continuous positive airway pressure $(16,17)$. More recently, pharmacological therapy with a combination of nasal steroid spray and leukotriene inhibitors has been shown to improve symptoms and polysomnography findings in children with mild residual OSA postadenotonsillectomy $(18,19)$. Lastly, treatment of selected children who have both OSA and dental malocclusion with a rapid-technique maxillary spacing device has shown promising results (20).

\section{SUMMARY}

OSA in children is a common disorder that presents most frequently with learning and/or behavior problems. Polysomnographic diagnostic criteria are well established but there remains a paucity of data regarding which markers correlate most closely with clinically significant outcomes. The mainstay of treatment for otherwise typical children continues to be adenotonsillectomy, but continuous positive airway pressure can be used with success when needed. Newer pharmacological and orthodontic treatment techniques are currently being developed.

\section{CONFLICTS OF INTEREST: None.}

\section{REFERENCES}

1. Hill W. On some causes of backwardness and stupidity in children. BMJ 1889;2:711-2.

2. Loughlin GM, Brouillette RT, Brooke LJ. American Thoracic Society Standards and indications for cardiopulmonary sleep studies in children. Am J Respir Crit Care Med 1996;153:866-78.

3. Ali NJ, Pitson DJ, Stradling JR. Snoring, sleep disturbance, and behaviour in 4-5 year olds. Arch Dis Child 1993;68:360-6.

4. Redline S, Tishler PV, Schluchter M, Aylor J, Clark K, Graham G. Risk factors for sleep-disordered breathing in children. Associations with obesity, race, and respiratory problems. Am J Respir Crit Care Med 1999;159:1527-32.

5. Marcus CL, McColley SA, Carroll JL, Loughlin GM, Smith PL, Schwartz AR. Upper airway collapsibility in children with obstructive sleep apnea syndrome. J Appl Physiol 1994;77:918-24.

6. Marcus CL, Omlin KJ, Basinki DJ, et al. Normal polysomnographic values for children and adolescents. Am Rev Respir Dis 1992;146:1235-9.

7. Witmans MB, Keens TG, Davidson Ward SL, Marcus C. Obstructive hypopneas in children and adults: Normal values. Am J Respir Crit Care Med 2003;168:1540.

8. Marcus CL, Keens TG, Bautista DB, von Pechmann WS, Ward SL. Obstructive sleep apnea in children with Down syndrome. Pediatrics 1991;88:132-9.

9. Rosen GM, Muckle RP, Mahowald MW, Goding GS, Ullevig C. Postoperative respiratory compromise in children with obstructive sleep apnea syndrome: Can it be anticipated? Pediatrics 1994;935:784-8.
10. Rosen CL, Storfer-Isser A, Taylor HG, Kirchner HL, Emancipator JL, Redline S. Increased behavioral morbidity in school-aged children with sleep-disordered breathing. Pediatrics 2004;114:1640-8.

11. Urschitz MS, Eitner S, Guenther A, et al. Habitual snoring, intermittent hypoxia, and impaired behavior in primary school children. Pediatrics 2004;114:1041-8.

12. Gozal D. Sleep-disordered breathing and school performance in children. Pediatrics 1998;102:616-20.

13. Gozal D, Kheirandish-Gozal L, Serpero LD, Capdevila OS, Dayyat E. Obstructive sleep apnea and endothelial function in school-aged nonobese children. Circulation 2007;116:2307-14.

14. Gozal D, Sans Capdevila O, Kheirandish-Gozal L. Metabolic alterations and systemic inflammation in obstructive sleep apnea among nonobese and obese prepubertal children. Am J Respir Crit Care Med 2008;177:1142-9.

15. Goldbart AD, Goldman GL, Li RC, Brittian KR, Tauman R, Gozal D. Differential expression of cysteinyl leukotriene receptors 1 and 2 in tonsils of children with obstructive sleep apnea and recurrent infection. Chest 2004;126:13-8.

16. Mitchell R. Outcome of adenotonsillectomy for obstructive sleep apnea in obese and normal-weight children. J Otolaryngol Head Neck Surg 2007;137:43-8.

17. Merrell S, Shott S. OSAS in Down syndrome: T\&A versus T\&A plus lateral pharyngoplasty. Int J Ped Otorhinolaryngol 2007;71:1197-203.

18. Brouillette RT, Manoukian JJ, Ducharme FM. Efficacy of fluticasone nasal spray for pediatric obstructive sleep apnea. J Pediatr 2001;138:838-44.

19. Kheirandish-Gozal L, Goldbart AD, Gozal D. Intranasal steroids and oral leukotriene modifier therapy in residual sleep-disordered breathing after tonsillectomy and adenoidectomy in children. Pediatrics 2006;117:e61-6.

20. Villa M, Malagola C, Pagani J, Montesano M, Rizzoli A, Guilleminault C. Rapid maxillary expansion in children with obstructive sleep apnea syndrome: 12 month follow-up. Sleep Medicine 2007;8:128-34.

21. Uliel S, Tauman R, Greenfield M, Sivan Y. Normal polysomnographic respiratory values in children and adolescents. Chest 2004;125:872-8.

22. Verhulst SL, Schrauwen N, Haentjens D. Reference values for sleeprelated breathing disorders in asymptomatic European children and adolescents. Pediatr Pulmonol 2007;42:159-67.

\section{The future of Canadian respiratory clinical research}

\author{
Shawn D Aaron MD \\ Division of Respiratory Medicine, The Ottawa Hospital, \\ Ottawa, Ontario \\ E-mail saaron@ohri.ca
}

$T^{\mathrm{h}}$ he objectives of the present article are to identify future challenges in Canadian clinical respiratory research; and new opportunities in Canadian clinical respiratory research.

Clinical research is usually defined as patient-oriented research. It is: "Research that requires interaction between a clinician-investigator and a patient." Clinical researchers study diseases in humans both at a population level and at an individual patient-level. They study disease causation, treatment, and delivery of health care services. High-quality clinical research is essential to understanding disease in humans and to improving health care. Without clinical research, we cannot possibly understand risk factors for development of disease, whether new therapies may be beneficial, or which current therapies might be harmful.

Canadian respiratory research has performed strongly in the recent past. From 1995 to 2003, Canadians collectively published 2612 respiratory research articles in journals with an average impact factor of three. Our respiratory research output during these eight years, adjusted per population and gross domestic product, is ranked number one in the world (1). 
However there are storm clouds on the research horizon. Funding for clinical research in Canada is very constrained; at the Canadian Institutes of Health Research (CIHR), there are 52 research grant review committees but only seven of these are devoted to funding clinical research. Currently, there are three Cardiovascular Disease committees at the CIHR, but only one Respiratory Systems Committee. Of 35 grants submitted to the Respiratory Systems Committee in September 2007, only 10 could be funded, and of these 10 grants, only one was for a clinical research project.

Lung cancer killed more than 18,000 Canadians in 2005, more than twice the number of the next most deadly cancer, colorectal cancer, which killed 8000 Canadians. However, in that same year, lung cancer received less than $\$ 8$ million in total research funding in Canada, compared with $\$ 38$ million for breast cancer, $\$ 20$ million for leukemia and \$12 million for colorectal cancer. Similarly, total 2006 funding for AIDS research was more than double the amount of funding awarded to all pulmonary diseases combined. Clearly, research pertaining to lung diseases is chronically underfunded, and this is a threat to the future of respiratory clinical research in Canada.

Other challenges for clinical research in Canada include a complex regulatory environment that includes needs for clinical trial agreements, Health Canada approval of clinical trials, ethics submissions and data safety monitoring. All of these requirements are necessary to ensure safe clinical research practices, but add complexity and challenges to clinical research projects. The hurdles involved in setting up a clinical research project are thus considerable. This may discourage young physician investigators or other young health professionals from pursuing a career in clinical research. Finally, competition is intense, and to be published in top-rated journals, clinical research studies now have to be large, often enrolling thousands of patients. This requires clinical researchers to collaborate with one another to enroll an adequate number of patients.

Recently, to meet the above listed challenges, respiratory clinical researchers in Canada have come together to form The Canadian Respiratory Clinical Research Consortium (CRCRC). The goals of the CRCRC are to foster national collaborative multicentre research in pulmonary medicine, to attract additional funding for Canadian collaborative research, and to foster additional collaborative Canadian studies such as randomized clinical trials, cohort studies, systematic reviews, epidemiological studies and evaluations of diagnostic tests. The CRCRC has thus far been very successful, and has held three annual national meetings and published several large collaborative Canadian clinical research studies (www.crcrc.ca).

What can we do to move the future of Canadian clinical research forward? We can work together as a group to establish strong, successful collaborative clinical research networks, and this is being done through the CRCRC. We can lobby governments and the CIHR to create more funding opportunities for respiratory research and for clinical research, so that funding becomes commensurate with the burden of respiratory diseases within Canada. Nothing breeds success like success. If we continue to be productive as respiratory researchers, and if we work together as a group, then we will be recognized nationally and internationally, and this will eventually breed more opportunity and more funding and more excellent research.
CONFLICTS OF INTEREST: None.

\section{REFERENCES}

1. Michalopoulos A, Falagas ME. A bibliometric analysis of global research production in respiratory medicine. Chest 2005;128:3993-8.

\section{Canadian adult and pediatric 2008 asthma update}

\author{
Andrew Mclvor MD MSc FRCPC \\ McMaster University, St Joseph's Healthcare, Firestone Institute \\ for Respiratory Health, Hamilton, Ontario \\ E-mail amcivor@stjosham.on.ca
}

$T^{\mathrm{i}}$ 2008 asthma update comprises a series of cases with 'key points' for asthma management. This will be accompanied by the simultaneous distribution of a number of related knowledgetranslation tools. For the first time, the guidelines and collateral materials have been designed with the overarching goal of transforming evidence-based knowledge into clinical practice. By focusing on knowledge translation - as well as on the need for family doctors, certified asthma educators, pharmacists, and allied health care professionals to apply a chronic disease management model to asthma - the Asthma Committee of the Canadian Thoracic Society (CTS) believes that it can lead the way to improving asthma control, reducing exacerbations and mortality, and improving asthma report cards in future patient surveys.

The first asthma guidelines were produced by the CTS's multidisciplinary Asthma Committee nearly two decades ago (1). Initially created via a process that included a consensus meeting, subsequent revisions and updates of the guidelines have involved extensive critical appraisal of emerging medical literature, thereby ensuring the creation of relevant, evidencebased reports $(2,3)$.

However, in spite of the creation and dissemination of the sets of guidelines, various concomitant supportive initiatives, a number of comprehensive patient and physician surveys, and follow-up reports, poor asthma control persists in Canada. The most recent study assessing asthma control in Canada, the Personal Practice Assessment Programme, included more than 350 Canadian primary care physicians (4). It revealed that $59 \%$ of the more than 10,000 patients under a physicians' treatment had uncontrolled asthma. It also clearly identified that if a patient is uncontrolled by one or more of the subjective criteria of asthma control (ie, no need to perform objective tests of lung function such as spirometry or peak flow), the patient is nearly six times as likely to have a subsequent unscheduled health care visit, 3.5 times more likely to have an emergency visit and twice as likely to be admitted to hospital.

It is somewhat disheartening that despite the excellent and constantly evolving therapeutic armamentarium, clinicians in Canada are not, for some reason, integrating guideline based recommendations into clinical care. They are not routinely performing office assessment of control, nor are they changing the way they manage their patients with asthma.

The CTS Asthma Committee therefore re-examined the way in which it had been producing and disseminating guidelines. The group came to the conclusion that it should shift more of its effort to knowledge translation rather than focusing almost exclusively on guideline production (5). The next set of 
asthma guidelines are being created to promote knowledge translation and to optimize patient outcomes. One sign of this refocus is the recent integration of our pediatric respirologist colleagues in the CTS, and hence of both adult and pediatric asthma treatment with a focus on emergency care, chronic disease management and education, as part of the 2008 asthma update. Another change is that, rather than being a large document, the guidelines will be relatively short and will focus on a discrete number of practice areas.

The Asthma Committee, in partnership with the Education committee of the CTS, also had the pleasure of launching a new initiative; an interactive Web-based case study series with input from a number of asthma committee members, called "Asthma Case Studies: The Right Course of Action." This online course has been approved by Memorial University of Newfoundland for MainCert credits as defined by the Royal College of Physicians and Surgeons of Canada. Course Registration can be found at wwwMDcme.ca, and I encourage you all to access this.

The goal of these concerted and targeted efforts is to make it easy for health care professionals to utilize the new constellation of diagnostic and therapeutic tools that represents best practices in asthma care. We hope the result will be improved patient care and hence a drastic reduction of the burden imposed by asthma on Canadian society.

CONFLICTS OF INTEREST: Dr McIvor has received honoraria for providing CME and attending advisory boards from AstraZeneca, Boehringer-Ingelheim, Graceway, GlaxoSmithKline, Merck, Novartis and Pfizer.

\section{REFERENCES}

1. Hargreave FE, Dolovitch J, Newhouse M. The assessment and treatment of asthma: A conference report. J Allergy Clin Immunol 1990;85:1098-111.

2. Boulet LP, Becker A, Berube D, et al. Canadian Asthma Consensus report 1999. Canadian Consensus Group. Can Med Assoc J 1999;161(11 Suppl):S1-61.

3. Lemière $\mathrm{C}$, Bai $\mathrm{T}$, Balter $\mathrm{M}$, et al. Adult asthma consensus guidelines update 2003. Can Respir J 2004;11(Suppl A):9A-18A.

4. Chapman KR, Boulet LP, Rea RM, et al. Suboptimal asthma control: Prevalence, detection and consequences in general practice. Eur Respir J 2008;31:320-5.

5. Graham ID, Logan J, Harrison MB, et al. Lost in knowledge translation: Time for a map? J Contin Educ Health Care Prof 2006;26:13-24.

\section{Chronic obstructive pulmonary disease: The importance of early diagnosis}

\author{
Denis E O'Donnell MD \\ Division of Respiratory \& Critical Care Medicine, Queens \\ University, Kingston, Ontario \\ E-mail odonnell@queensu.ca
}

Oputo hronic obstructive pulmonary disease (COPD) is a major public health problem in Canada. It is currently the fourth leading cause of death and is destined to be the third by 2020 (1). Death rates and hospitalizations continue to escalate, particularly in older women $(1,2)$. A recent study in Vancouver, British Columbia, undertaken as part of a global survey, determined prevalence rates of $7.3 \%$ and $9.3 \%$ in women and men, respectively (3). The Canadian Thoracic
Society COPD management recommendations highlighted the central importance of early diagnosis (4).

Most patients with COPD escape diagnosis until their respiratory reserve is critically diminished. The respiratory impairment reflects a combination of the natural decline of lung function with aging and a superimposed airway and lung inflammation from tobacco smoke. Symptomatic smokers, with a high pretest probability of having the disease, should undergo simple spirometry (Table 1). A post-bronchodilator forced expiratory volume in $1 \mathrm{~s}\left(\mathrm{FVC}_{1}\right) /$ forced vital capacity ratio of less than 0.7 confirms the presence of airflow obstruction that is not fully reversible. Mild COPD is an $\mathrm{FEV}_{1}$ greater than $80 \%$ predicted. A recent study has provided reassurance that fixed ratio criteria have sufficient diagnostic sensitivity for targeted screening of the disease (5).

\section{TABLE 1}

Who should be targeted for spirometry?

\begin{tabular}{l} 
Smokers or ex-smokers older than $\mathbf{4 0}$ years of age if they answer 'yes' \\
to any of the following questions: \\
\hline 1. Do you cough regularly? \\
2. Do you cough up phlegm regularly? \\
3. Do even simple chores make you short of breath? \\
4. Do you wheeze when you exert yourself or at night? \\
5. Do you get frequent colds that persist longer than those of other \\
$\quad$ people you know?
\end{tabular}

Recent studies by Hogg et al (6) have confirmed that patients with mild airflow obstruction have evidence of airway inflammation. Patients with preserved $\mathrm{FEV}_{1}$ may have extensive small airway dysfunction as measured by closing volume and tests of abnormal distribution of ventilation (7-9). Ventilation-perfusion inequalities contribute to a higher than normal ventilatory requirement during physical exertion. Some patients with mild airflow obstruction seek medical attention because of reduced health status, chronic activity-related dyspnea and reduced activity levels (10). During cardiopulmonary exercise testing, they exhibit expiratory flow limitation and dynamic pulmonary hyperinflation which contributes to exertional dyspnea and exercise intolerance (11).

The identification of mild COPD should lead to activation of a strategic management plan that includes smoking cessation, which favourably impacts the natural history of the disease (12). Other interventions include annual influenza vaccination $(13,14)$, active encouragement of regular physical activity and annual follow-up that includes spirometry. No evidence-based guidelines exist with respect to pharmacotherapy in mild COPD. The Canadian Thoracic Society panel recommended a trial of short-acting bronchodilator therapy in spirometry-confirmed symptomatic patients (4). If activity-related dyspnea persists, a long-acting bronchodilator could be added. Inhaled corticosteroids are not beneficial in early COPD $(15,16)$.

CONFLICTS OF INTEREST: None.

\section{REFERENCES}

1. Statistics Canada. Death by selected group causes, sex and geography - Canada. <www.statcan.ca/english/freepub/84F0209XIE/2003000/ t001_en.pdf $>$ (Version current at December 1, 2008). 
2. The Centre for Chronic Disease Prevention and Control, Health Canada, Canadian Institute for Health Information. Editorial Board Respiratory Disease in Canada. Ottawa: Health Canada, 2003.

3. Buist AS, McBurnie M, Vollmer WM, et al; on behalf of the BOLD Collaborative Research Group. International variation in the prevalence of COPD (The BOLD Study): A population-based prevalence study. Lancet 2007;370:741-50.

4. O'Donnell DE, Hernandez P, Kaplan A, et al. Canadian Thoracic Society recommendations for management of chronic obstructive pulmonary disease - 2008 update - highlights for primary care. Can Respir J 2008;15(Suppl A):1A-8A.

5. Mannino DM, Sonia BA, Vollmer WM. Chronic obstructive pulmonary disease in the older adult: What defines abnormal lung function? Thorax 2007;62:237-41.

6. Hogg JC, Chu F, Utokaparch S, et al. The nature of small-airway obstruction in chronic obstructive pulmonary disease. N Engl J Med 2004;350:2645-53.

7. Buist AS, Ross BB. Quantitative analysis of the alveolar plateau in the diagnosis of early airway obstruction. Am Rev Respir Dis 1973;108:1078-87.

8. Verbanck S, Schuermans D, Paiva M, Meysman M, Vincken W. Small airway function improvement after smoking cessation in smokers without airway obstruction. Am J Respir Crit Care Med 2006;174:853-7.

9. Stanescu D, Sanna A, Veriter C, Robert A. Identification of smokers susceptible to development of chronic airflow limitation: A 13-year follow-up. Chest 1998;114:416-25.
10. Jones PW. Health status measurement in chronic obstructive pulmonary disease. Thorax 2001;56:880-7.

11. Ofir D, Laveneziana P, Webb KA, Lam Y-M, O’Donnell DE. Mechanisms of dyspnea during cycle exercise in symptomatic patients with GOLD stage I COPD. Am J Respir Crit Care Med 2008;177;622-9.

12. Anthonisen NR, Connett JE, Murray RP, for the Lung Health Study Research Group. Smoking and lung function of Lung Health Study participants after 11 years. Am J Respir Crit Care Med 2002;166:675-9.

13. Nichol K, Baken L, Nelson A. Relation between influenza vaccination and outpatient visits, hospitalizations and mortality among elderly patients with chronic lung disease. Ann Intern Med 1999;130:397-403.

14. Wongsuakiat P, Maranetra KN, Wasi C, Kositanont U, Dejsomritrutai W, Charoenratanakul S. Acute respiratory illness in patients with COPD and the effectiveness of influenza vaccination: A randomized controlled study. Chest 2004;125:2011-20.

15. Pauwels RA, Lofdahl CG, Laitinen LA, et al; for the European Respiratory Society Study on Chronic Obstructive Pulmonary Disease. Long-term treatment with inhaled budesonide in persons with mild chronic obstructive pulmonary disease who continue smoking. N Engl J Med 1999;340:1948-53.

16. Vestbo J, Sorensen T, Lange P, Brix A, Torre P, Viskum K. Long-term effect of inhaled budesonide in mild and moderate chronic obstructive pulmonary disease: A randomized controlled trial. Lancet 1999;353:1818-23. 


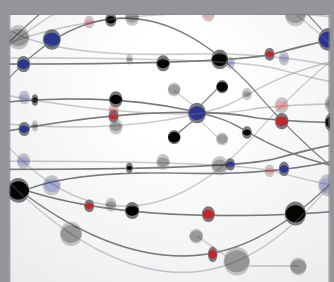

The Scientific World Journal
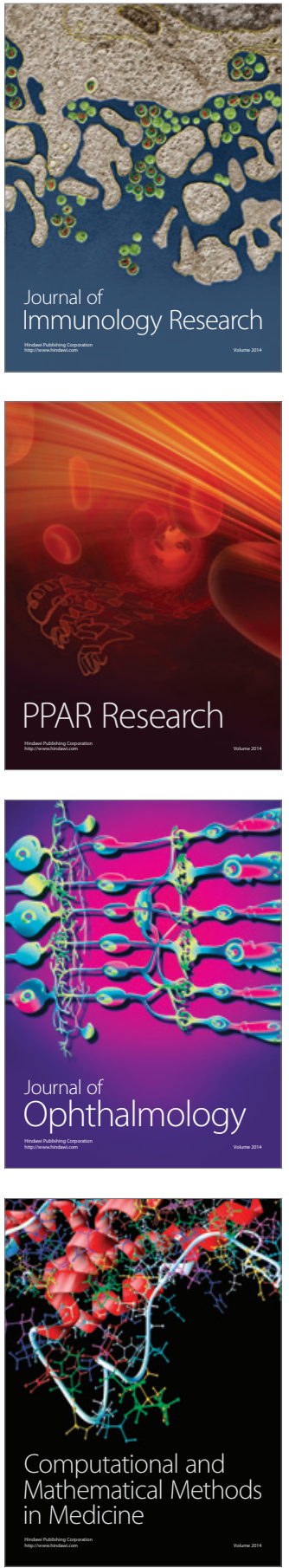

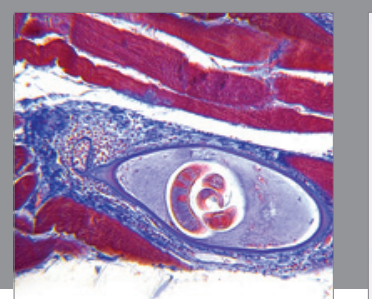

Gastroenterology Research and Practice

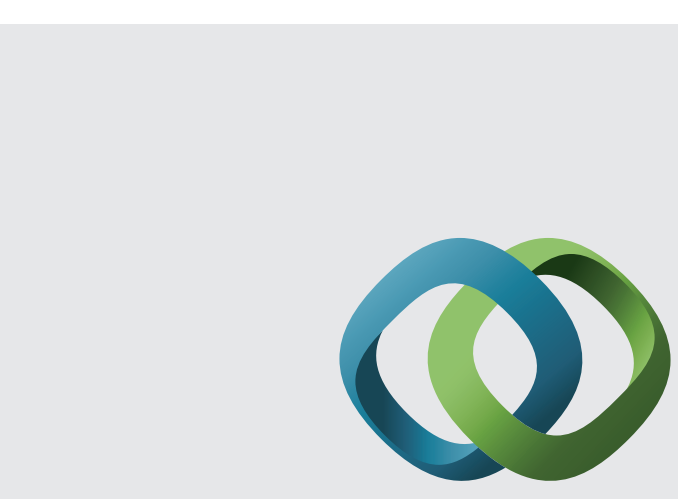

\section{Hindawi}

Submit your manuscripts at

http://www.hindawi.com
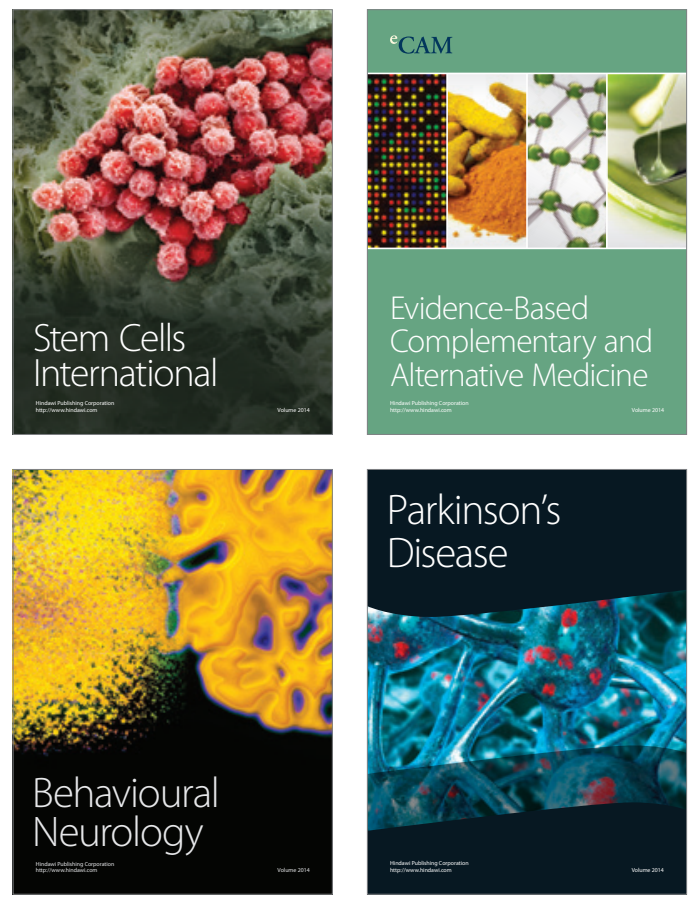
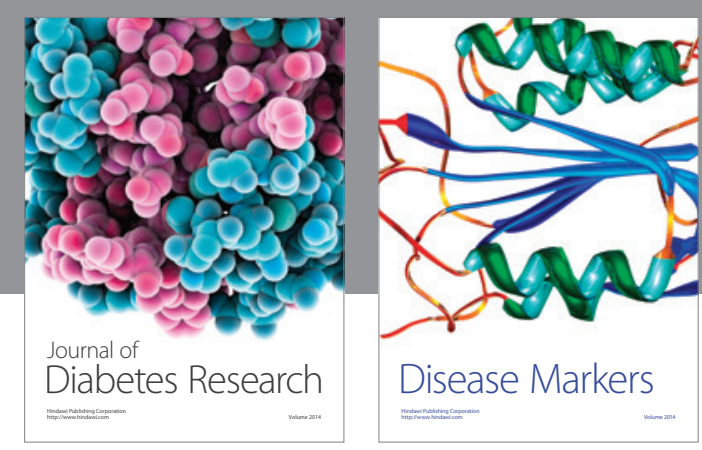

Disease Markers
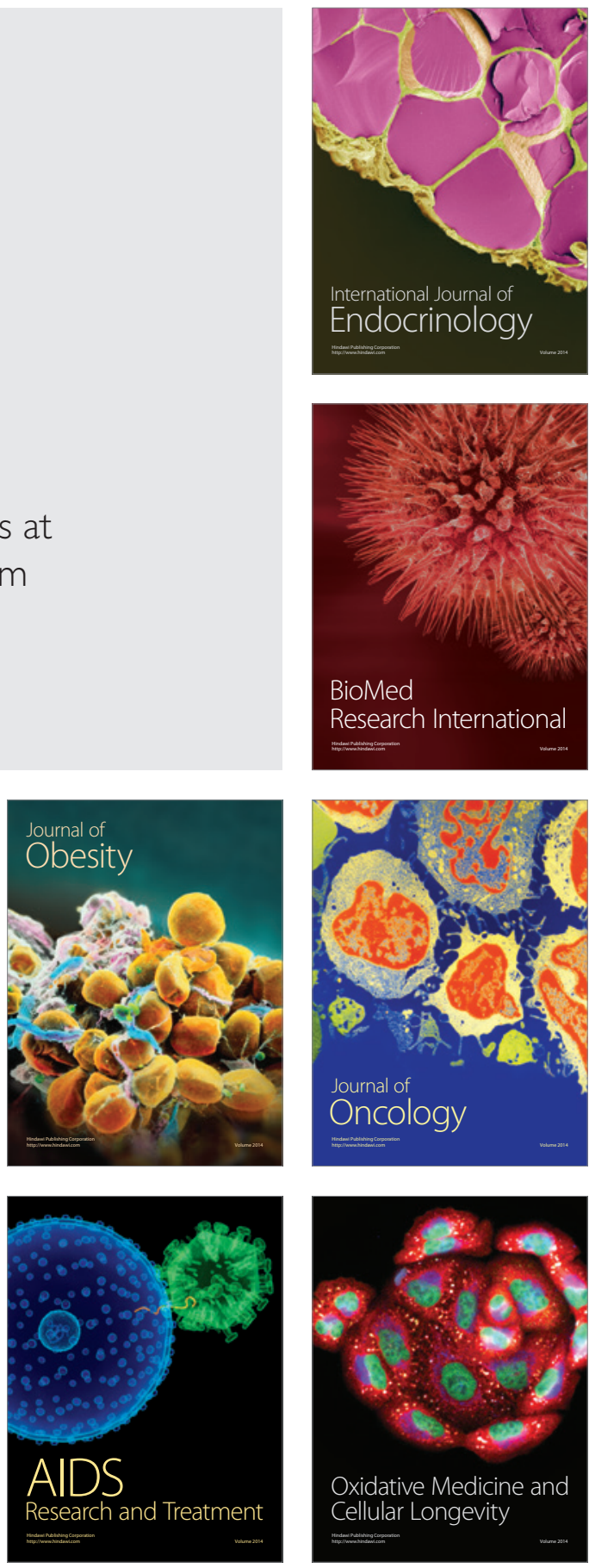